\title{
Development of Halogenase Enzymes for Use in Synthesis
}

\section{Document Version}

Accepted author manuscript

Link to publication record in Manchester Research Explorer

\section{Citation for published version (APA):}

Latham, J., Brandenburger, E., Shepherd, S., Menon, B., \& Micklefield, J. (2018). Development of Halogenase Enzymes for Use in Synthesis. Chemical Reviews, 118(1), 232-269.

\section{Published in:}

Chemical Reviews

\section{Citing this paper}

Please note that where the full-text provided on Manchester Research Explorer is the Author Accepted Manuscript or Proof version this may differ from the final Published version. If citing, it is advised that you check and use the publisher's definitive version.

\section{General rights}

Copyright and moral rights for the publications made accessible in the Research Explorer are retained by the authors and/or other copyright owners and it is a condition of accessing publications that users recognise and abide by the legal requirements associated with these rights.

\section{Takedown policy}

If you believe that this document breaches copyright please refer to the University of Manchester's Takedown Procedures [http://man.ac.uk/04Y6Bo] or contact uml.scholarlycommunications@manchester.ac.uk providing relevant details, so we can investigate your claim.

\section{OPEN ACCESS}




\section{Development of Halogenase Enzymes for Use in Synthesis}

Jonathan Latham, Eileen Brandenburger, Sarah A. Shepherd, Binuraj R. K. Menon and Jason Micklefield.

School of Chemistry and Manchester Institute of Biotechnology, The University of Manchester, 131 Princess Street, Manchester, M1 7DN, United Kingdom.

Email: jason.micklefield@manchester.ac.uk

\section{Abstract}

Nature has evolved halogenase enzymes to regioselectively halogenate a diverse range of biosynthetic precursors, with the halogens introduced often having a profound effect on the biological activity of the resulting natural products. Synthetic endeavours to create non-natural bioactive small molecules for pharmaceutical and agrochemical applications have also arrived at a similar conclusion - halogens can dramatically improve the properties of organic molecules for selective modulation of biological targets in vivo. Consequently a high proportion of pharmaceuticals and agrochemicals on the market today possess halogens. Halogenated organic compounds are also common intermediates in synthesis and are particularly valuable in metal catalyzed cross-coupling reactions. Despite the potential utility of organohalogens, traditional non-enzymatic halogenation chemistry utilizes deleterious reagents and often lacks regiocontrol. Reliable, facile and cleaner methods for the regioselective halogenation of organic compounds are therefore essential in the development of economical and environmentally-friendly industrial processes. A potential avenue towards such methods is the use of halogenase enzymes, responsible for the biosynthesis of halogenated natural products, as biocatalysts. This review will discuss the advances towards this goal thus far, in addition to untapped potential sources of such biocatalysts and how further development of the enzymes may be focused in order to achieve the goal of industrial scale biohalogenation.

\section{$\underline{\text { Table of Contents }}$}

1. Introduction. 3

2. Haloperoxidases. 6

2.1 Heme-Iron dependent Haloperoxidases. 6 


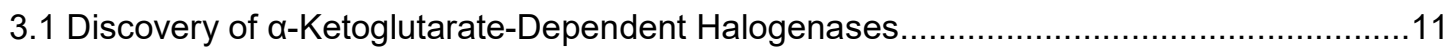

3.2 Application of Fe(II)/a-KG Dependent Halogenases as Biocatalysts..............................15

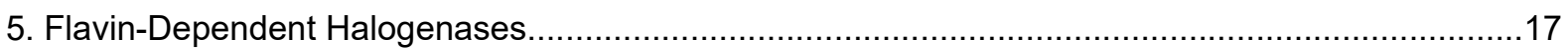

5.1 Flavin-Dependent Halogenases in Nature ..............................................................17

5.1.1 Flavin-Dependent Tryptophan Halogenases...................................19

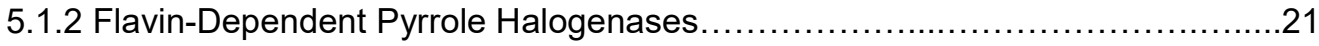

5.1.3 Flavin-Dependent Phenolic Halogenases.........................................23

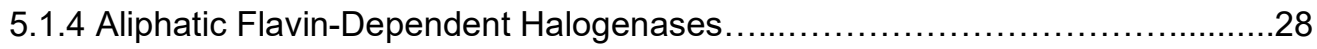

5.2 Flavin-Dependent Halogenases as Biocatalysts............................................29

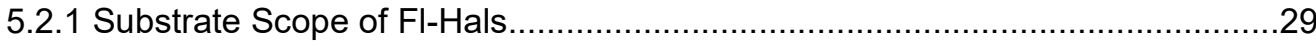

5.2.2 Engineering FI-Hals to Alter Substrate Scope and Regioselectivity.................32

5.2.3 Engineering FI-Hals to Improve Activity and Stability...................................35

5.2.4 Integration of Fl-Hals into Non-Native Biosynthetic Pathways.........................39

5.2.5 Integration of FI-Hal with Transition-Metal Catalysis....................................40

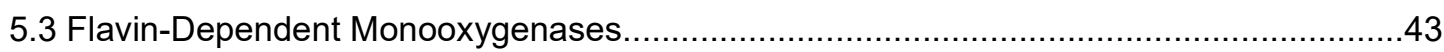

5.3.1 Natural Occurrence and Mechanism......................................................43

5.3.2 Flavin-dependent Monooxygenases as Biocatalysts.....................................45

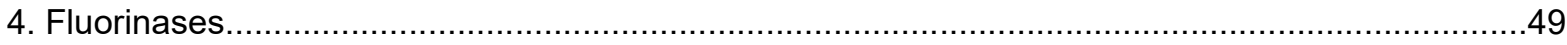

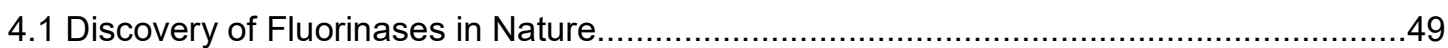

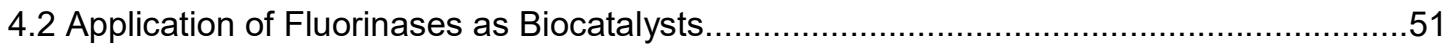

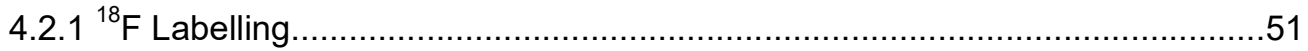

4.2.2 Production of Fluorinated Natural Products..............................................53

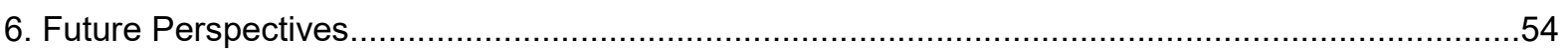

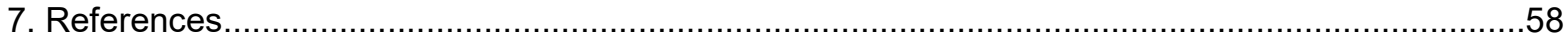

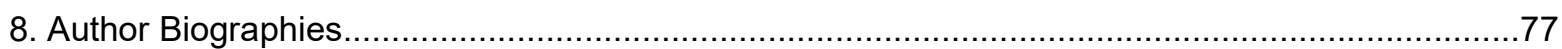

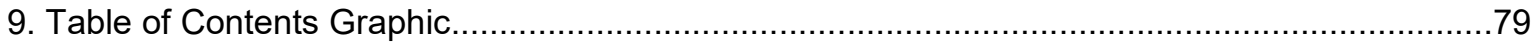




\section{Introduction}

Organohalogen compounds are present in many pharmaceuticals and agrochemicals, as well as other valuable products, and are also widely used in all sectors of the chemical industry as synthetic intermediates. Transition metal-catalysed cross-coupling reactions have become indispensable tools for the synthesis of complex molecules because of the multitude of C-C, C-F, C-N and other Cheteroatom couplings which are possible. ${ }^{1-9}$ Many of these reactions utilise organohalogens because of the ability to metallate $\mathrm{C}-\mathrm{X}$ bonds and consequently halogenated compounds are now ubiquitous intermediates in organic synthesis. ${ }^{3,6}$ Additionally, the introduction of a halogen atom can have a profound effect on the bioactivity and physicochemical properties of small molecules, which has been exploited in medicinal chemistry, with a large proportion of all drugs in clinical trials or on the market containing halogen atoms (Figure 1A).$^{10-14}$ In the case of the antibiotic vancomycin for example, it has been demonstrated that the halogen substituents are important for antimicrobial activity, with dechlorovancomycin derivatives exhibiting significantly reduced binding affinity for the peptidoglycan biological target. ${ }^{15}$ The privileged effect of the halogen upon biological activity has also transcended to the design of agrochemicals, where many of the bestselling herbicides, pesticides and insecticides are halogen-containing (Figure 1B). ${ }^{16,17}$ Organohalogen compounds have also been found to have desirable properties in polymers and therefore are receiving increased attention for the next generations of materials. ${ }^{18-20}$

The effect of halogens upon bioactivity and bioavailability was thought to be due solely to modulation of lipophilicity and non-specific hydrophobic interactions with protein targets. More recently however, it has been shown that carbon-halogen bonds can form directional intermolecular interactions with proteins - called halogen bonds. ${ }^{10,11,21-25}$ These come about because of the electron deficient "sigmahole" of the halogen in a C-X bond, which allows interaction of halogens with the lone pairs of heteroatoms like $\mathrm{N}, \mathrm{O}, \mathrm{S}$ and $\mathrm{P}$ in protein targets in an analogous manner to hydrogen bonding. ${ }^{23-28}$ As such, the incorporation of halogen atoms during medicinal chemistry efforts is a well-established practice as it can allow the introduction of additional ligand-target interactions without the need to significantly alter other interactions with the target. The C-F bond in particular is of long-standing importance in the development of pharmaceuticals - indeed fluorine is the most prevalent halogen found in drugs and a number of the best-selling small molecule pharmaceutical compounds contain 
fluorine. ${ }^{12-14}$ This effect is due in part to fluorine's similar size to hydrogen but significantly increased electronegativity. This combination facilitates the replacement of metabolically labile $\mathrm{C}-\mathrm{H}$ bonds with C-F, without significantly disturbing interactions with the biological target, in addition to the formation of strong halogen bonds and significant changes in lipophilicity.

As with many synthetic endeavours, the development and application of organohalogen compounds has to a large extent been inspired by nature. A plethora of halogenated natural products have been isolated from a diverse range of microorganisms, many of which possess potent anti-microbial and anti-tumour activities, amongst others (Figure 1C). ${ }^{29-31}$ In marine organisms, organobromine compounds prevail whilst chlorinated compounds are found mostly from terrestrial sources and naturally-occurring organoiodine is relatively rare. Elucidation of the biosynthetic pathways responsible for the production of these compounds has revealed a number of enzymes capable of halogenating both aliphatic and aromatic carbons on either protein-tethered or free-standing substrates. ${ }^{32-34}$ These enzymes have received much interest since their first discoveries and now a number of fundamentally different classes of halogenases are known - categorised based upon the mechanism by which they generate and utilise activated halide.

Given the critical importance of organohalogens, methods for the facile and selective installation of halogen substituents are necessary. Many of the traditional methods, especially for aromatic halogenation, require electrophilic halogen sources which are typically toxic and harmful to the environment. ${ }^{35}$ The selectivity of these methods is typically poor, affording mixtures of halogenated regioisomers - limiting material efficiency and requiring careful disposal of persistent environmental pollutants. ${ }^{36}$ More recent synthetic methods address some of these issues, ${ }^{37}$ but often confer selectivity through subtle differences in the acidity of certain $\mathrm{C}-\mathrm{H}$ bonds or require directing groups to control the position of functionalisation which can limit the substrate scope and number of regiochemistries accessible. ${ }^{38-42}$ The use of halogenase enzymes from secondary metabolism for the installation of halogens into both natural and synthetic scaffolds, is therefore an attractive prospect which has potential to develop greener and more selective processes for the production of important halogenated compounds. The use of enzymes in aqueous reaction media and at ambient temperatures, in addition to reducing the waste generated from production of unwanted regioisomers, 
could have a profound effect on all sectors of the chemical industry. This review will focus on the work, reported to date, that aims to develop these enzymes towards reliable biocatalysts for industrial biotransformations, in addition to work on closely related monooxygenase enzymes may aid their development.

A<smiles>O=C1CN=C(c2ccccn2)c2cc(Br)ccc2N1</smiles><smiles>CC(=O)C(c1ccccc1Cl)N1CCc2sccc2C1</smiles>

Clopidogrel

Bromazepam Anxiety

Anti-platelet<smiles>O=C1Nc2ccc(Cl)cc2[C@](C#CC2CC2)(C#CC(F)(F)F)O1</smiles>

Efavirenz Anti-retroviral<smiles>CN1C(=O)CN=C(c2ccccc2)c2cc(Cl)ccc21</smiles>

Diazepam Anxiety

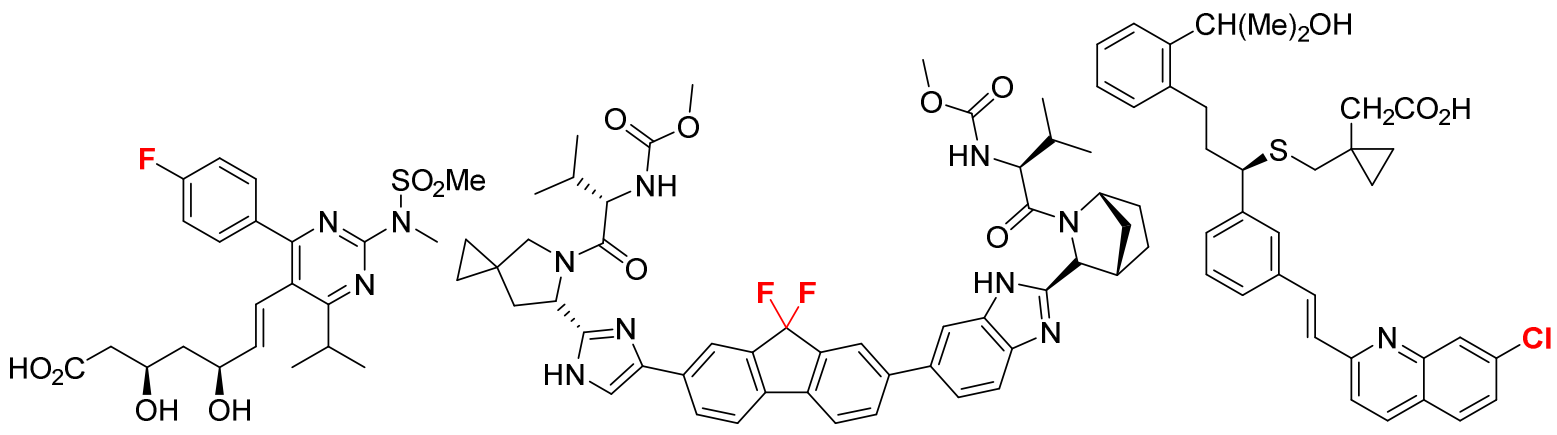

Rosuvastatin Statin
Ledipasvir Hepatitis C
Montelukast Asthma

B<smiles>Cc1ncc(CN2COCN(C)/C2=N\[N+](=O)[O-])s1</smiles><smiles>Fc1ccc(C2(Cn3cncn3)OC2c2ccccc2Cl)cc1</smiles>
Imidacloprid Thiamethoxam Insecticide

Epoxiconazole Fungicide<smiles>CCOCN(C(=O)CCl)c1c(C)cccc1CC</smiles>

Acetochlor Herbicide<smiles>CCNc1cc(NC(C)C)nc(Cl)n1</smiles>

Atrazine Herbicide<smiles>COC(O)C(O)C(O)C(O)CO</smiles>

Rebeccamycin

Anti-tumour properties<smiles>CON1C(=O)C2SSC3c4cc(Cl)c(O)cc4OC1C3C2=O</smiles>

\section{Aspirochlorine} Mycotoxin<smiles>O=C(N[C@H](CO)[C@@H](O)c1ccc([N+](=O)[O-])cc1)C(Cl)Cl</smiles>

\section{Chloramphenicol} Antibiotic

Figure 1: (A) Examples of top-selling halogen-containing pharmaceuticals. (B) Halogenated agrochemicals. (C) Halogenated natural products with known potent bioactivity. 


\section{Haloperoxidases}

Haloperoxidases were amongst the first halogenase enzymes to be discovered and characterised in vitro. Enzymes of this class generate hypohalous acid as the halogenating agent from hydrogen peroxide and halide ions. Chlorination, bromination and iodination can be observed with this type of enzyme, however fluorination has yet to be detected - most likely due to the high redox potential and tight aqueous solvation of fluoride. These enzymes are classified by the most electronegative halide they can activate. For example, a chloroperoxidase can activate chloride, bromide and iodide, whereas a bromoperoxidase can activate bromide and iodide but not chloride - although this does not always correlate with the rate of halogenation. ${ }^{43}$ Haloperoxidases can be further classified based on the cofactor that they utilise and this will be discussed in the sections that follow.

Generally, haloperoxidase activity can be screened for using substrates whose spectral properties change upon halogenation. Monochlorodimedone (1) has been used in numerous assays to assess both bromination and chlorination activity following the change in UV absorbance maxima from 290 $\mathrm{nm}$ to $270 \mathrm{~nm}$ (Figure 2). ${ }^{43-46}$ This assay does have its draw backs with both false negatives and false positives reported for specific vanadium-dependent chloroperoxidases. ${ }^{47-49}$ Other assays utilise phenol red and form bromophenol blue ${ }^{50-53}$ or monitor the formation of triiodide. ${ }^{43,54}$

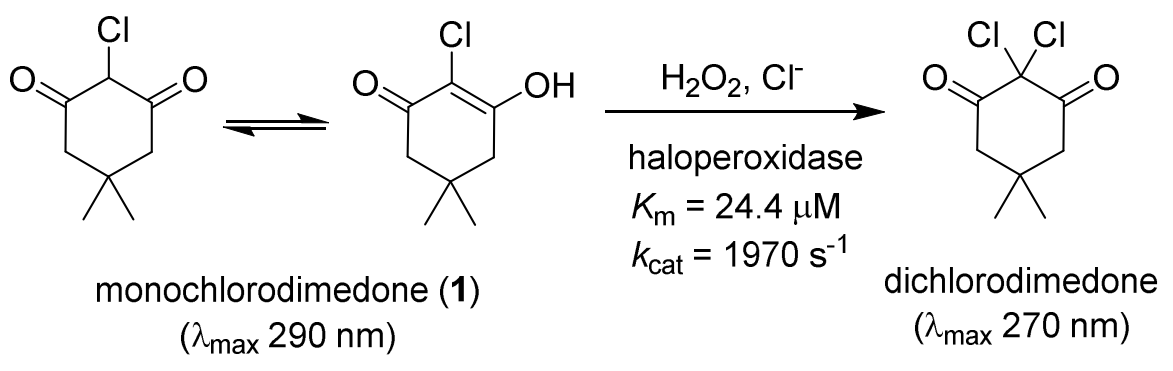

Figure 2: Monochlorodimedone-based assay for detecting haloperoxidase activity. The kinetic parameters displayed are for the chlorination of 1 by CPO from Caldariomyces fumago. ${ }^{55}$

\subsection{Heme-Iron Dependent Haloperoxidases}

The first halogenating enzyme to be identified was the chloroperoxidase from the fungus Caldariomyces fumago (Leptoxyphium fumago) which was discovered during the investigation of caldariomycin biosynthesis. ${ }^{46,56,57}$ The C. fumago chloroperoxidase dihalogenates 1,3cyclopentanedione leading to caldariomycin, however it is also capable of halogenating other electron rich substrates. ${ }^{58}$ 
Crystallography revealed the $C$. fumago chloroperoxidase to be a $42 \mathrm{kDa}$ glycoprotein with a heme cofactor and unusual tertiary structure dominated by 8 helicies (Figure 3A). ${ }^{59-62}$ The enzyme shares features of both cytochrome P450s and peroxidases. ${ }^{59}$ The proximal heme ligand is cysteine (Cys29), as in cytochrome P450s, but the distal side of the heme is polar like peroxidases (Figure 3B). A further difference between the traditional peroxidases and chloroperoxidase can be noted in the general acid-base catalytic group which is a glutamate in chloroperoxidase, rather than a histidine which is found in the peroxidases. Glutamate is thought to participate in peroxide O-O bond cleavage. When this glutamate residue is mutated to histidine, chlorination activity is severely reduced. ${ }^{63}$

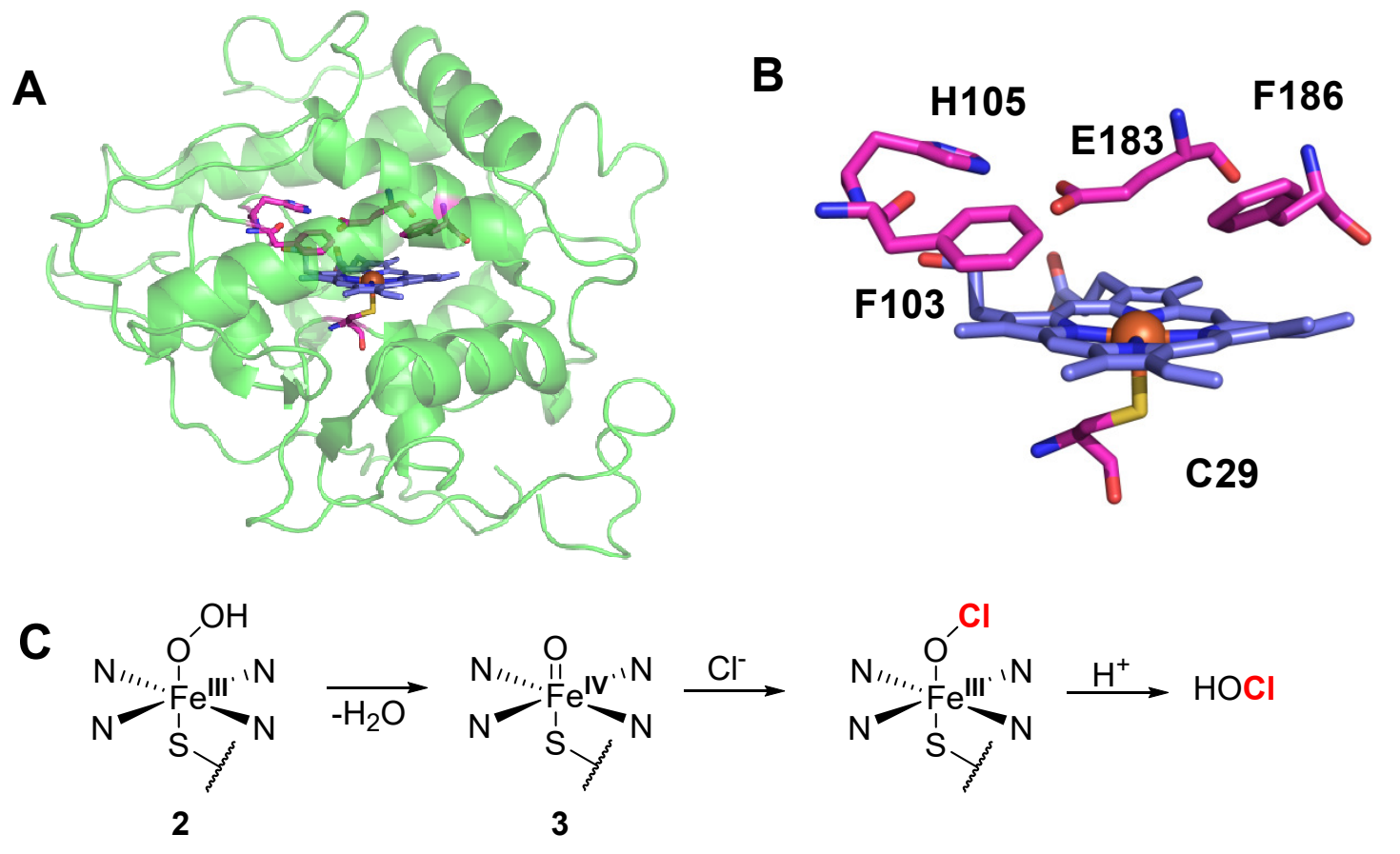

Figure 3: (A) Overall structure of chloroperoxidase from C. Fumago (PDB 1CPO). (B) Active site of CPO from C. Fumago (PDB 1CPO). Blue sticks represent heme and orange spheres represent Fe. (C) Proposed catalytic cycle of hypochlorus acid eneration by Fe"-heme halogenases.

The catalytic cycle of chloroperoxidase is initiated through the binding of peroxide to the axial position of the $\mathrm{Fe}^{\text {III }}$ complex (2), followed by the heterolytic O-O bond cleavage leading to the formation of the $\mathrm{Fe}^{\mathrm{IV}}$-oxo species (3) which is known as compound I. The halide ion is then oxidised by compound I generating hypohalous acid and regenerating the Fe ${ }^{\text {III }}$ resting state (Figure $3 \mathbf{C}$ ). ${ }^{6064,65}$ There has been considerable debate about how hypohalous acid then reacts with substrates, however due to the lack of selectivity conferred by the enzyme, it is likely that hypohalous acid is freely diffusible and can therefore react with many substrates that are susceptible to electrophilic attack (Figure 4). ${ }^{66-72}$ 

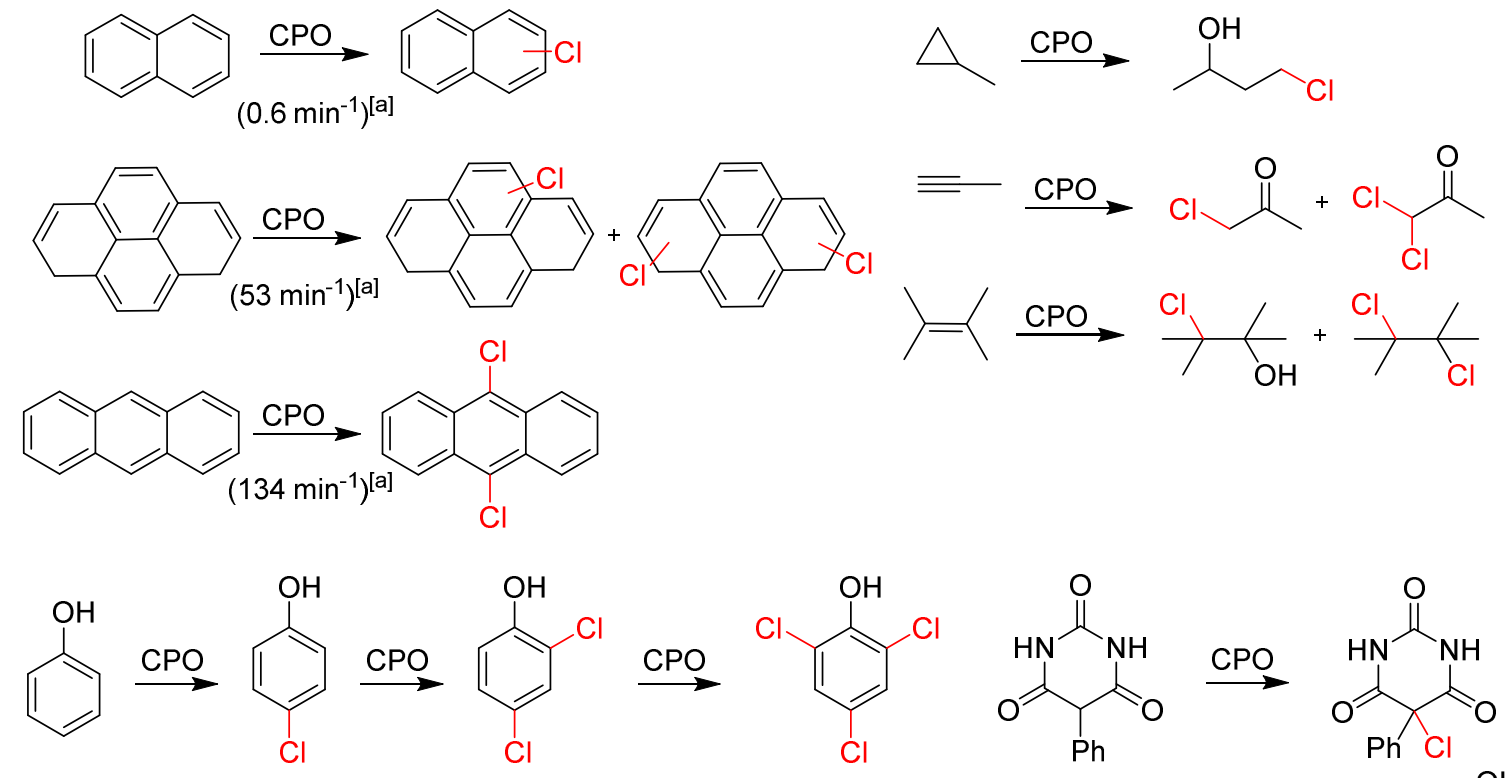<smiles>Cc1cc(Cl)c(C(=O)Cc2ccccc2C(=O)O)c(O)c1O</smiles>

Figure 4: Fe-heme halogenase-catalyzed biotransformations.[a] Specific activity of substrate halogenation by CPO. ${ }^{66}$

\subsection{Vanadium-Dependent Haloperoxidases}

A number of vanadium-dependent haloperoxidases are also known, the first of which to be identified was from the brown algae Ascophyllum nodosum. ${ }^{73,74}$ Vanadium-dependent haloperoxidases are mainly found in marine organisms with bromoperoxidases predominating. ${ }^{45,75-79}$ Vanadium-dependent haloperoxidases have been found in algae, fungi, lichens and more recently bacteria. ${ }^{48,73,80-83}$ These enzymes can be recombinantly expressed in $E$. coli and yeast and the bromoperoxidase from $A$. nodosum is commercially available..$^{50,77,84-86}$ Vanadium-dependent haloperoxidases have been subject to mutagenesis to further improve their thermal stability as well as solvent and $\mathrm{pH}$ tolerance. ${ }^{50,87,88}$

Structurally, the vanadium-dependent haloperoxidases are similar to the acid phosphatases, therefore it is not surprising that these enzymes can bind phosphate in place of vanadate and exhibit phosphatase activity. ${ }^{89}$ Phosphate buffers can be therefore be useful for the crystallisation of the enzymes, but should be avoided in assays as phosphate can act as a competitive inhibitor. ${ }^{90,91}$ The vanadate ion is bound at the bottom of a wide funnel which is between $15-20 \AA$ in length at the core of 
two four helix bundles. A conserved histidine bonds to the vanadium, whilst vanadate oxygens are coordinated to basic residues (one lysine and two arginines) (Figure 5B). ${ }^{92,93}$ While the active site is highly conserved amongst the vanadium-dependent haloperoxidases, their quaternary state is highly variable. The vanadium-dependent chloroperoxidase from Curvularia inaequalis is monomeric, whereas the vanadium-dependent bromoperoxidases from $A$. nodosum and Corallina pilulifera are a homodimer and a homododecamer respectively. ${ }^{43,93-95}$
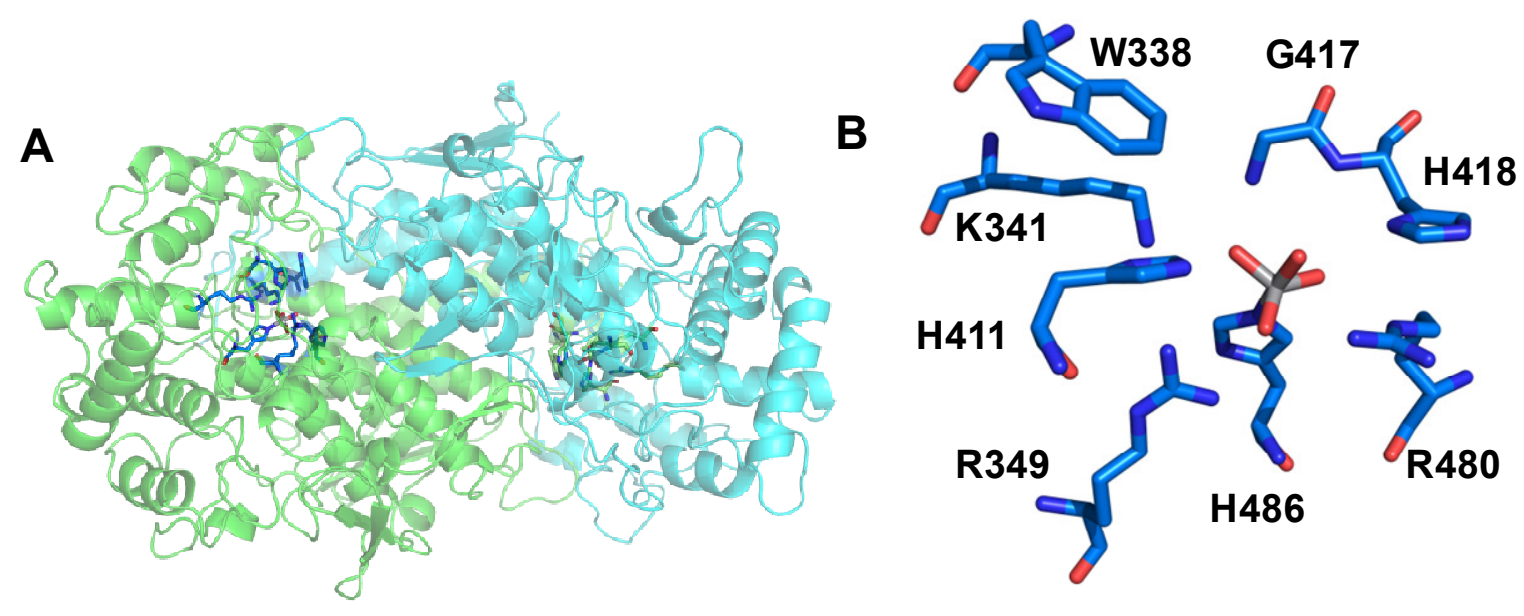

C

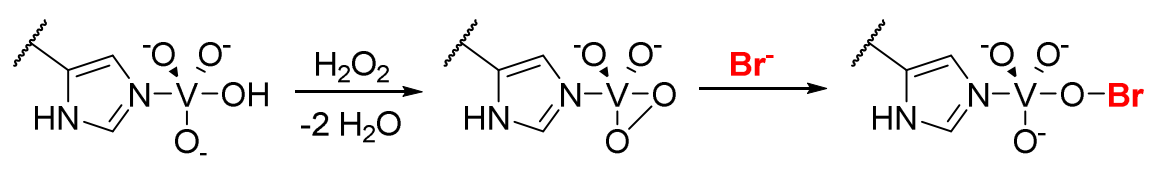

Figure 5: (A) Overall structure of C-BPO from A. nodosum (PDB 1QI9). (B) Active site of C-BPO from A. nodosum (PDB 1QI9). (C) Proposed catalytic cycle of hypobromous acid generation by vanadiumdependent haloperoxidases.

Unlike the heme-dependent haloperoxidases, oxidation state of the catalytic vanadium center is maintained throughout the catalytic cycle offering the advantage that these enzymes do not suffer from oxidative inactivation. Initially, hydrogen peroxide binds to the distal position of the vanadate complex leading to a loss of water and the formation of peroxo-vanadate intermediate. Halide ion is then oxidised, leading to the formation of hypohalous acid (Figure 5C). Examples in the literature suggest that, like the heme-dependent haloperoxidases, the vanadium-dependent haloperoxidases can release free hypohalous acid allowing halogenation of a variety of substrates (Figure 6), ${ }^{76,96-98}$ although some examples of substrate specificity have been observed. ${ }^{92,99,100}$ 


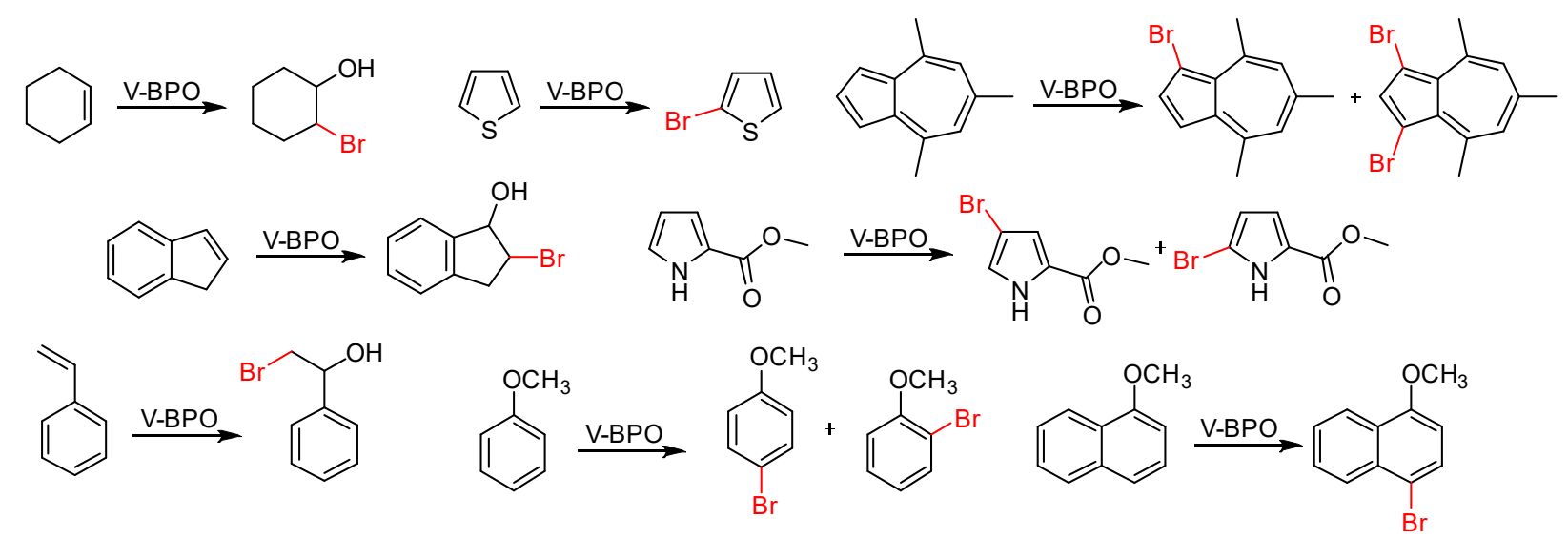

Figure 6: Typical substrates from vanadium-dependent haloperoxidases.

The vanadium-dependent bromoperoxidase from Corallina officinalis was found to be selective and utilised to asymmetrically brominate and cyclize the sesquiterpene $(E)-(+)$-nerolidol $(4)$ to the marine natural products $\alpha-, \beta$ - and $\gamma$-snyderol (5 to 7, Figure 7A). Non-enzymatic bromination of $E-(+)-$ nerolidol $(\mathbf{X})$ produced a mixture diastereomers, whereas the bromoperoxidase only formed a single diastereomer. This study demonstrated the stereo- and regio-selectivity of these enzymes for the first time, thereby suggesting that the substrate binds to active site in a specific manner (Figure 7) ${ }^{76}$

More recently, the first example of a bacterial vanadium-dependent chloroperoxidase was reported from Streptomyces sp. CNQ-525. Three genes were identified, napH1, H3 and $H 4$ with homology to other known vanadium-dependent haloperoxidases. It was hypothesized that at least one of these genes encoded for an enzyme that was involved in the halogenation and cyclisation of SF2415B1 (8) to SF2415B3 (9) in a similar manner to $(E)-(+)$-nerolidol (4). All three enzymes were heterologously expressed in E. coli, however $\mathrm{NapH} 4$ proved to be insoluble. $\mathrm{NapH} 3$ was found to be unable to catalyse the formation of SF2415B3 (9), however NapH1 demonstrated the ability to catalyse the halocyclisation in the presence of hydrogen peroxide and chloride at $\mathrm{pH} 6$ (Figure 7B). Interestingly, $\mathrm{NapH} 1$ was not able to chlorinate non-native substrates, $( \pm)$-nerolidol or lapachol, however nonspecific activity was exhibited with $( \pm)$-nerolidol and lapachol in the presence of bromide ions. ${ }^{48}$ Another bacterial vanadium-dependent haloperoxidase (Mcl24) has been identified from the marine bacterium Streptomyces $\mathrm{CNH}-189$. Mcl24 is a vanadium-dependent chloroperoxidase involved in the late stages of merochlorin (10 and 11) biosynthesis catalysing a site-selective napthol chlorination, followed by a sequence of oxidative dearomatization and terpene cyclization reactions (Figure 7C). Like NapH1, Mcl24 is specific for chloride, however in the presence of bromide monochlorodimedone 
was also brominated, suggesting that halogenation by freely-diffusing hypohalous acid may also occur if substrate is not bound to active site. $49,83,101$

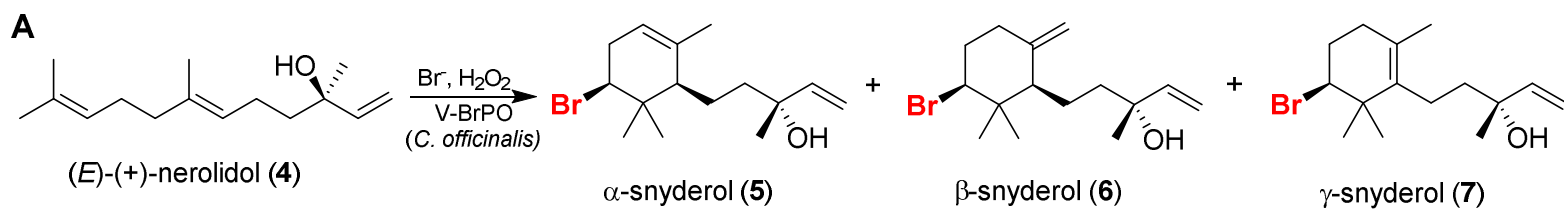

B<smiles>CC(C)=CCCC(C)=CC1C(=O)c2cc(O)c(C)c(O)c2C(=O)C1(O)C=CC(C)C</smiles>

SF2415B1 (8)<smiles>CC(C)=CCC/C(C)=C/C1OC(C)(C)C(Cl)CC12C(=O)c1cc(O)c(C)c(O)c1C2=O</smiles>

SF2415B3 (9)

C

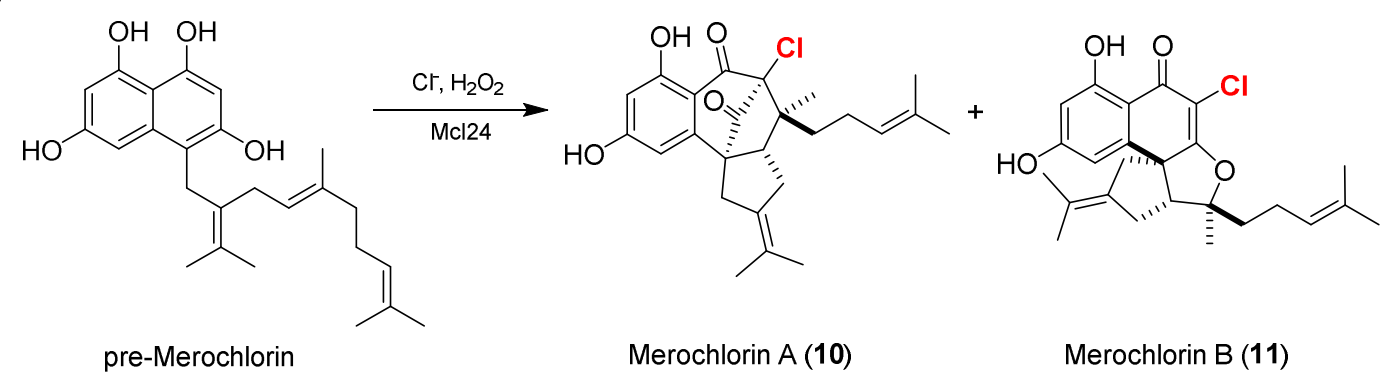

Figure 7: Examples of specific halogenations by vanadium-dependent haloperoxidases using (A) VBrPO from C. officinalis, (B) NapH1 and (C) Mcl24.

While haloperoxidases can halogenate a wide range of substrates under mild conditions, as shown in Figure 4 and Figure 6, they generally either lack specificity or, as in the case of the bacterial vanadium-dependent haloperoxidases, are highly specific and therefore are limited in biocatalytic application.

\section{3. $\alpha$-Ketoglutarate-Dependent Halogenases}

\subsection{Discovery of $\alpha$-Ketoglutarate-Dependent Halogenases}

Non-heme Fe(II)- $\alpha$-ketoglutarate-dependent ( $\alpha-K G)$ halogenases are involved in the halogenation of inactivated carbon centres on aliphatic moieties such as terminal methyl groups and predominately utilize substrates tethered to acyl or peptidyl carrier proteins (PCP). The enzyme class was first 
reported in 2005 , with the first example forming part of the biosynthetic assembly line required for production of the non-ribosomal peptide Syringomycin E (12) in Pseudomonas syringae (Figure 8). The carrier protein tethered L-threonine (L-Thr-S-SyrB1) from Syringomycin biosynthesis was demonstrated to act as a substrate for the SyrB2-mediated chlorination. ${ }^{102}$

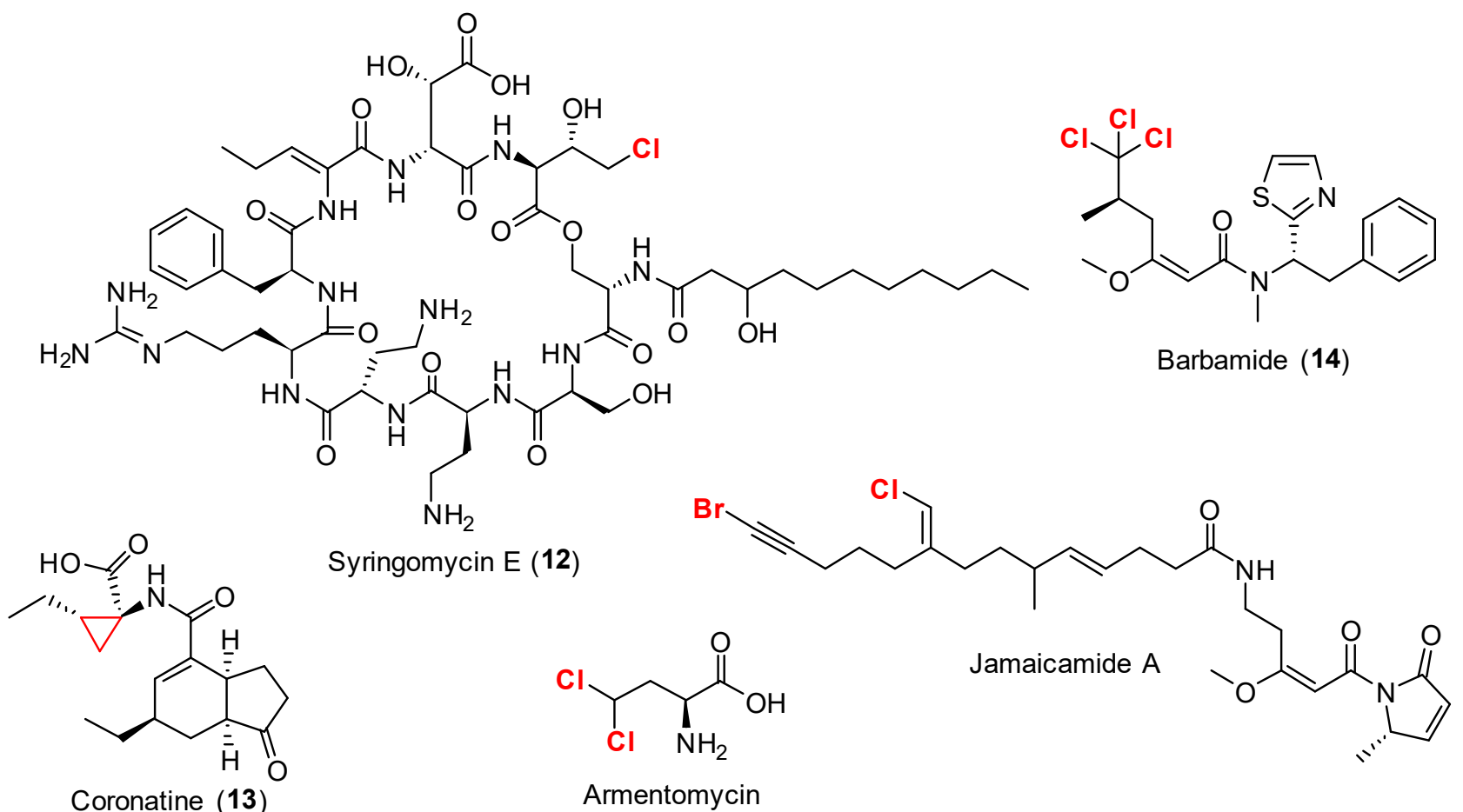

Figure 8: Halogenated natural products produced using non-heme $\mathrm{Fe}(\mathrm{II})-\alpha-\mathrm{KG}$ dependent halogenases. The coronatine cyclopropyl moiety is formed after $\mathrm{y}$-halogenation of I-allo-isoleucine followed by intramolecular ring closure.

The selectivity of SyrB1 for L-Thr was confirmed by kinetic comparison with other amino acids showing a 60-fold preference for threonine over serine $\left(\mathrm{L}-\mathrm{Thr}-K_{\mathrm{m}}=3.1 \pm 0.2 \mathrm{mM}, k_{\text {cat }}=29.1 \pm 0.9\right.$ $\mathrm{min}^{-1}$; L-Ser $-K_{\mathrm{m}} 7.7 \pm 0.5 \mathrm{mM}, k_{\text {cat }} 1.23 \pm 0.05 \mathrm{~min}^{-1}$ ). Isolation of the final product from SyrB2mediated chlorinations confirmed the product to be 4-Cl-L-threonine. SyrB2 was found to not accept free L-threonine at all, meaning that substrate must be tethered to the phosphopantetheine arm of halo-SyrB1 thiolation domain for chlorination to occur. Tethering of the substrate to SyrB1 was confirmed by the detection of $\left[{ }^{36} \mathrm{Cl}\right]-\mathrm{L}-\mathrm{Thr}-\mathrm{S}$-SyrB1 using the radioactive ${ }^{36} \mathrm{Cl}$ and gel dosimetry. In vitro studies revealed a requirement for $\mathrm{Fe}(\mathrm{II}), \mathrm{O}_{2}$ and $\mathrm{Cl}^{-}$for halogenase activity, in addition to quick deactivation of halogenase activity such that no more than seven turnovers could be detected. ${ }^{102}$

Based on the observed cofactor and cosubstrate requirement, and analogy to the $\alpha-K G$ hydroxylases, a mechanism for the $\alpha-K G$ halogenases was proposed involving radical abstraction of the methyl 
hydrogen by a high-valent $\mathrm{Fe}^{\mathrm{IV}}$-oxido species. Recombination of this radical with $\mathrm{Fe}$-bound $\mathrm{Cl}^{-}$was then thought to afford 4-chloro-L-theronine. At a similar time, investigation of the biosynthetic pathway leading to coronatine (13) in $P$. syringae identified $\mathrm{CmaB}$ and $\mathrm{CmaC}$ to be involved in halogenation of the methyl group of L-allo-isolecine which undergoes subsequent cyclisation to generate the cyclopropyl ring of the side chain amino acid (corronamic acid). ${ }^{103}$ The trichloromethyl group of barbamide (14) derivatives from the marine cyanobacterium Lyngbya majuscule was also found to be derived from the pro- $R$ methyl group of leucine. ${ }^{104,105}$ Subsequent in vitro studies have confirmed that two $\alpha-K G$ dependent halogenases (BarB1 and BarB2) are required to trichlorinate a carrier protein tethered L-Leu precursor in barbamide (14) biosynthesis (Figure 8). ${ }^{106}$

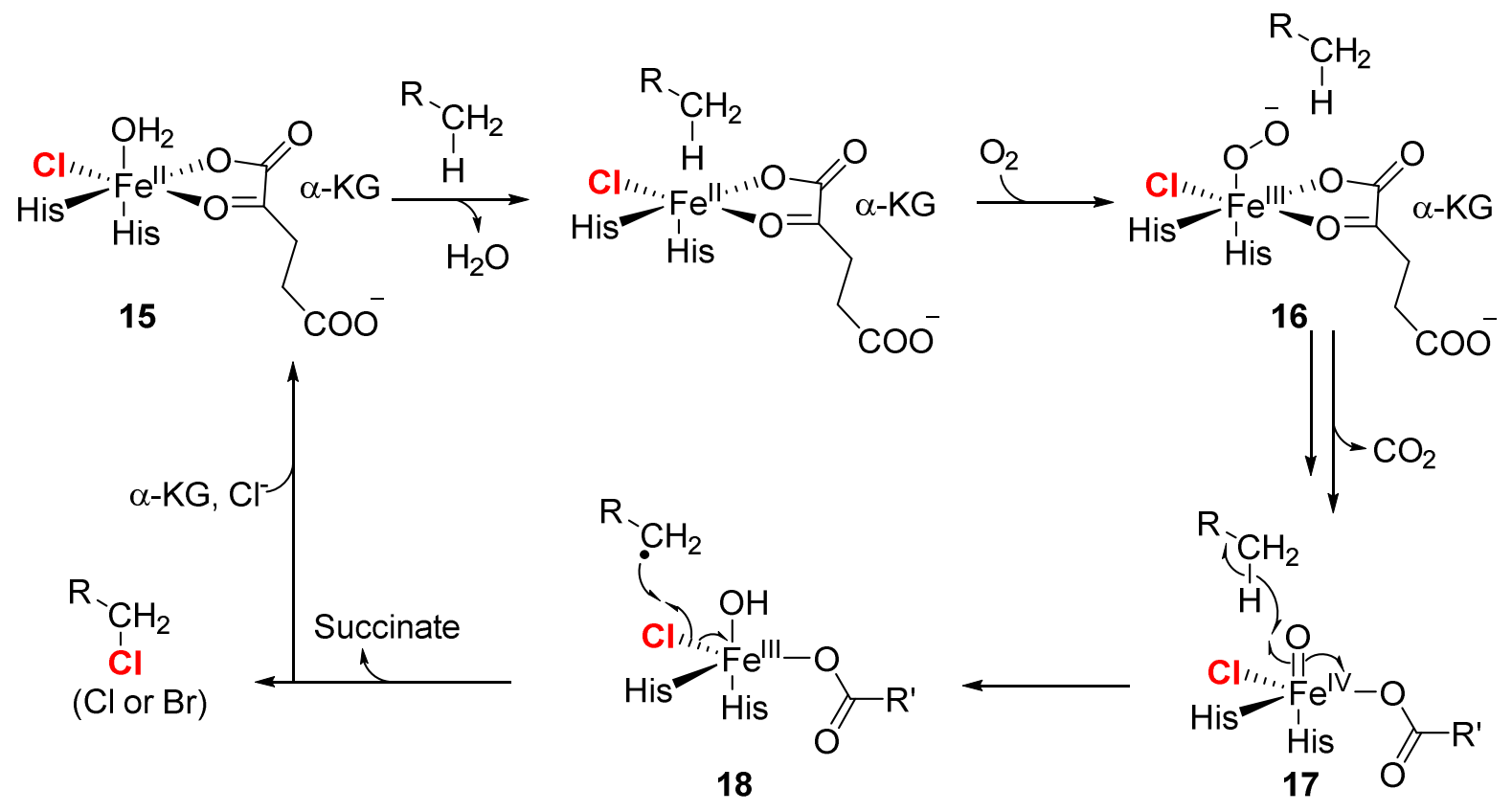

Figure 9: Proposed mechanism for Fe(II)a-KG-dependent halogenases.

Crystallography of SyrB2 subsequently shed further light on the mechanistic aspects of the $\mathrm{Fe}(\mathrm{II}) / \mathrm{a}-$ KG dependent halogenases. ${ }^{107}$ Analogous to the hydroxylation mechanism of TauD, a working mechanism was proposed for these terminal halogenations. SyrB2 was the first structurally characterised mononuclear iron protein which did not display the characteristic 2-His, 1-carboxylate iron coordination. Instead two histidine ligands are present (His116 and His235) and the iron coordinates to a chloride ion rather than carboxylate. It was also observed that water and $\alpha-K G$ coordinate to iron in the resting state (15) (Figure 9). Upon L-Thr-S-SyrB1 binding, water is displaced 
by dioxygen (16) and decarboxylation of $\alpha-K G$ would then lead to a high valent $F e^{\mathrm{IV}}$-oxido intermediate (17). This highly reactive species is then able to radically abstract a hydrogen atom from substrate (18), which can then recombine with a complex bound chlorine producing chlorinated L-Thr$\mathrm{S}$-SyrB1 and regenerated $\mathrm{Fe}(\mathrm{II})$. Although there is clearly the possibility of hydroxylation during the course of the reaction, chlorination seems to be greatly favoured. One possible explanation is the relative positioning of the chloride ligand towards the substrate, exclusively affording halogenation.

Recently the $\mathrm{Fe}(\mathrm{II}) / \mathrm{a}-\mathrm{KG}$ dependent halogenase WelO5 was discovered from the welwitindoline biosynthetic pathway in Hapalosiphon welwitschii. ${ }^{108-110}$ It was shown that this enzyme can regioselectivley monochlorinate an aliphatic carbons to afford 12-epi-Fischerindole G (19) and 12-epiHapalindol E (20, Figure 10A). ${ }^{111}$ WelO5 is particularly notable, as the first example of an Fe(II)/a-KG dependent halogenase that functions independently of a carrier protein. It is also the first example of a halogenase installing a halogen atom stereoselectively on a non-activated position, C13 of 12-epifischerindole $\mathrm{G}$, to create a new stereogenic centre. When the WelO5 sequence was compared to other members of the $\alpha-K G$ dependent oxygenase superfamily, the $D / E$ residue in the characteristic $\mathrm{HX}(\mathrm{D} / \mathrm{E}) \mathrm{XnH}$ motif for iron binding was found to be absent and replaced by the glycine 166 residue. The two histidine residues $\mathrm{H} 164$ and $\mathrm{H} 259$ were found crucial for iron coordination. Site directed mutagenesis of $\mathrm{H} 259$ to phenylalanine completely abolished activity towards the 12-epi-fischerindole $\mathrm{U}$. The recent publication of the WelO5 crystal structure revealed the close proximity of the $\mathrm{C} 13$ halogenation site to the putative cis-halo-oxo-Fe ${ }^{I V}$ complex which confirms its preferred activity towards halogenation (Figure 10C). ${ }^{111}$ Unlike the standard $\alpha-K G$ hydroxylases, WelO5 contains a glycine (Gly166) at the sequence position of an aspartate or glutamate ligand. Accordingly, it was shown that the G166D variant exclusively gives C13 hydroxylation, as predicted. It was also demonstrated that the second-sphere mutant S189A produced a mixture of hydroxylated and halogenated product showing how outer sphere hydrogen bonding can influence chemoselectivity. ${ }^{111}$ 
A<smiles>C=C[C@@]1(C)[C@H](C(C)(C)C)[C@H]2c3c([nH]c4ccccc34)[C@@H](C)[C@@H]2C[C@H]1Cl</smiles>

12-epi-Fischerindole G (19)<smiles>C=C[C@]1(C)C(Cl)CC(C(=C)C)C(c2c[nH]c3ccccc23)C1N</smiles>

12-epi-Hapalindol E (20)
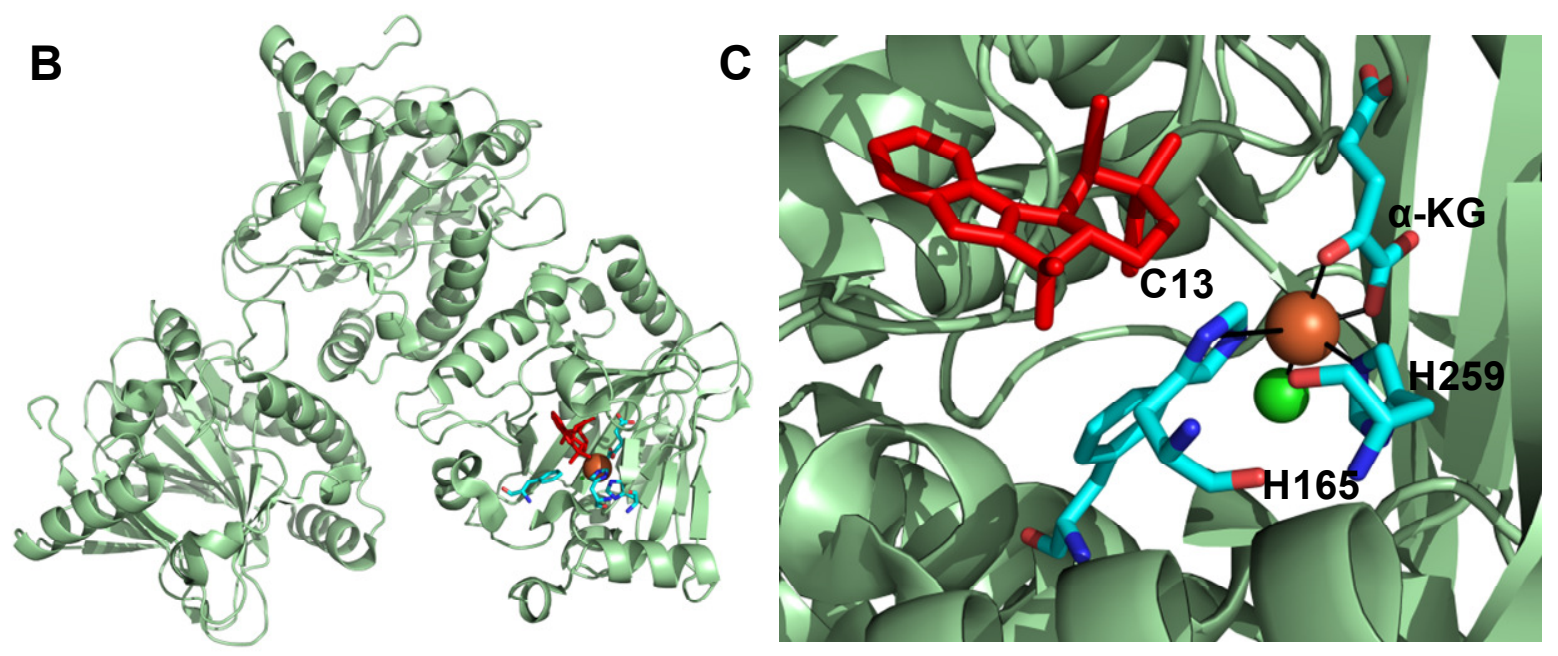

Figure 10: (A) Selectively chlorinated products from WelO5-catalysed halogenation. (B) Crystal structure of Wel05 showing overall structure (PDB 5IQV). (C) Active site coordination of Wel05 (PDB $5 \mathrm{IQV})$. $\mathrm{Fe}$ and $\mathrm{Cl}$ are represented by orange and green spheres respectively.

\subsection{Application of Fe(II)/ $\alpha-K G$ Dependent Halogenases as Biocatalysts}

The proteinaceous nature of substrates for the majority of $\mathrm{Fe}(\mathrm{II}) / \alpha-\mathrm{KG}$ halogenases forms a barrier for their application as biocatalysts. These enzymes also have to be purified under inert conditions and their turnover numbers are generally low. In fact kinetic parameters are difficult to determine due to auto-oxidative inactivation of the biocatalyst and limited substrate availability (maximum of 75 turnovers) which restricts their application in industrial biocatalysis. Moreover, the substrate scope identified to date seems to be largely limited to natural amino acids (Figure 11). However the recent discovery of WelO5 allowing halogenations without the requirement of a carrier protein opens new opportunities for the application of those enzymes in synthesis. Moreover, given that mutagenesis studies and have shown that the Fe(II)/a-KG halogenases can be switched to hydroxylases, ${ }^{107,111,112}$ it seems plausible halogenases can be engineered from $\mathrm{Fe}(\mathrm{II}) / \alpha-\mathrm{KG}$ dependent hydroxyases. Indeed a recent report has demonstrated that it is possible to engineer a new halogenase enzyme from an $\mathrm{Fe}(\mathrm{II}) / \alpha-K G$ dependent hydroxylase using structure guided mutagenesis. ${ }^{113}$ This approach ${ }^{113}$ is attractive given that there are more known $\mathrm{Fe}(\mathrm{II}) / \mathrm{a}-\mathrm{KG}$-dependent hydroxylases than halogenases, 
and the range of substrates that are processed by the hydroxylases is greater and more structurally diverse. Moreover, unlike halogenases which, with the exception of WelO5 halogenate carrier proteintethered substrates, the majority of hydroxylases utilise simple non-tethered substrates. Despite their low catalytic activity, the fact that $\mathrm{Fe}(\mathrm{II}) / \alpha-\mathrm{KG}$ enzymes halogenate, or hydroxylate, unactivated aliphatic substrates with regio- and stereo-selectively is attractive for further investigation given that there are few viable synthetic alternatives.

(i)

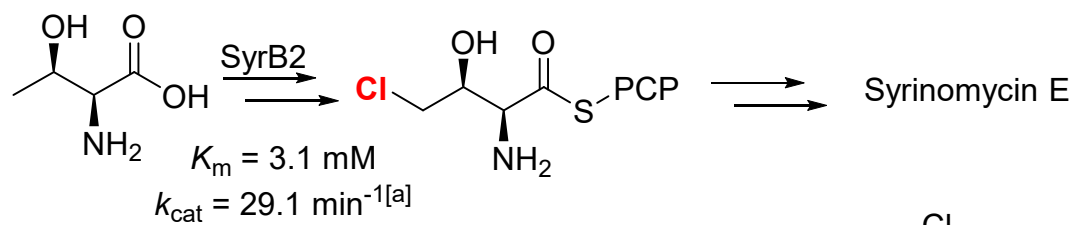

(ii)<smiles>CC(C)CC(N)C(=O)O</smiles>

(iii)<smiles>CC[C@H](N)C(=O)O</smiles>

(iv)<smiles>C#CP=PSC(=O)C(N)[C@H](CC)CCl</smiles>

(v)<smiles>N[C@@H](Cc1c[nH]c2ccccc12)C(=O)O</smiles><smiles>CC#CP=PSC(=O)C(N)C[C@H](C)C(Cl)(Cl)Cl</smiles><smiles>[CH-]=C</smiles><smiles>C=C[C@]1(C)CC[C@@H]2c3c([nH]c4ccccc34)[C@@H](C)[C@H]2C1C</smiles><smiles>O=N[Se+2]O</smiles><smiles>CO/C(=C/C(=O)N(C)[C@H](Cc1ccccc1)c1nccs1)CC(C)C(Cl)(Cl)Cl</smiles>

Barbamide<smiles>C#C[C@H](N)CC(Cl)C(=O)O[Pb]SC(=O)C(N)CCCl</smiles><smiles>CC[C@@H]1C[C@]1(N)C(=O)O</smiles>

Coronamic acid

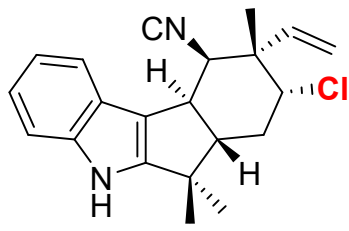

12-epi-Fischerindole G (19)

Figure 11: Involvement of $\mathrm{Fe}(\mathrm{II}) / \mathrm{\alpha}-\mathrm{KG}$ dependent halogenases in the biosynthesis of halogenated natural products. [a] Refers to the loading of L-Thr onto SyrB1 as those for SyrB2 could not be obtained due to enzyme deactivation. TON for chlorination of L-Thr-S-PCP by SyrB2 is $<7 .{ }^{102}[b]$ Refers to the chlorination of free-standing substrate by WelO5. ${ }^{108} \mathrm{PCP}=$ peptidyl carrier protein. TON $=$ turnover number. 


\section{$\underline{\text { 4. Flavin-Dependent Halogenases }}$}

\subsection{Flavin-Dependent Halogenases in Nature}

Flavin dependent halogenase (Fl-Hal) enzymes belong to the superfamily of flavin-dependent monooxygenases. ${ }^{114,115} \mathrm{~A}$ key feature of this class of enzymes is their activation of molecular oxygen using reduced flavin $\left(\mathrm{FADH}_{2}\right)$ to generate C4a-hydroperoxy flavin (21), ${ }^{116-118}$ which allows diverse reactions such as hydroxylation, epoxidation, Baeyer-Villager oxidation and heteroatom oxidations. ${ }^{119-}$ 121 The flavin-dependent halogenases are typically classified as two-component monooxygenases, meaning that they utilise freely-diffusing reduced flavin co-factors produced by an additional flavinreductase enzyme. ${ }^{115}$ In addition to the flavin reductase, several FI-Hals from NRPS and PKS pathways also require enzymes for substrate activation or tethering. ${ }^{32}$ In the last two decades, a number of flavin-dependent halogenases from both bacterial and fungal biosynthetic pathways have been identified. ${ }^{114,122-126}$

The flavin-dependent halogenases were originally thought to operate via a mechanism analogous to other flavin-dependent monooxygenases through direct reaction of substrate with C4a-hydroperoxyflavin (FAD-OOH, 21), followed by subsequent reaction with halide anion. ${ }^{123,127-129}$ However crystallography of the tryptophan (22) 7-halogenase PrnA revealed that the substrate and flavin binding sites were spatially distinct, separated by a $10 \AA$ tunnel, and therefore direct interaction of the substrate with the co-factor is not possible. ${ }^{130,131}$ Mechanistic studies subsequently demonstrated that $\mathrm{FAD}-\mathrm{OOH}(\mathbf{2 1})$ was generated prior to halogenation, even in absence of substrate, suggesting that nucleophilic attack of chloride on $\mathbf{2 1}$ may result in hypochlorous acid generation in the flavin-binding domain. ${ }^{132}$ Further work demonstrated the formation of a long-lived enzyme-chloride adduct which, after identifying the vital importance of an active site lysine residue, is believed to be a covalent chloramine adduct or hydrogen-bonded lysine-hypochlorous acid species. ${ }^{133}$ This electrophilic chlorine species is believed to be ultimately responsible for aromatic substitution of the substrate to generate the Wheland intermediate (23), which is then deprotonated by a conserved glutamate residue to afford chlorinated product (24, Figure 12). ${ }^{114,131,133-135}$ Positioning of this active site lysine relative to substrate is therefore believed to control which position of the substrate is halogenated. ${ }^{130}$ Direct monooxygenase-type activity is thought to be prevented in the tryptophan $\mathrm{Fl}$-Hals by a 
conserved structural motif (WxWxIP) which blocks direct contact between FAD-OOH (21) and substrate. ${ }^{130,136}$

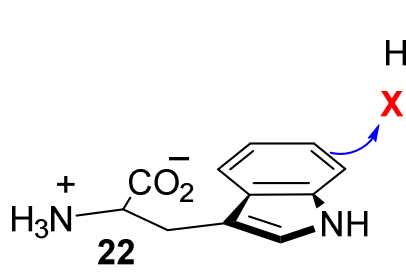

22

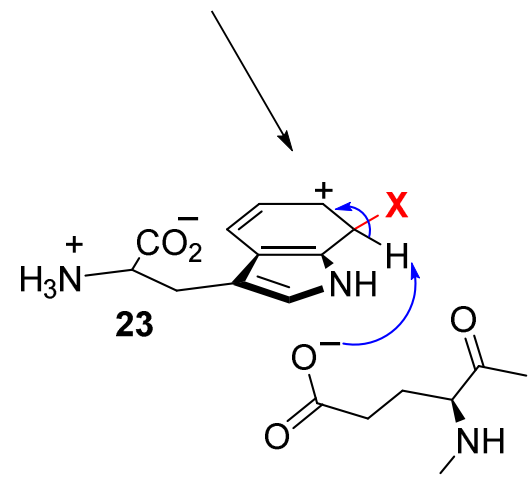

Lys79<smiles></smiles>

( $\mathrm{x}-\mathrm{OH}$

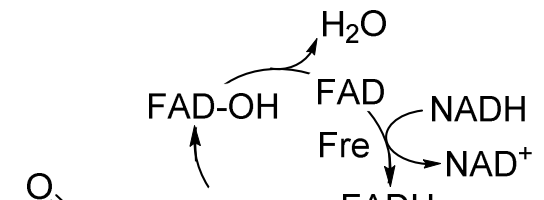

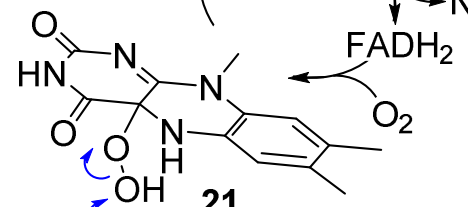

21<smiles></smiles><smiles>[X]c1cccc(CC([NH3+])[O-])c1</smiles>

Figure 12: Proposed mechanism of flavin-dependent tryptophan halogenase catalysed halogenation.

This highly conserved motif, along with the nucleoside-binding motif GxGxxG responsible for binding $\mathrm{FADH}_{2}$, are therefore considered to be the signature motifs for identifying putative Fl-Hal genes. These signature motifs have been used to identify flavin-dependent halogenases from diverse biosynthetic pathways that are responsible for the halogenation of pyroles, phenols and other aromatic natural product precursors (Figure 13). Similar to other flavin-dependent monoxygenases, Fl-Hals of different substrate scope are thought to conserve the core flavin-binding domain with most structural changes coming about from the recruitment of different substrate binding domains. ${ }^{115} \mathrm{Fl}-$ Hals can therefore be further sub-divided based upon their natural substrate. 


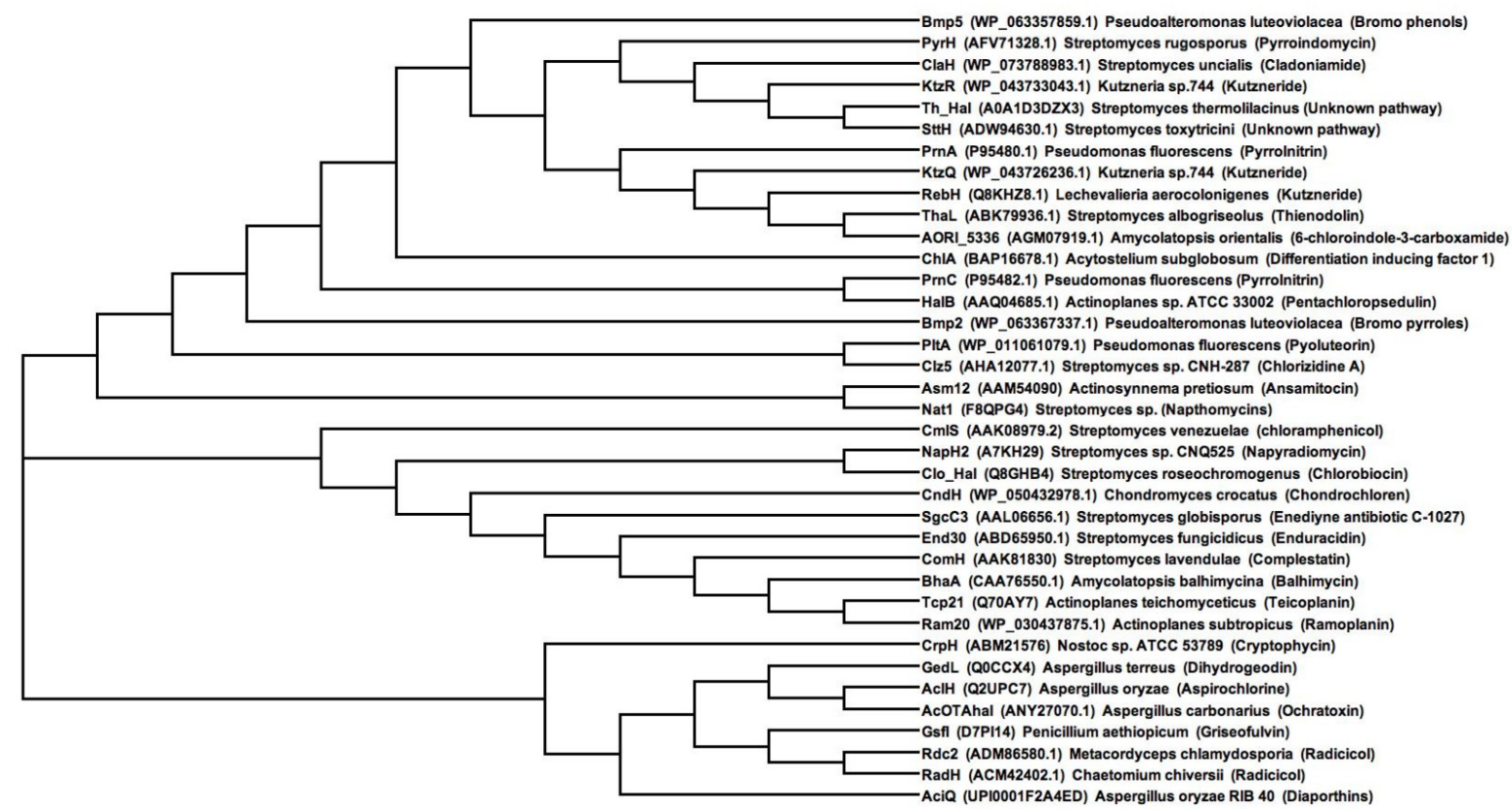

Figure 13: Phylogenetic tree of the Fl-Hals discussed herein. Generated using the neighbour-joining tree method without distance corrections via Dendroscope 3.

\subsubsection{Flavin-Dependent Tryptophan Halogenases}

The flavin-dependent tryptophan halogenases are the most extensively studied and characterised $\mathrm{Fl}-$ Hals. ${ }^{32-34}$ The first tryptophan Fl-Hal to be identified was PrnA which is required for the biosynthesis of pyrrolnitrin (25), a broad spectrum antifungal compound, produced by Pseudomonas fluorescens. ${ }^{127,137,138}$ In the pyrrolnitrin pathway, PrnA chlorinates the 7-position of tryptophan, whilst a second Fl-Hal, PrnC, chlorinates the pyrrolic intermediate 26 (Figure 14). Another tryptophan 7halogenase $\mathrm{RebH}$, with $55 \%$ sequence identity to $\operatorname{PrnA}$, was subsequently identified from the rebaccamycin biosynthetic pathway in Lechevalieria aerocolonigenes. ${ }^{123,124,139} \mathrm{X}$-ray crystal structures of these two FI-Hals were subsequently determined which, along with further biochemical studies, provided the basis of our understanding of the mechanism and reactivity of Fl-Hals. ${ }^{114,123,127,132,134,135}$

Studies into the biosynthesis of the di-chlorinated nonribosomal peptide kutzneride (27), an antifungal from actinobacteria Kutzneria sp. 744, revealed that two tryptophan Fl-Hals (KtzQ and KtzR) and a cryptic $\mathrm{Fe}(\mathrm{II}) / \alpha-\mathrm{KG}$ dependent halogenase (KtzD), were required from kutzneride biosynthesis. ${ }^{140-142}$ $\mathrm{KtzQ}$ and KtzR work sequentially, with KtzQ catalysing the formation of 7-chlorotryptophan prior to halogenation at the 6-position by KtzR to produce 6,7-dichlorotryptophan (28, Figure 14). ${ }^{141}$ In vitro studies showed that KtzR exhibits a 120-fold substrate preference for 7-chlorotryptophan (24) over 
non-chlorinated tryptophan. ${ }^{141} \mathrm{~A}$ number of independent tryptophan 6-halogenases have also been identified recently. ${ }^{143-147}$ For example, ThaL from the indole alkaloid thienodolin (29) pathway in Streptomyces albogriseolus is responsible for the 6-chlorination of tryptophan prior to thiophene ring formation. ${ }^{144,146,148,149} \mathrm{SttH}$ from Streptomyces toxytricini and Th_Hal from the thermophile Streptomyces violaceusniger SPC6 have also been shown to function as tryptophan 6halogenases. ${ }^{143,145}$ Although both have been characterised in vitro and their structures determined, ${ }^{143,145,150}$ the biosynthetic pathways in which they function are yet to be explored. Recently a tryptophan 6-halogenase (AORI_5336) was identified in a hydrid NRPS/PKS hybrid gene cluster of Amycolatopsis orientalis, which appears to be involved in the biosynthesis of the plant growthregulating compound $30 .{ }^{147}$

The only fully characterised tryptophan 5-halogenase is $\mathrm{PyrH}$ from the pyrroindomycin producing strain Streptomyces rugosporus. ${ }^{130,151}$ Although a tryptophan 5-halogenase is known to be involved in the biosynthesis of the bis-indole alkaloid cladoniamide (31) in Streptomyces uncialis, details of in vitro activity are still lacking, although in vivo studies suggest it may be of low activity compared to other tryptophan halogenases. ${ }^{152,153}$ Additionally, a recent report suggests that a tryptophan 5halogenase may be responsible for halogenation of a tryptophan moiety in a peptide chain, rather than freely-diffusing tryptophan, in biosynthesis of the lantibiotic NAI-107. ${ }^{154}$ Structural and phylogenetic analyses (Figure 13) provide details of the similarities between halogenases of different regioselectivity. Many of the structural differences are present in a single loop region, with the tryptophan 7-halogenase PrnA containing a larger loop region (L443-W455) compared to the 5- and 6-halogenases, suggesting that the 5-, 6- and 7-tryptophan halogenases may have evolved from the same ancestral enzyme via loop insertions and deletions to give rise to different orientations of substrate in the active site. ${ }^{130,150}$ 
<smiles>Cc1ccc(-c2c[nH]cc2Cl)c([N+](=O)[O-])c1Cl</smiles>

22

$K_{\mathrm{m}}=0.7 \mu \mathrm{M}$

$\mathrm{k}_{\text {cat }}=1.1 \mathrm{~min}^{-1}$

Pyrrolnitrin (25)

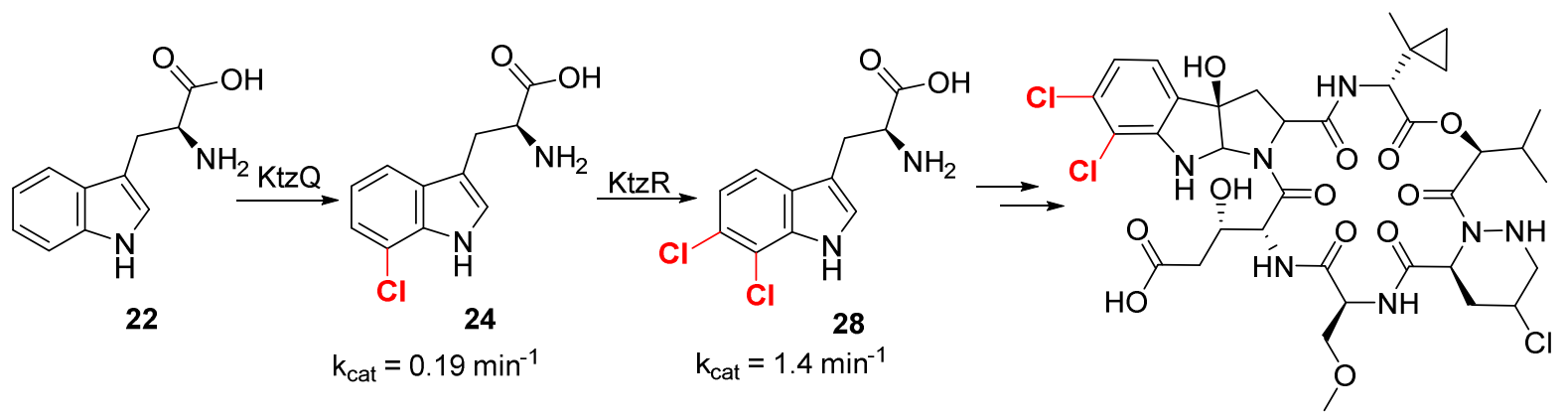<smiles>NC(=O)c1cc2c([nH]c3cc(Cl)ccc32)s1</smiles>

Thienodolin (29)<smiles>NC(=O)c1c[nH]c2cc(Cl)ccc12</smiles>

30

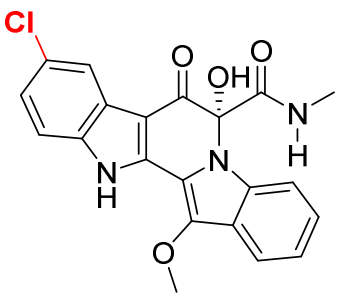

Cladoniamide D (31)

Kutzneride $135(27)$

Figure 14: Halogenated natural products biosynthesised using flavin-dependent tryptophan halogenases. ${ }^{141,155}$

\subsubsection{Flavin-Dependent Pyrrole Halogenases}

In addition to the pyrrolnitrilin halogenase, PrnC, which halogenates a free standing pyrrolic substrate, there are a number of $\mathrm{Fl}-\mathrm{Hals}$ that process pyrrol-2-carboxy thioester substrates (32) tethered to peptidyl carrier proteins in NRPS or hybrid NRPS-PKS assembly lines (Figure 15). ${ }^{122,156}$ This includes PItA from the pyoluteorin biosynthetic gene cluster. ${ }^{122,137,157}$ The crystal structure of PItA revealed a unique helical region at the C-terminus which blocks the substrate binding cleft. Binding of PItLtethered substrate induces a conformation change however, which allows access to the substratebinding cleft. ${ }^{122}$ Interestingly PItA does not contain a residue analogous to the catalytic glutamate found with the tryptophan halogenases, suggesting a water molecule, or an as yet unidentified active site residue, might function to deprotonate the Wheland intermediate. Both PrnC and PItA appear to have relaxed regioselectivity compared to the tryptophan halogenases and mixtures of mono- and dichlorinated products are observed more frequently in vitro. ${ }^{122,158}$ HalB is another pyrrole halogenase with high sequence similarity to PrnC and PItA, involved in the biosynthesis of pentachloropseduilin 
(33) from Actinoplanes sp. ATCC3302. ${ }^{159,160}$ Clz5 from Streptomyces sp. CNQ-418 is also similar to PItA and has been identified as the pyrrole $\mathrm{Fl}-\mathrm{Hal}$ in the biosynthesis of chlorizidine A (34, Figure 15A). ${ }^{161-163}$ The peptidyl carrier protein (PCP) tethered substrates of Clz5, PItA and HalB are all derived from oxidation of proline-S-PCP intermediates in NRPS or NRPS-PKS assembly lines. ${ }^{162,163}$<smiles>Oc1c(Cl)cc(Cl)cc1-c1[nH]c(Cl)c(Cl)c1Cl</smiles>

Pentachloropseudilin (33)

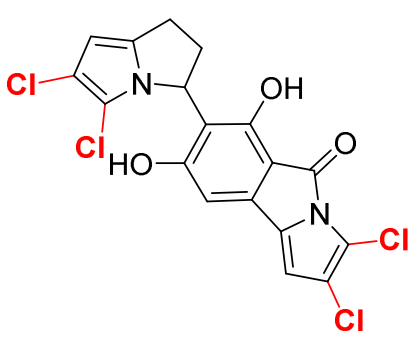

Chlorizidine A (34)<smiles>[B]C#CCCCC(=O)OC1CCCN1</smiles>

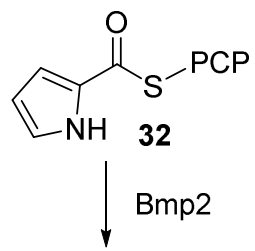

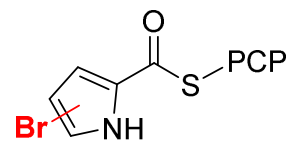

Figure 15: Flavin-dependent pyrrole halogenases in natural product biosynthesis. A: Natural products containing chlorinated pyrrole moieties. B: Halogenation of PCP-S-pyrole by Bmp2.

Genome mining of the marine organisms responsible for the biosynthesis of brominated marine natural products has led to the identification of an interesting pyrrole $\mathrm{Fl}-\mathrm{Hal}$, Bmp2, from Pseudoalteromonas luteoviolacea. ${ }^{156,164,165}$ Similar to the gene cluster containing PItA, Bmp2 is associated with a thioesterase (TE, Bmp1) and proline adenyltransferase (Bmp4). ${ }^{156,164}$ Reconstitution of these enzymes in vitro showed Bmp2 to brominate pyrrole-2-carboxy-S-Bmp1 (32) to mono-, diand tri-bromo products (Figure 15B). ${ }^{164}$ Unlike the other Fl-Hals studied to date, Bmp2 appeared capable of iodination of $\mathbf{3 2}$ in addition to bromination, but not chlorination. ${ }^{164}$ Investigation of the structural features which allow Bmp2 to iodinate may be of interest in the engineering of other FI-Hals, as the tryptophan $\mathrm{Fl}-\mathrm{Hals}$ have been demonstrated to be inhibited by the presence of $\mathrm{I}^{-114,166}$ Biocatalytic iodination is attractive for synthetic applications, as aryl iodides are typically more reactive, and thus more readily derivatized, than the corresponding aryl chlorides or bromides. Comparison of Bmp2 to its closest analogue Myp16 and point mutations of Bmp2 to mimic this chlorinase did not afford a Bmp2 mutant capable of chlorination, suggesting that other, more subtle, features may be responsible for the observed halide preference. ${ }^{156}$ 


\subsubsection{Flavin-Dependent Phenolic Halogenases}

Three classes of phenolic flavin-dependent halogenase enzymes have been identified to date: those which act on free-standing substrates (Class A); those which require substrates tethered to a carrier protein (Class B); and halogenases that follow a decarboxylative halogenation mechanism (Class C).

\subsubsection{Predicted Class A Phenolic Halogenases}

The fungal halogenase Rdc2 from Pochonia chlamydosporia and the similar enzyme RadH from Caetonium chiversi, are both involved in biosynthesis of the resorcinylic acid lactone (RAL) radicicol (35), and act on free-standing phenolic substrates. ${ }^{125,167-170}$ Radicicol is a potent inhibitor of heat shock protein 90 (Hsp90), a medically important target due to its involvement in many cancer causing pathways, and also exhibits anti-fungal activity. ${ }^{170} \mathrm{Rdc} 2$ was heterologously expressed in E. coli and demonstrated to be capable of halogenating the macrocyclic natural products zearaleone, dihydrosorcylide, curvularin and curcumin in vitro. ${ }^{169-172}$ Both chlorination and bromination reactions were found to form di-halogenated compounds after prolonged periods when multiple $\mathrm{OH}$ groups were present on the aromatic ring. ${ }^{169-172} \mathrm{Rdc} 2$ and RadH are both post-PKS tailoring enzymes, which is a plausible explanation for why these enzymes act on free-standing substrates. A number of other class A phenolic FI-Hals have been identified that are involved in the biosynthesis of a range of fungal natural products including griseofulvin $(36, \mathrm{Gsfl}),{ }^{173-175}$ aspirochlorine $(37, \mathrm{AclH}),{ }^{176-178}$ chaetoviridin (38, Cazl), ${ }^{179-181}$ ochratoxin (39, AcOTAhal) ${ }^{126,182-184}$ and dihydrogeodin (40, GedL) (Figure 16). ${ }^{185,186}$ Like Rdc2 and RadH, these related fungal enzymes ( $\mathrm{Gfsl}, \mathrm{AclH}, \mathrm{Cazl}$ and $\mathrm{GedL}$ ) halogenate ortho to a phenolic hydroxyl group of late stage biosynthetic intermediates, except for the ochratoxin (39) halogenase (AcOTAhal), which installs a chloro substituent para to the hydroxyl.

Although not directly phylogenetically linked to Rdc2 or RadH, the differentiation-inducing factor 1 (DIF-1, 41) halogenase (ChIA) from Dictyostelium discoideum is a Class A flavin-dependent phenolic halogenase. ${ }^{187-190}$ ChIA was overexpressed and purified in E. coli and demonstrated in vitro to produce both mono- and di-halogenated DIF-1 (41 and 42 ) in the presence of an external flavin reductase. ${ }^{187}$ The observation that many of the phenolic halogenases appear to require substrates with a hydroxyl group ortho to the halogenation site (vide infra) suggests that electrophilic aromatic substitution may be mediated through deprotonation of the ortho-hydroxyl. 
<smiles></smiles><smiles>COc1cc(/C=C/C(=O)CC(=O)/C=C/c2ccc(O)c(OC)c2)ccc1O</smiles>

Radicicol (35)<smiles>COC1=CC(=O)CC(C)[C@]12Oc1c(Cl)c(OC)cc(OC)c1C2=O</smiles>

Grisofulvin (36)<smiles>CON1C(=O)C2NC(=O)C3(Oc4cc(O)c(Cl)cc43)SSC21</smiles>

Aspirochlorine (37)<smiles>[X]c1c(O)c(C(=O)CCCCC)c(O)c([X])c1OC</smiles>

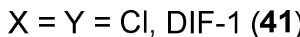

$\mathrm{X}=\mathrm{Cl}, \mathrm{Y}=\mathrm{H}, 42$<smiles>CCC(C)/C=C/C1=CC2=C(Cl)C(=O)C3(C)OC(=O)C(C(=O)[C@H](C)C(C)O)=C3C2=CO1</smiles>

Chaetoviridin A (38)<smiles>C[C@@H]1Cc2c(Cl)cc(C(=O)N[C@@H](Cc3ccccc3)C(=O)O)c(O)c2C(=O)O1</smiles>

Ochratoxin B (39)<smiles>COC(=O)c1cc(O)cc(OC)c1C(=O)c1c(O)c(Cl)c(C)c(Cl)c1O</smiles>

Dihydrogeodin (40)

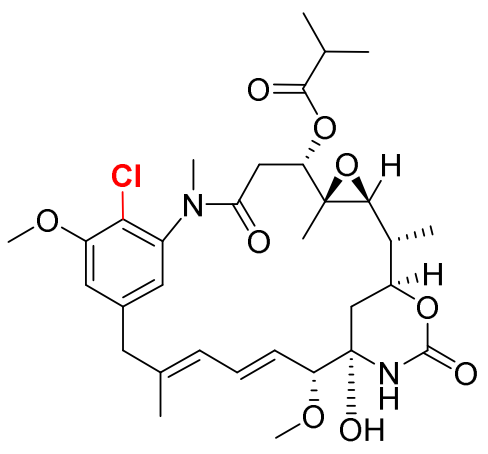

Ansamitocin (43)<smiles>CC(C)=CCC/C(C)=C/CC12OC(C)(C)C(Cl)CC1(Cl)C(=O)c1cc(O)cc(O)c1C2=O</smiles>

Napyradiomycin A1 (45)<smiles>C/C=C(\C)C(=O)C[C@@H](O)[C@H](C)/C=C\C=C/C=C(\C)C(=O)NC1=C(Cl)C(=O)c2c(cc(C)c(O)c2C(=O)/C(C)=C/[C@H](C)[C@H](O)[C@@H](C)/C=C/[C@@H](O)C/C=C(\C)C(=O)O)C1=O</smiles>

Naphthomycin A (44)

Figure 16: Natural products biosynthesised using phenolic flavin-dependent halogenases.

Another halogenase, predicted to process a free-standing phenolic substrate, is Asm12 from ansamitocin (43) biosynthesis. ${ }^{191-193}$ Asm12 shares $73 \%$ sequence identity with Nat1, a halogenase involved in the biosynthesis of napthomycins (44, NATs) by Streptomyces sp. CS. ${ }^{194}$ Napthomycins are 29-membered napthalenic ansamacrolactam antibiotics with similarities to the ansamitocin type scaffold. Inactivation of the nat1 gene in the napthomycin biosynthetic gene cluster abolished production of the chlorinated napthomycin A, which was restored on complementation with Asm12 demonstrating the functional similarity between the two enzymes. ${ }^{194}$ Finally, $\mathrm{NapH} 2$ is the halogenase 
from the napyradiomycin (45) biosynthetic cluster (nap) in Streptomyces sp. CNQ-525. ${ }^{195}$ In vivo studies suggest that $\mathrm{NapH} 2$ may halogenate the $\mathrm{C} 2$ position of a napthoquinone precursor facilitating subsequent prenylation during napyradiomycin biosynthesis. ${ }^{195,196}$

\subsubsection{Predicted Class B Phenolic Halogenases}

A number of putative phenolic halogenases such as Clo-Hal (involved in the biosynthesis of chlorobiocin (46) in Streptomyces roseochromogenes), ${ }^{197,198}$ BhaA (from the balhimycin (47) biosynthetic pathway in Amycolatopsis mediterranei), ${ }^{199-201}$ and ComH (responsible for chlorination en route to complestatin (46) in Streptomyces lavendulae) $)^{202-204}$ have been identified (Figure 17). Whilst further in vitro studies are required to elucidate the true substrates of these enzymes, it is likely that Clo-Hal, BhaA and ComH are all Class B, carrier protein-dependent, phenolic halogenases. In chlorobiocin (59) biosynthesis, it is suggested that Clo-Hal halogenases a PCP tethered tyrosine or $\beta$ hydroxy tyrosine $(\beta-\mathrm{HT})$ intermediate prior to formation of the aminocoumarin ring system. ${ }^{197}$ The location of the BhaA encoding gene in the balhimycin gene cluster, alongside NRPS encoding genes, and in vitro experiments also suggest that BhaA halogenates a PCP tethered tyrosine or $\beta-\mathrm{HT}$ intermediate. ${ }^{199-205}$ The halogenase (Tcp21) in the teicoplanin gene cluster of Actinoplanes teichomyceticus is similarly predicted to process a Tyr-or $\beta$-HT-S-PCP substrate..$^{205-207}$

Crystallography of the related chondrochloren halogenase $\mathrm{CndH}$, revealed that the substrate for $\mathrm{CndH}$ may also be a tyrosine-related intermediate that is most likely PCP tethered. ${ }^{208} \mathrm{CndH}$ has a large non-polar surface patch that could accommodate the putative carrier protein and it was also proposed that the catalytic base required for halogenation (Glu in tryptophan halogenases) might be supplied by C-terminal domain of the carrier protein. ${ }^{208}$ 


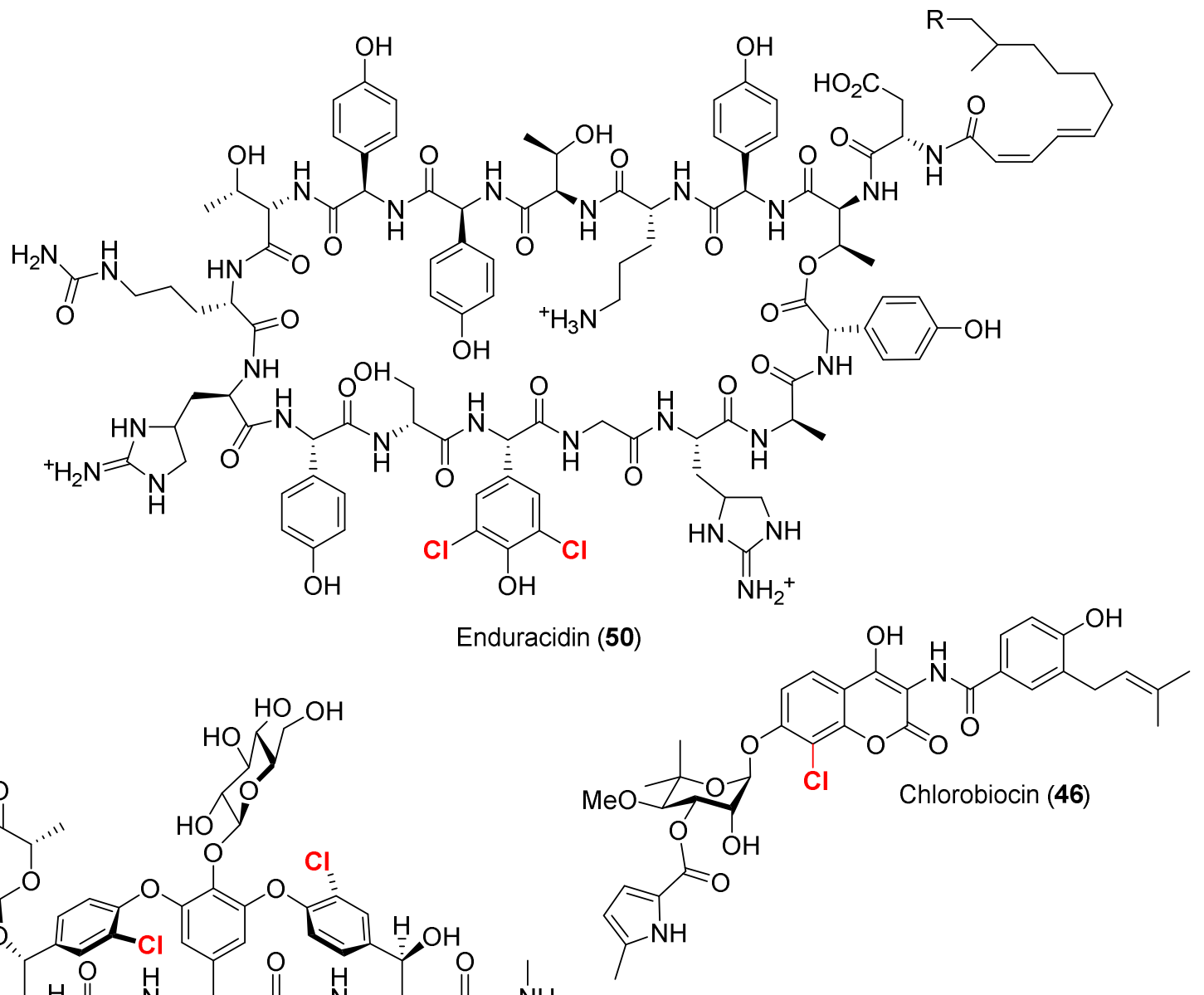

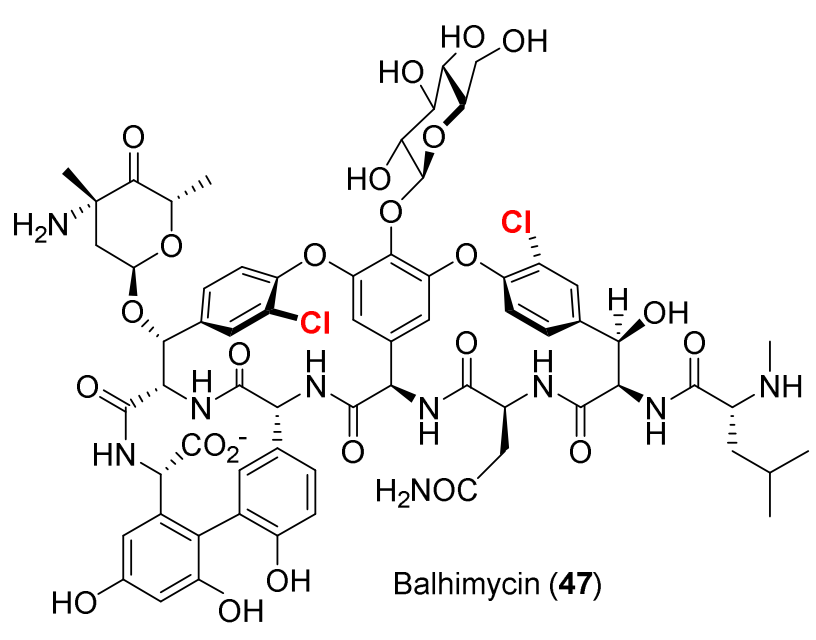

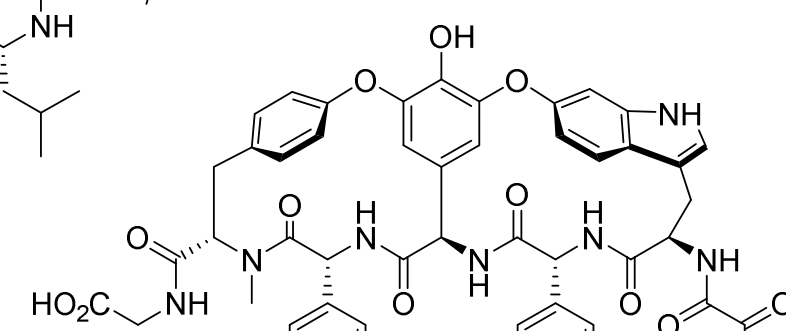

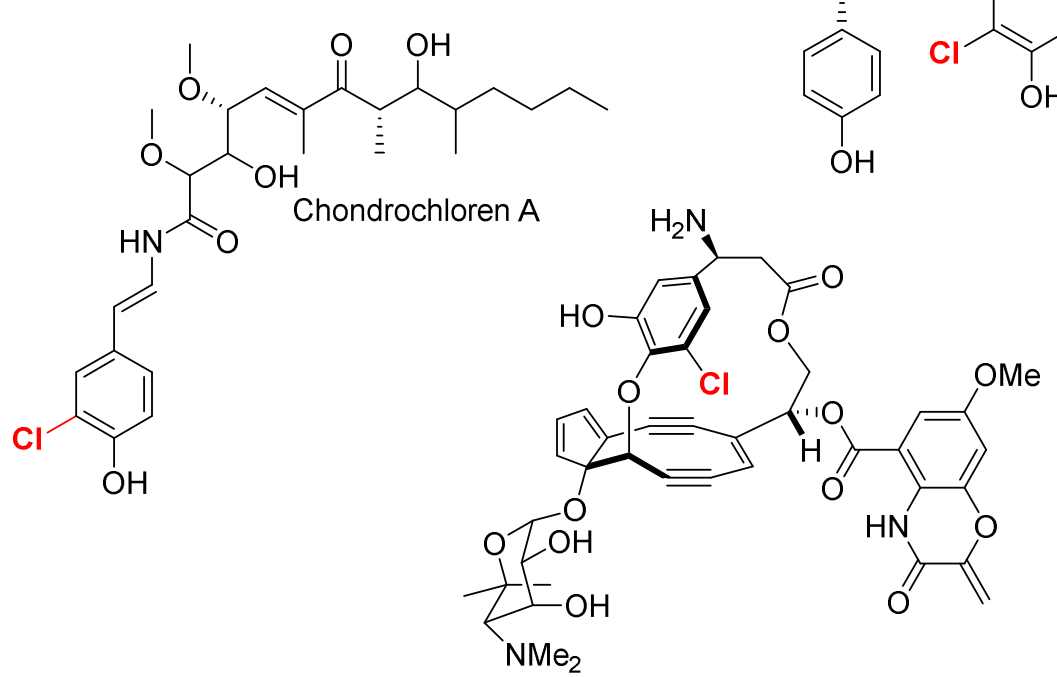

Enediyne antibiotic C-1027 (49)

Figure 17: Natural products biosynthesised using phenolic flavin-dependent halogenases. 
Other Class B phenolic halogenases that require a carrier protein include $\mathrm{SgcC} 3$ involved in the biosynthesis of C-1027 (49), a chromoprotein antitumor antibiotic isolated from Streptomyces globisporus. ${ }^{209}$ In vitro activity of SgcC3, overexpressed in E. coli., was observed only in the presence of SgcC2 peptidyl carrier protein-tethered substrates. SgcC3 was found to utilise both $(S)$ - and $(R)-\beta$ tyrosyl-S-SgcC2 but not 3-hydroxy-ß-tyrosyl-S-SgcC2. ${ }^{209-211}$

The halogenases Ram20 and End30 have also been described that are suggested to halogenate hydroxyphenylglycine $(\mathrm{Hpg})$ residues during the biosynthesis of related lipopeptide antibiotics ramoplanin and enuracidin (50). ${ }^{212-215}$ Despite exhibiting high sequence similarity, End30 is responsible for dichlorination of Hpg13 in enduracidin, whilst Ram20 monohalogenates the Hpg17 residue of ramoplanin. Interestingly, deletion of ram20 from the ramoplanin biosynthetic gene cluster and complementation with end30 resulted in mono-halogenation of Hpg17, whilst the same complementation experiment in a strain lacking the ramoplanin mannosyltransferase resulted in halogenation of Hpg13. ${ }^{212}$ This suggests that halogenation occurs after peptide assembly and mannosylation of Hpg11, with the bulky mannosyl groups blocking halogenation at the more proximal Hpg13 residue. Further in vitro experiments are required to fully evaluate the regioselectivities of End30 and Ram20.

\subsubsection{Class C Phenolic Halogenases}

A decarboxylating phenol brominase enzyme, Bmp5, was discovered from Pseudoalteromonas luteoviolacea, which was the first example of a class C phenolic Fl-Hal. ${ }^{156,164,165}$ This enzyme lacks sequence similarity with other canonical flavin-dependent halogenases and has sequence homology to known single-component flavin-dependent monooxygenases. ${ }^{156,164,165}$ Bmp5 does not require an external flavin reductase enzyme for in vitro activity and activity was abolished in the absence of either bromide or NADPH - indicating Bmp5 alone is capable of flavin reduction and bromination. Reaction of Bmp5 with 4-hydroxybenzoic acid (51) in the presence of bromide, NADPH and FAD led to the formation of 3-bromo-4-hydroxybenzoic acid 52. A second bromination is then proceeded by de-carboxylation to afford di-bromo phenol 53 (Figure 18A). Bmp5 showed no chlorination activity, while it forms iodophenols, indicating a highly evolved bromide or iodide binding site in the protein, 
which is not present in other canonical flavin-dependent halogenases. ${ }^{164}$ The full mechanistic and structural details of Bmp5 are still lacking, and the proposed decarboxylative flavin-dependent halogenase mechanism has no precedent. Whether the two steps are consecutive or require involvement of any specific catalytic residues is unclear, however identification of Bmp5 homologues from different genomic clusters may shed light on those questions. ${ }^{164}$

A<smiles>O=C(O)c1ccc(O)cc1</smiles><smiles>O=C(O)c1ccc(O)c(Br)c1</smiles>

52<smiles>Oc1ccc(Br)cc1Br</smiles>

51

53<smiles>[B]C(O)Cc1cc2cc(O)cc(O)c2c(=O)o1</smiles>

54

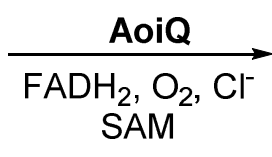
SAM<smiles>COc1cc(OC)c2c(=O)oc(C[C@H](O)C(Cl)Cl)cc2c1</smiles>

55

Figure 18: (A) Decarboxylative bromiantion catalysed by Bmp5. (B)Halogenation and methylation activity of the proposed Fl-Hal-methyl transferase fusion protein AoiQ.

\subsubsection{Aliphatic Flavin-Dependent Halogenases}

A small number of flavin-dependent halogenases have recently been identified which are capable of halogenating aliphatic $\mathrm{C}-\mathrm{H}$ bonds. The crystal structure of the chloramphenicol halogenase $\mathrm{CmIS}$ from Streptomyces venezuelae for example has been solved and displays a number of structural features not found in other Fl-Hals. A unique dynamic C-terminal domain creates a T-shaped tunnel leading to the active site. Most surprisingly, FAD appears to be covalently bound to the halogenase by the $8 \alpha$ carbon - not found in other FI-Hals. ${ }^{136}$ A number of non-polar surface patches suggest an activator or substrate-tethering protein is also involved, as with $\mathrm{CndH}^{208} \mathrm{ClmK}$, the proposed activator protein, has sequence homology to acyl-CoA synthetases leading to the postulation that ClmS may halogenate the CoA-thioester or free acyl group directly. The active site residue E44 is thought to catalyse $\mathrm{HOCl}$ generation, whilst $\mathrm{Y} 350$ is believed to stabilise the enolate intermediate which can then act as a nucleophile to generate chlorinated product. ${ }^{136}$ 
A bifunctional methyl-transferase halogenase has recently been identified from the diapothins genome cluster of Aspergillus oryzae RIB40 (AoiQ) and found to be responsible for the geminal dichlorination of a methyl group in diaporthin (54) both in vitro and in vivo affording 55 (Figure 18B). ${ }^{216,217}$ The position of halogenation suggests a mechanism different from both canonical FI-Hals and $\mathrm{CmlS}$ as generation of an enolate from a secondary alcohol would likely require additional oxidoreductases. ${ }^{217}$ Genomic analysis of AoiQ revealed that homologous enzymes are encoded in various other fungal biosynthetic gene clusters. ${ }^{217}$ Identification of these aliphatic Fl-Hals, in addition to further in vitro structural and functional characterisation, may provide exciting insight into their mechanism, as well as providing the potential for regio- and stereo-selective aliphatic halogenation reactions for biocatalytic applications.

\subsection{Flavin-Dependent Halogenases as Biocatalysts}

\subsubsection{Substrate Scope of FI-Hals}

There has been significant interest in using flavin-dependent halogenases as biocatalysts because of their potential to regioselectivley halogenate aromatic substrates under benign conditions. Thus far, most of this work has been focussed on the tryptophan halogenases and has revealed a number of enzymes capable of halogenating tryptophan derivatives, ${ }^{218}$ non-natural indolic substrates, ${ }^{150,155,219-221}$ in addition to benzamides and benzoic acids ${ }^{150,155}$ as well as napthols and napthyl amines (Figure 19). ${ }^{220,221}$ In a number of cases, halogenation occurs with good regioselectivity. The tryptophan-7-halogenase RebH has been demonstrated to solely halogenate the 7-position of a number of non-natural indoles (56 to 58) and ortho- to the $-\mathrm{NH}_{2}$ and $-\mathrm{OH}$ groups in $\mathbf{5 9}$ and $\mathbf{6 0}$ respectivley. ${ }^{220,221}$ Interestingly PrnA, another tryptophan-7-halogenase, was found to halogenate some of these indolic substrates at the more electronically-favoured C2 position. ${ }^{219}$ 

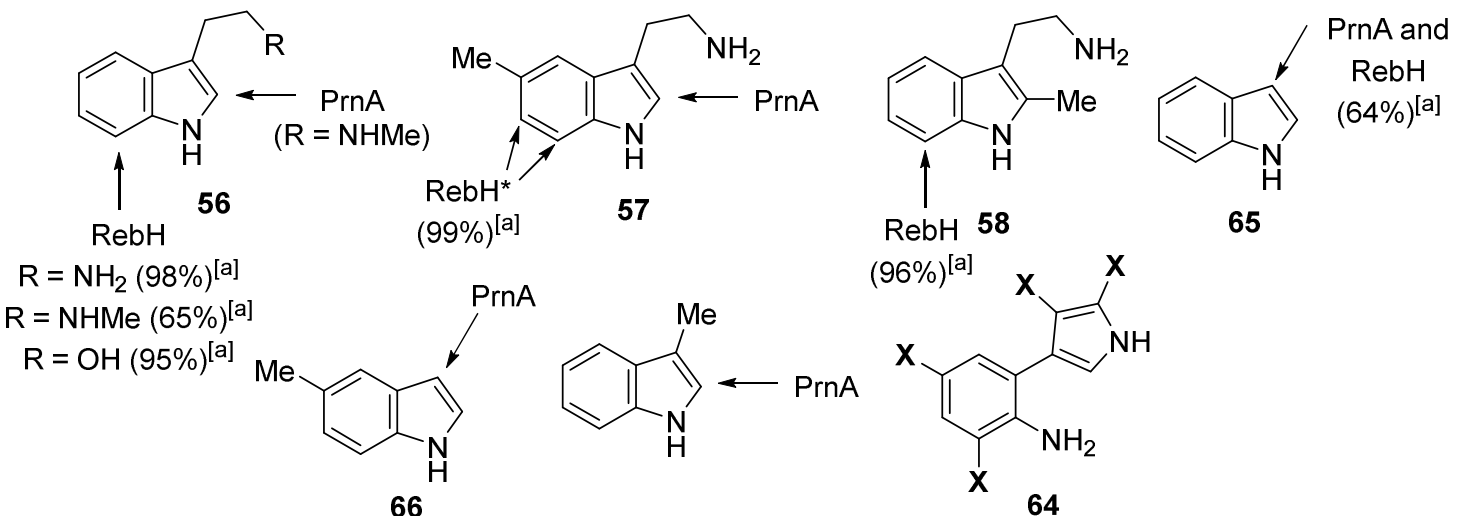<smiles>[X]c1cc([X])c(N)c(-c2c[nH]c([X])c2[X])c1</smiles><smiles>[Z6]C(=O)[C@H](N)CCc1cn(C(C)=O)c2ccccc12</smiles>

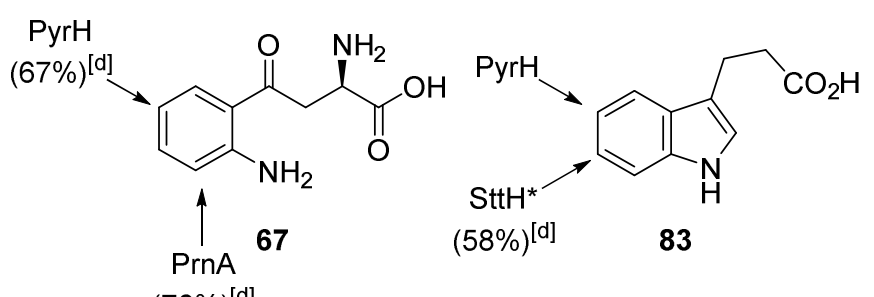

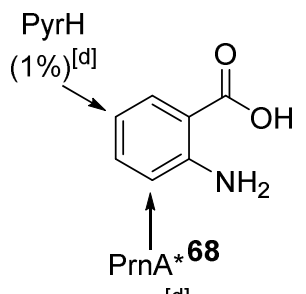
$(76 \%)^{[\mathrm{d}]}$

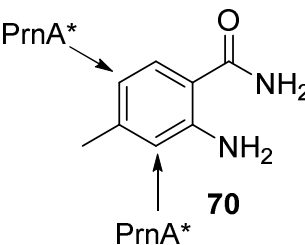<smiles></smiles>

$(1 \%)^{[d]}$<smiles>O=C(O)c1ccccc1Nc1ccc(C#P)cc1</smiles>

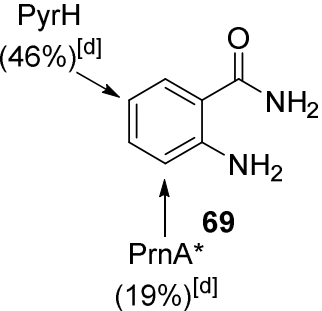

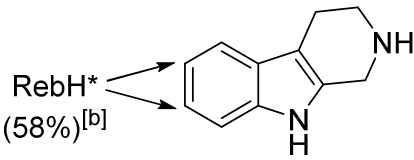

85

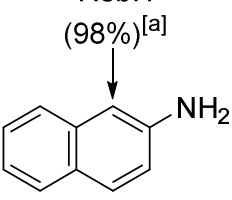

59

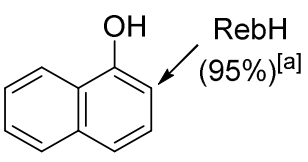

60

Figure 19: Known substrate scope and regioselectivity of the flavin-dependent tryptophan halogenases. * Indicates examples where halogenation at multiple positions occurs. Conversions are shown in brackets. [a] Measured using $5 \mathrm{~mol} \%$ of RebH. ${ }^{220}$ [b] Measured using $10 \mathrm{~mol} \%$ of RebH. ${ }^{220}$ [c] TTN = total turnover number determined using $0.4 \mathrm{~mol} \% \mathrm{RebH}^{218}$ [d] Conversions are reported relative to the conversion of tryptophan by the relevant enzyme under the same conditions. ${ }^{155}$

Introduction of electron-donating substituents onto the indole ring, which activate the substrate towards electrophilic aromatic substitution, led to the formation of di-chlorinated products with 
$\mathrm{RebH}^{220,221}$ The formation of dichlorinated products and regioisomers has also been observed from the halogenation of tryptophan derivatives bearing electron-donating substituents with RebH (61 to 63), and in the halogenation of 3-(2'-aminophenyl)pyrrole (64) with $\operatorname{PrnA},{ }^{218,219}$ demonstrating that substrate electronics influence regioselectivity when substrate positioning relative to the active site lysine is perturbed or flexible. Indeed, both RebH and PrnA have been shown to halogenate the most nucleophilic C3 position of indole (65 and 66 ) when this position is not functionalised. ${ }^{219-221}$ Moreover, with the highly activated substrate 64, seven halogenated products were formed (including regioisomers and di-chlorinated products) due to the electron-rich nature of both the pyrrole and aniline moieties. ${ }^{219}$ Most of the tryptophan halogenases have also been shown to chlorinate both L- and Dtryptophan, with preference for the natural L- enantiomer. ${ }^{219-221}$

In an attempt to broaden substrate scope of the enzymatic halogenation, the tryptophan-5- and tryptophan-6-halogenases $\mathrm{PyrH}$ and $\mathrm{SttH}$ have also been studied. With a number of 2-amino benzamides and benzoic acids ( 67 to 72 ), $\mathrm{PyrH}$ and SttH were found to solely chlorinate para to the $\mathrm{NH}_{2}$, whilst PrnA afforded mixtures of both ortho- and para-chlorinated products in most cases. ${ }^{150,155}$ The formation of regioisomers with the smaller substrates 68 to 72 is thought to be due to their flexibility upon binding within the active site and hence undefined positioning relative to the catalytic lysine. Notably kynurenine (67), a larger substrate which can potentially form more hydrogen bonding contacts with the active site, could be halogenated in a regio-divergent manner at the 3- or 5-position by PrnA or PyrH and SttH respectively, ${ }^{150,155}$ demonstrating the potential for these biocatalysts to offer a halogenation with catalyst-controlled regioselectivity. Additionally, SttH halogenates the 6-position of $\mathrm{N}$-methylated tryptophan (73) with good efficency, ${ }^{150}$ whilst PrnA and RebH do not accept this or other $N$-functionalised tryptophans $(\mathbf{7 3}$ and $\mathbf{7 4}) .{ }^{219-221}$

Halogenases of different natural substrate scope have been explored for the halogenation of alternative aromatic scaffolds. Notably Rdc2, a phenolic flavin-dependent halogenase, was shown to halogenate the hydroxyisoquinolines $\mathbf{7 5}$ to $\mathbf{7 8}$ in addition to a number of other macrocyclic lactones (79 to 82, Figure 20). ${ }^{125,167,168,172}$ In most cases, these highly activated phenolic compounds are halogenated regioselectivley ortho- to the hydroxy functionality, suggesting that hydrogen-bonding or 
deprotonation of this hydroxyl may be important in the control of regioselectivity and activity of Rdc2 and related phenolic Fl-Hals.<smiles>Oc1ccc2ncccc2c1Cl</smiles><smiles>Oc1c(Cl)ccc2ncccc12</smiles>

75

RadH and Rdc2
76

Rdc2<smiles>Oc1cnc2ccccc2c1Cl</smiles>

77

Rdc2<smiles>C[C@H]1CCCC(=O)CCC/C=C/c2cc(O)cc(O)c2C(=O)O1</smiles>

79<smiles>CO[C@H](C)CCCCCC(=O)c1c(O)cc(Cl)cc1CC(=O)O</smiles>

80

Rdc2<smiles>CO[C@H](C)CCCC(=O)CCC/C=C/c1cc(O)cc(O)c1C(=O)O</smiles>

81<smiles>Oc1ccc2cccnc2c1Cl</smiles>

Rdc2

Rdc2

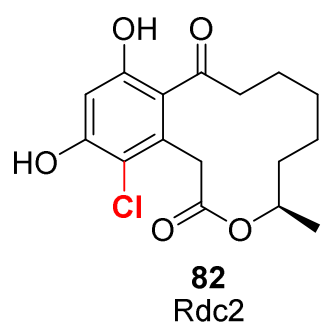

Figure 20: Substrate scope and regioselectivity of the flavin-dependent phenolic halogenases.

Each of the flavin-dependent halogenases mentioned above catalyses the halogenation of an aromatic $\mathrm{C}-\mathrm{H}$. Interestingly the bi-functional halogenase-methyl transferase fusion protein from Aspergillus oryzae RIB40 is believed to be responsible for the dichlorination of 54 (Figure 18B). ${ }^{217}$ Whilst significant work is likely to be required to understand the mechanism of this aliphatic chlorination and develop this enzyme as a biocatalyst, there is an exciting prospect of regioselective and stereoselective chlorination of alkyl C-H's using this or related enzymes.

\subsubsection{Engineering FI-Hals to Alter Substrate Scope and Regioselectivity}

In order to deliver biocatalysts with improved or better regioselectivity, a number of attempts have been made using rational mutagenesis to change the regioselectivity of the flavin-dependent tryptophan halogenases. ${ }^{150,155,222}$ The first example using PrnA found that mutation of the bulky active site residue F103, which would usually shield the C5 position of tryptophan from approach by active site lysine, to alanine led to the formation of 7 - and 5-brominated tryptophan in a 2:1 ratio whilst the wild-type afforded only 7-brominated product (Figure 21A). ${ }^{222}$ Although a modest shift in regioselectivity, this work set the precedent that site-directed mutagenesis could be used to alter the regioselectivity of the tryptophan halogenases. Subsequent work used active site mutations to stabilise one postulated orientation of anthranilic acid (68) in the active site of PrnA and found a single mutant capable of increasing activity towards this substrate evidenced as a change in binding affinity 
by an almost 10 -fold reduction in $K_{\mathrm{m}}$ compared to wild-type $(3161 \mu \mathrm{M}$ to $384 \mu \mathrm{M}) .{ }^{155}$ The same work also identified a double mutant capable of shifting regioselectivity from predominantly 3- to 5chlorination (Figure 21B), with further improved kinetic parameters $\left(K_{\mathrm{m}}=205 \mu \mathrm{M}, k_{\text {cat }}=1.82 \mathrm{~min}^{-1}\right)$ compared to wild-type $\left(k_{\text {cat }}=0.51 \mathrm{~min}^{-1}\right)$ and the single mutant $\left(k_{\mathrm{cat}}=0.93 \mathrm{~min}^{-1}\right){ }^{155} \mathrm{~A}$ similar approach with SttH found a triple mutant capable of shifting the regioselectivity of halogenation from the 6 - to the 5- position on 3-indolepropionate (83). Mutations were rationalised based on comparison of the crystal structure of $\mathrm{SttH}$ with $\mathrm{PyrH}$, which revealed key differences in a region close to the active site of both. ${ }^{150}$ This example is the first to demonstrate that regioselectivity can be switched without altering the catalytic efficiency of the enzyme.

In addition to the rational and structure-guided approaches, random mutagenesis and directed evolution have been used to alter regioselectivity. ${ }^{223}$ In this work, substrates with a single deuterium in place of an aromatic $\mathrm{C}-\mathrm{H}$ were used in a MALDI-ToF based screen to detect mutants which halogenated at positions other than the deuterated one (Figure 21C). Starting from a RebH mutant previously found to be more thermostable ${ }^{224}$ and using a total of 6 rounds of screening, two RebH mutants were found which halogenated the 6- and 5- positions of an indolic substrate (84) with good selectivity and reasonable conversion. ${ }^{223}$ This method does not require structural information about the enzyme and can be used to modulate regioselectivity in a semi high-throughput manner, in contrast to most high-throughput screening (HTPS) methods which focus on improving stability or activity of an enzyme. 
A

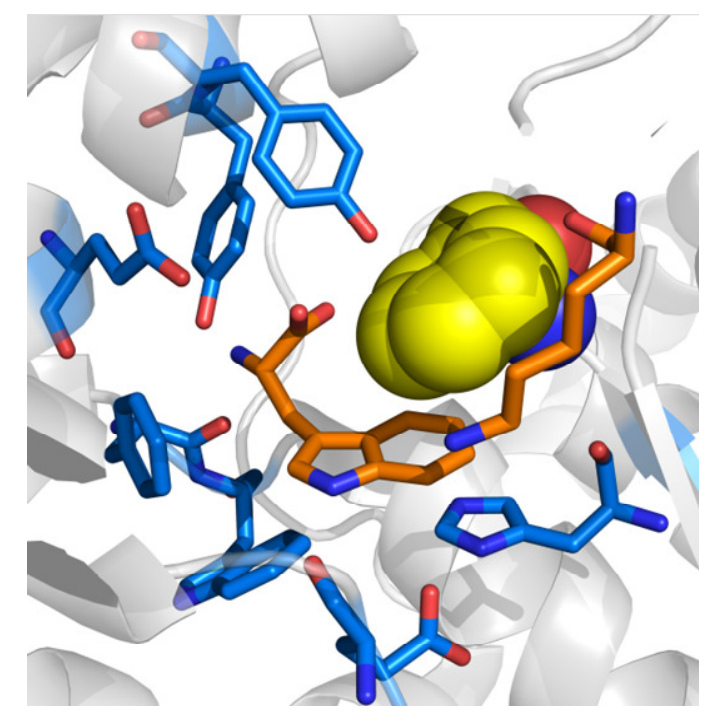

B

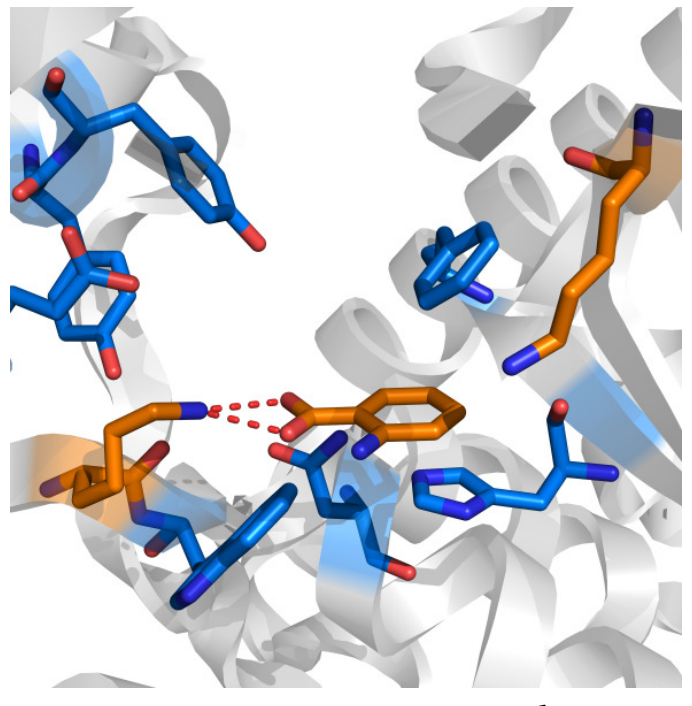

C<smiles>O=C(O)CCc1c[nH]c2cc(Cl)ccc12</smiles>

D<smiles>[R9]c1cccc2c(CCN)c[nH]c12</smiles>

Figure 21: (A) Active site of PrnA with tryptophan bound, with F103 highlighted as yellow spheres showing how this residues prevents approach of catalytic lysine at position 5- (PDB 2AQJ). (B) Active site of PrnA E450K mutant with anthranilic acid placed showing how the lysine mutation could increase binding affinity of anthranilic acid through hydrogen bonding (PDB 4Z43). (C) Regiodivergent halogenation of indole-3-propinoic acid by SttH and a triple mutant based upon structural differences between $\mathrm{SttH}$ and PyrH. (D) MALDI-ToF HTPS of halogenase variant regioselectivity using deuterated substrates.

Random mutagenesis has also been used in a "substrate walking" approach to allow the late-stage halogenation of a number of large bioactive substrates such as 85 to 88 (Figure 22). ${ }^{225}$ Over a total of 
4 generations of error-prone PCR, RebH was mutated to a quintuple mutant capable of halogenating the large C4-functionalised substrate $\mathbf{8 7}$ with complete regioselectivity. Together, these methods demonstrate the potential to develop a suite of biocatalysts for regiodivergent halogenation; either from a single parent enzyme or using halogenases of different natural regioselectivity.<smiles>[Z4]C(C)NCC(O)COc1ccc(Cl)c2[nH]ccc12</smiles>

87
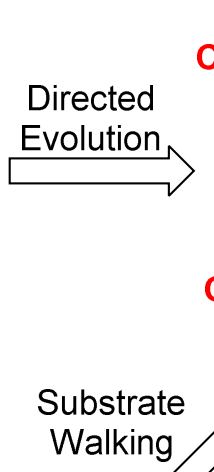

$\mathrm{Cl}$<smiles>C=CC(C)(C)c1[nH]c2ccc(Cl)cc2c1CCNC</smiles><smiles>O=C(O)[C@H]1[C@H]2C[C@H]3c4[nH]c5ccc(Cl)cc5c4CCN3C[C@H]2CC[C@H]1O</smiles>

88
A.R. $=1.3$
A.R. $=16.5$

Figure 22: Products from the halogenation of large bioactive natural products by RebH variants generated through directed evolution and substrate walking. A.R. relates to the Activity Ratio of each substrate with the best variant RebH compared to wild-type. ${ }^{225}$ Substrate $\mathbf{8 6}$ showed negligible activity with wild-type and therefore A.R. cannot be determined.

\subsubsection{Engineering FI-Hals to Improve Activity and Stability}

Whilst the flavin-dependent halogenases are promising biocatalysts for regioselective and regiodivergent halogenation of aromatic compounds, their applications are still limited to the analytical and semi-preparative scale because of low $k_{\text {cat }}$ values, poor stability and susceptibility to substrateproduct inhibition. ${ }^{32-34,218,224,225}$ This is likely to be an artefact of these enzymes evolving as part of the biosynthetic pathways to non-essential secondary metabolites. Halogenases are not essential for the survival or growth of the native host, and hence there has been little evolutionary pressure for highly active halogenase enzymes. ${ }^{226}$ Although attempts have been made to improve biocatalytic halogenations using Fl-Hals through reaction optimisation, design-of-experiment approaches were required due to the large number of variables in such a system and only modest improvements were 
obatined. ${ }^{227}$ Significant work has therefore been focussed on the engineering of Fl-Hals with improved biocatalytic properties.

One strategy to find more stable enzymes, which are therefore usually more amenable biocatalysts, is to look for analogous enzymes found in thermophilic organisms. Thermostable enzyme variants have been demonstrated to confer many advantages, including prolonged lifetime and increased tolerance to organic solvents and proteolysis. ${ }^{228-231}$ This approach has been employed with the flavin-dependent halogenases. A thermophilic tryptophan 6-halogenase (Th_Hal) was identified from Streptomyces violaceusniger SPC6, a thermophilic and halotolerant bacterium, ${ }^{232,233}$ with a melting temperature $\left(T_{m}\right)$ almost $10{ }^{\circ} \mathrm{C}$ higher than that of the mesophilic tryptophan 6-halogenase SttH and higher $\mathrm{k}_{\text {cat }}$ than a number of other tryptophan halogenases. ${ }^{145}$ This thermophilic halogenase (Th_Hal) was partnered with a flavin-reductase from a thermophilic Bacillus strain, ${ }^{234}$ allowing biocatalytic halogenation reactions to occur at $45{ }^{\circ} \mathrm{C}$ in vitro with a number of non-natural substrates. The regioselectivity of Th_Hal was the same as with $\mathrm{SttH}^{150}$ A crystal structure of Th_Hal found that $40 \%$ of the total differences with the nearest homologue SttH were polar residues on the surface of Th_Hal (Figure 23A), suggesting that increasing surface charge is likely to be largely responsible for the higher stability of Th_Hal. ${ }^{145}$ In the case of the naturally evolved thermophilic Fl-Hal, this is likely to be because it is easier to modify the surface of a protein rather than the inner catalytic core. ${ }^{235-237}$ Increasing surface charge is thought to confer stability by deterring protein aggregation and increasing hydrogen bonding to water. ${ }^{235,237,238}$

Other methods have involved using error-prone PCR (ePCR) and directed evolution to mutate a mesophilic enzyme towards increased stability using temperature as the selection factor. ${ }^{224}$ After three rounds of ePCR two variants with seven and eight mutations possessing $T_{\text {opt }}$ and $T_{m}$ higher than the wild-type starting point were found, both of which proved to be stable over longer reaction times than wild-type, but with decreased turnover. Crystallography of one of these variants (PDB 4LU6) revealed a number of structural features which may have contributed to increased enzyme stability. ${ }^{224}$ Notably, the mutation of a surface glutamine to arginine resulting in increased surface charge, similar to the thermophilic Th_Hal. ${ }^{145,238}$ In other portions of the RebH variant, charge density was reduced to 
reduce repulsion with nearby residues (Figure 23B) and an $\mathrm{N}$-terminal serine was mutated to proline and is believed to increase protein rigidity at this terminus and hence improve stability.

A

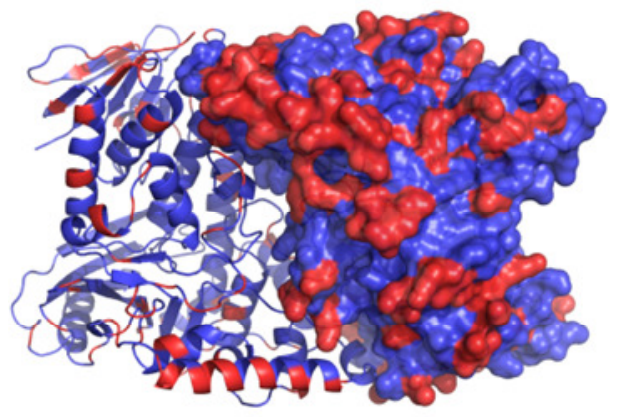

B

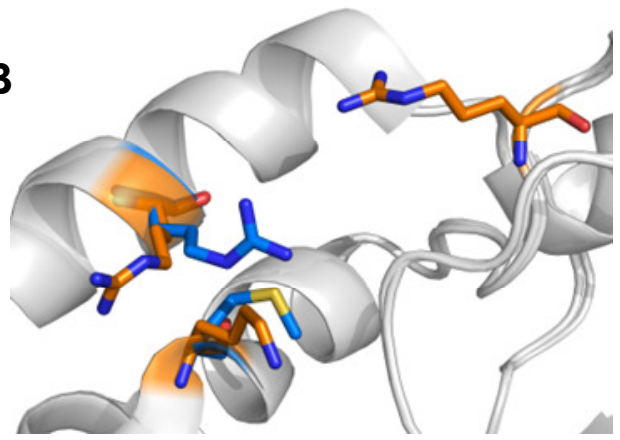

C<smiles>CCCCCCCCCCCCCc1ccc(N)cc1</smiles><smiles>C[C@H](O)PC1=CC(=O)C(=O)C=C1</smiles><smiles>O=C1C=CC(Nc2ccc(Cl)cc2)=CC1=O</smiles>
89

90<smiles>NC(Cc1c[nH]c2ccccc12)C(=O)O</smiles>

22<smiles>NC(=O)Cc1c[nH]c2ccc(-c3cccc(N)c3)cc12</smiles>

Figure 23: (A) Crystal structure of $\mathrm{SttH}$ with differences in amino acid sequence from T_Hal highlighted in red (PDB 5HY5). (B) Crystal structures of wild-type (orange, PDB 2OA1) and 3-SLR (blue, PDB 4LU6) variant RebH overlaid to show some of the amino acid substitutions thought to contribute to increased stability. (C) UV-Visible based screen for halogenase activity using either conjugation of aryl halide with ortho-quinones (D): High-throughput halogenase activity screen through combination of enzymatic halogenation with palladium-catalysed Suzuki chemistry to generate fluorescent adducts.

To achieve full synthetic utility, it is likely that the flavin-dependent halogenases will need significantly more engineering than the reported low-throughput chromatographic methods of screening can offer in a reasonable time-frame with economical resource comsuption. ${ }^{224,225}$ For this purpose, a number of high-throughput screens for halogenase activity have been developed (Figures 23C and 23D). ${ }^{240,} 241$ One such example relies upon the formation of aryl chloride-ortho-quinone adducts (89) with distinct UV/Visible absorbance properties. ${ }^{241}$ The generation of such adducts requires HRP (horseradish peroxidase) in addition to the halogenase and co-factor recycling enzymes in order to generate the ortho-quinone 90 from catechol. Michael addition of the arylchloride and spontaneous re-oxidation 
then generates the probe of interest (89, Figure $23 \mathrm{C})$. Although this method does allow reliable monitoring of halogenase reactions using UV-Vis in 96-well plates rather than chromatographic methods, the need to quench reactions and use additional enzymes and substrates may limit its applicability. In a similar vein, a recent report of a fluorescence-based screen involves the combination of the enzymatic halogenation with palladium-catalysed cross-coupling chemistry to create an adduct (91) with fluorescence sufficiently distinct from the co-factors and proteins required for biocatalytic halogenation - thereby allowing detection in a high-throughput manner using a fluorescence plate-reader (Figure 23D). ${ }^{240}$ After applying this method to screen variants from errorprone PCR, a double mutant of Thal was found with a $\mathrm{T}_{\mathrm{m}} 10^{\circ} \mathrm{C}$ higher than that of wild-type. The structural differences thought to be responsible for stabilisation of the engineered and naturallyoccurring halogenase enzymes, as well as the methods used to discover them, could be used as the basis of engineering halogenase variants with further improved activity. Combination of these screening methods with strategies for targeting the generation of variant libraries to specific sites, as have been demonstrated to afford a minor improvement in RebH catalytic parameters by targeting mutations to the flavin-binding pocket, ${ }^{242}$ could be used to focus such engineering efforts.

The stability and scalability of a number of FI-Hals has been improved by their immobilisation into heterogeneous cross-linked enzyme aggregates (CLEAs) of a Fl-Hal, flavin reductase and alcohol dehydrogenase, for concurrent co-factor re-generation, ${ }^{150,243,244}$ allowing enzymatic halogenation on a gram scale. ${ }^{244}$ CLEAs are well-known to improve the efficiency of biocatalysts by improving catalyst lifetime, reducing the effects of substrate/product inhibition and allowing more efficient biocatalyst removal and recycling. ${ }^{245-247}$ In the case of the FI-Hals, this cross-linking may help to stabilise interdomain interactions, or effectively "protect" some of the biocatalyst from high substrate concentration by shielding it within the heterogeneous catalyst. ${ }^{244,248}$ The preparation of such biocatalysts from crude cell lysates, rather than needing to purify enzymes, ${ }^{244}$ is also advantageous.

\subsubsection{Integration of FI-Hals into Non-Native Biosynthetic Pathways}

There are a number of examples where the Fl-Hals have been incorporated into natural product biosynthetic pathways, in order to increase the diversity of the products obtained and therefore attenuate bioactivity of the resulting compounds (Figure 24). ${ }^{33,249-254}$ Generation of natural product 
analogues via this method is significantly more efficient, and therefore economical and ecologicallyfriendly, than via laborious total synthesis. ${ }^{255} \mathrm{~A}$ number of these reported examples rely upon the chlorination of tryptophan prior to incorporation into a biosynthetic pathway, thereby resulting in a natural product with a chlorinated tryptophan moiety. ${ }^{249,251,252}$ The seminal work in this area involved the combinatorial reconstitution of genes from the biosynthesis of rebeccamycin and staurosporine (natural product anti-tumour agents) with genes encoding for tryptophan halogenases of different regioselectivity to afford different regioisomers of chlorinated indolocarbazole 'non-natural' products $\left(92\right.$, Figure 24A) ${ }^{252}$ Subsequent work involved the introduction of a tryptophan-7-halogenase directly into a pacidamycin-producing Streptomyces strain, previously found to incorporate 7-halo tryptophans through substrate-directed biosynthesis, ${ }^{256}$ to afford chlorinated pacidamycin. ${ }^{251}$ Halogenase genes have also been incorporated into plant secondary metabolism to produce chlorinated monoterpene indole alkaloids (93) in Catharanthus roseus root cultures. ${ }^{249}$ In this case, it was found that the tryptophan decarboxylase enzyme, in plants, was inefficient at turning over 7-chlorotryptophan to give the required 7-chlorotryptamine (94). Therefore a RebH mutant capable of selectively catalysing the chlorination of tryptamine was introduced to overcome this metabolic bottleneck and reduce accumulation of 7-chlorotryptophan (24) which has adverse effects on plant health (Figure 24B). ${ }^{250}$ Other groups have since expressed the tryptophan halogenases $\mathrm{SttH}$ and $\mathrm{RebH}$ in the chloroplasts of tobacco plants, allowing the production of 6- and 7-halogenated tryptophans and, when partnered with a tryptophan decarboxylase, chlorinated tryptamines (94). ${ }^{257}$

The ability of Rdc2 to catalyse the late-stage chlorination of a number of macrolactones, as well as smaller phenolic compounds, suggests it would be an ideal candidate for introduction into non-indolic secondary metabolite biosynthetic pathways. ${ }^{125,167,168}$ Rdc2 for example has been incorporated into a re-constituted resveratrol biosynthetic pathway in E. coli to afford production of the 2-chlorinated resveratrol derivative, which has been shown to have increased antimicrobial and antioxidant activity compared to the non-halogenated parent compound. ${ }^{258,259}$ Cazl was recently demonstrated to be a flavin-dependent halogenase responsible for chlorination during the biosynthesis of chaetoviridin, ${ }^{179}$ suggesting potential for the generation of halogenated polyketide non-natural products. 


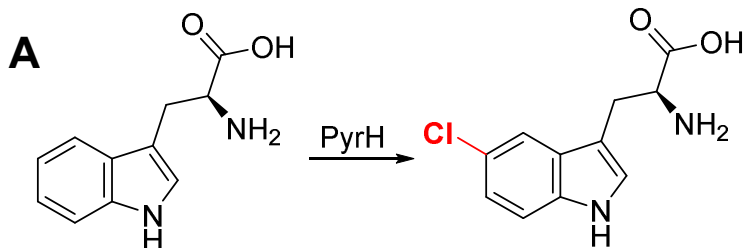

22<smiles>CC[Y]1CC=C[C@@]2(CC)CC(C(OC)OC)=C3Nc4ccc(Cl)cc4[C@@]34CCN1C24</smiles>

92<smiles>NCCc1c[nH]c2ccccc12</smiles>

22<smiles>CC[C@H]1CN2CC[C@H]3C4c5cccc(Cl)c5NC(=C(C(=O)OC)C1[C@@H]42)C3(C)C</smiles><smiles>C=C=C=Cc1c[nH]c2c(Cl)cccc12</smiles>

94

Figure 24: Integration of flavin-dependent halogenases into various biosynthetic pathways to yield chlorinated natural products. (A) use of PyrH to afford 5-chlorinated indolocarbazoles. (B) Use of an engineered $\mathrm{RebH}$ variant to selectively catalyse 7-chlorination of tryptamine. TDC $=$ tryptophan decarboxylase.

\subsubsection{Integration of Fl-Hal with Transition-Metal Catalysis}

The introduction of halogen atoms into complex natural products also provides a convenient moiety for further functionalisation by transition-metal catalysed cross-coupling chemistry. ${ }^{260}$ The number of $\mathrm{C}-\mathrm{C}, \mathrm{C}-\mathrm{N}, \mathrm{C}-\mathrm{F}$ and $\mathrm{C}-\mathrm{O}$ bond-forming reactions possible using this chemistry, has made it an indispensable tool in the synthesis of complex molecules of relevance in many sectors of the chemical industry. ${ }^{3}$ As the carbon-halide bond is a key substrate for these transformations, it seems logical that the combination of the regioselective enzymatic methods for installation of halides onto aromatic substrates with this powerful cross-coupling chemistry may provide methodologies for the regioselective formation of $\mathrm{C}-\mathrm{C}, \mathrm{C}-\mathrm{N}, \mathrm{C}-\mathrm{F}$ and $\mathrm{C}-\mathrm{O}$ bonds from unactivated $\mathrm{C}-\mathrm{H}$ bonds. Current methods for such transformations, termed $\mathrm{C}-\mathrm{H}$ activation, rely upon substrate-control whereby either the difference in acidity of $\mathrm{C}-\mathrm{H}$ bonds or intra-molecular coordination is used to control the position of functionalisation. ${ }^{42}$ As such, this often means that certain positions of key moieties are inaccessible. Use of a halogenase, whereby the position of functionalisation is controlled by coordinating effects between the substrate and a well-defined three-dimensional active site however, represents an example of catalyst-control as using different biocatalysts can functionalise different positions. 
The sequential application of biosynthetic halogenation followed by a subsequent transition-metal catalysed cross-coupling was demonstrated on crude extracts of chloropacidamycin from $S$. coeruleorubidus expressing the tryptophan 7-halogenase RebH to generate a number of 7-aryl pacidamycin derivatives through Suzuki-Miyarua chemistry. ${ }^{251} \mathrm{~A}$ similar rationale, whereby halo-aryl containing crude extracts from halogenase biotransformations are used for Pd-catalysed crosscoupling chemistry, has been extended to allow the regioselective formation of $\mathrm{C}-\mathrm{C}, \mathrm{C}-\mathrm{N}$ and $\mathrm{C}-\mathrm{O}$ bonds on a number of bioactive molecules (Figure 25). ${ }^{261}$

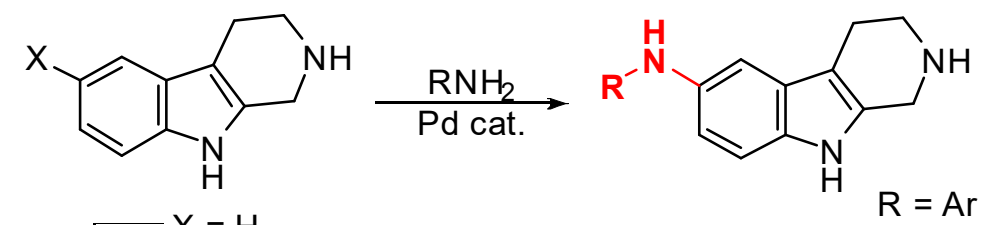

$$
\mathrm{RebH} \longrightarrow \mathrm{X}=\mathrm{H}
$$<smiles>[X]c1ccc(N(Cc2cccs2)C2CCN(C)CC2)cc1</smiles>

$$
\begin{aligned}
\mathrm{RebH} \longrightarrow \mathrm{X}=\mathrm{H} \\
\longrightarrow \mathrm{X}=\mathrm{Br}
\end{aligned}
$$

Figure 25: Integration of flavin-dependent halogenases with palladium-catalysed cross-coupling chemistries to allow regioselective $\mathrm{C}-\mathrm{C}$ and $\mathrm{C}-\mathrm{O}$ cross-coupling reactions.

Although these two examples demonstrate the possibility of regioselective cross-coupling reactions using halogenases to generate an aryl halide precursor, the requirement for a two-step process including isolating the intermediate aryl halide is not ideal. The combination of multiple reactions into single-pot transformations represents a potential step-change in the efficiency of chemical synthesis by; reducing solvent consumption and waste, eliminating the need for auxiliary chemicals and increasing space-time yield. ${ }^{262,263}$ The combination of biocatalytic and chemocatalytic reactions into single pot aqueous transformations is often not straightforward, however, and requires the compartmentalisation or removal of at least one of the components due to mutual deactivation of the bio- and chemocatalysts. ${ }^{264-266}$ This has been realised to some extent by using the heterogeneous CLEAs of the flavin-dependent halogenases (Figure 26). ${ }^{243,267}$ As the heterogeneous biocatalyst is 
easily removed from the reaction, compartmentalisation of biocatalysts and chemocatalysts can be achieved by filtration. ${ }^{243,267}$ Methods where such intermediary processing is not required have also been reported. ${ }^{243}$ Here compartmentalisation is achieved by using poly-dimethylsiloxane (PDMS) membranes which, due to their hydrophobic nature, allow only the non-polar arylhalide to diffuse freely between compartments whilst the charged chemocatalysts and biocatalysts are contained separately. ${ }^{264,268,269}$ Such one-pot transformations have been applied to the arylation, hetroarylation and alkenylation of isoquinolines and benzamides, in addition to the 5-, 6- and 7-positions of indoles and tryptophan derivaties (Figure 26). ${ }^{243,267}$ Notably, the direct functionalisation of the 7- and 6positions of indoles by non-enzymatic means requires the introduction and removal of directing groups, ${ }^{270,271}$ whilst the 5 -position remains inaccessible to our knowledge. The methods of compartmentalisation used here set the stage for the integration of other transition metal-catalysed processes and therefore additional regioselective transformations.

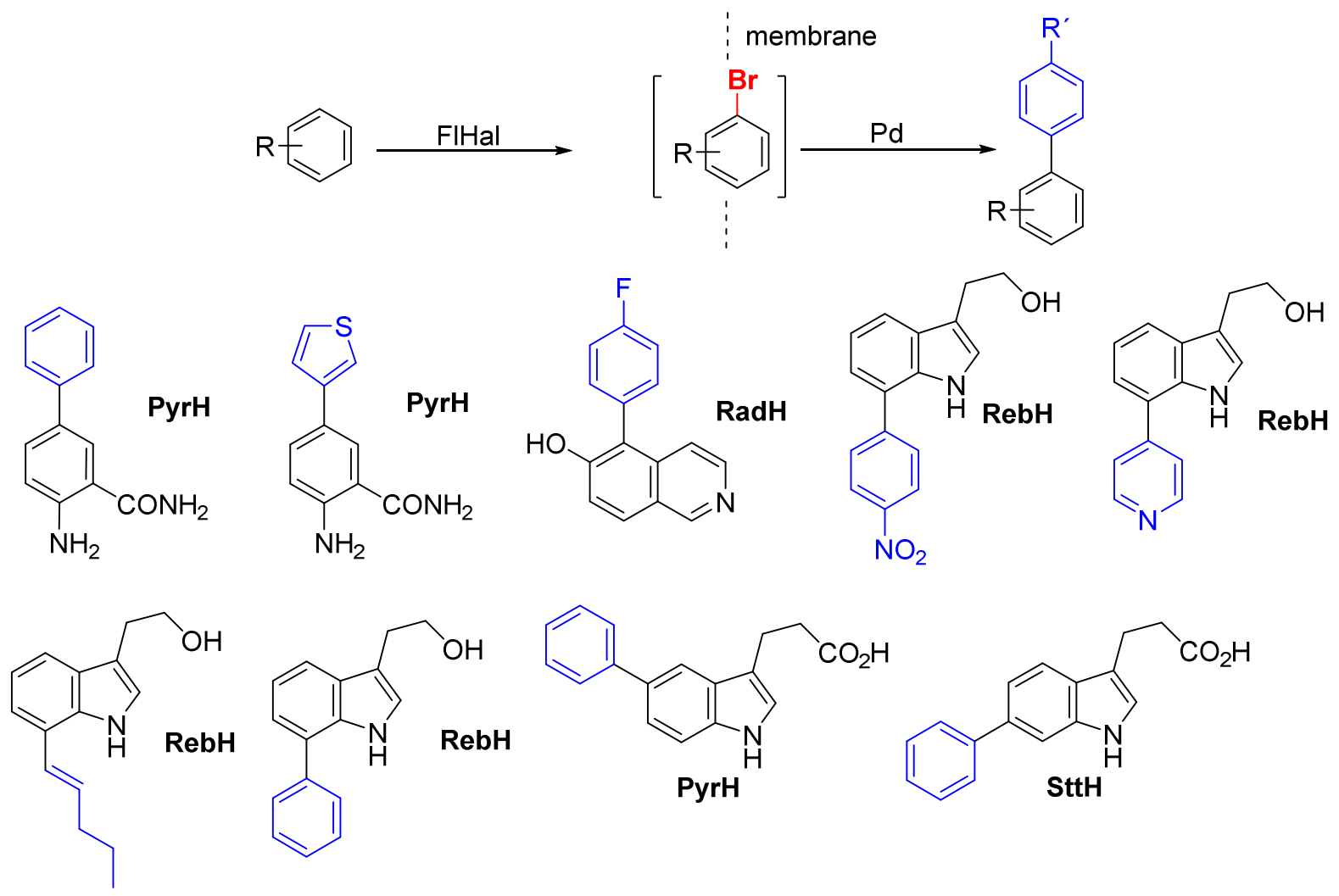

Figure 26: Integration of flavin-dependent halogenases with palladium-catalysed cross-coupling chemistries to allow regioselective and regiodivergent arylation, vinyl-ation and hetero-arylation in one-pot reactions using membrane compartmentalisation. 


\subsection{Flavin-Dependent Monooxygenases}

\subsubsection{Natural Occurrence and Mechanism of Flavin-Dependent Monooxygenases}

The flavin-dependent halogenases belong to the class of flavin-dependent monooxygenases, which operate via the activation of molecular oxygen using flavin co-factors. A number of other types of enzyme in this class have also been subject to significant interest as biocatalysts because of their ability to functionalise inert $\mathrm{C}-\mathrm{H}$ bonds. ${ }^{115,272-275} \mathrm{~A}$ number of recent reviews have extensively discussed these enzymes both in terms of structural biology and their applications as biocatalysts. ${ }^{115,116,275-277}$ This review will discuss how the methods employed to allow the application of some of these enzymes as industrial biocatalysts might be applied to improve the viability of using flavin-dependent halogenases in the same way.

The flavin-dependent hydroxylases and epoxidases in addition to the Bayer-Villager Monooxygenases (BVMO) operate via an analogous mechanism to Fl-Hals, except hydroperoxy-flavin (21) is believed to directly react with substrate to yield oxygenated product. ${ }^{118,120,278}$ All of these enzymes therefore share the conserved flavin-binding motif GxGxxG. With the flavin-dependent hydroxylases and BVMOs, reduced flavin is found in the form of an FMN prosthetic group which is reduced by a second domain using $\mathrm{NADH}$, whilst the epoxidases utilise freely-diffusing $\mathrm{FADH}_{2}$ generated by a separate flavin-reductase in the same way as the FI-Hals. Because of the mechanistic relationship between the FI-Hals and the hydroxylases, epoxidases and BVMO, useful insight may be gained as to how to apply the FI-Hals as industrial biocatalysts by studying others in the class.

The flavin-dependent hydroxylases typically hydroxylate the 2-position of phenols, ${ }^{272,279}$ most likely due to increased stabilisation of intermediate 95 and positioning relative to hydroperoxy-flavin (21). These enzymes are responsible for the catabolism of xenobiotics as well as the biosynthesis of fatty acids and sterols. ${ }^{274,280-282}$ Kynurenine-3-monooxygenase on the other hand hydroxylases ortho- to a $\mathrm{NH}_{2}$ group, due to stabilisation of the analogous ketamine intermediate. ${ }^{283}$ This particular hydroxylase has attracted much academic attention due to its involvement in tryptophan catabolism and neurodegenerative disease. ${ }^{283-285}$ Styrene monooxygenase is similarly involved in the microbial 
catabolism of styrene, catalysing epoxidation of the vinyl group prior to ultimate incorporation to the TCA cycle ${ }^{286}$ whilst BVMOs are responsible for the oxygenation of carbonyl-containing xenobiotics en route to innocuous products in addition to oxidation at heteroatoms such as $\mathrm{S}, \mathrm{N}$ and $\mathrm{B}^{287,288}$

The different mechanisms of flavin-dependent monooxygenases serve to illustrate the versatility of the flavin co-factors (Figure 27). Notably, in BVMOs the distal oxygen of hydroperxoy-flavin is deprotonated and functions as a nucleophile, in contrast to halogenases, hydroxylases and the styrene epoxidase where the distal oxygen is protonated and functions as an electrophile.

A<smiles>[R]N1C2=NC(=O)NC(=O)C2(C)Nc2cc(C)c(C)cc21</smiles>
21<smiles>[R]N1C2=NC(=O)NC(=O)C2(OOC2(O)CCCCC2C)Nc2cc(C)c(C)cc21</smiles><smiles>[R]N1Nc2cc(C)c(C)cc2NC2C(=O)NC(=O)N=C21</smiles>

B<smiles>[Z17]OO[C@]12Nc3cc(C)c(C)cc3N([R])C1=NC(=O)NC2=O</smiles><smiles>[R]N1C2=NC(=O)NC(=O)C2(O)Nc2cc(C)c(C)cc21</smiles>

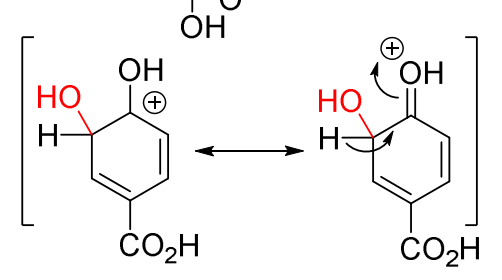<smiles>COc1cc(C(=O)O)ccc1O</smiles>

C<smiles>[R]N1NC(=O)C2(Nc3cc(C)c(C)cc3OC)C(=O)NC(=O)N=C12</smiles><smiles>C1CCCCC1</smiles><smiles>Cc1cc(C)c(C)cc1C</smiles>

95<smiles>COc1ccc2nc(SCc3ncc(C)c(OC)c3C)[nH]c2c1</smiles><smiles>COc1c(C)cnc(CS(C)(=O)(O)c2nc3ccc(OC[C@H]4C[C@H](C)C4(C)C)cc3[nH]2)c1C</smiles>

96

Figure 27: Reactivity of hydroperoxy-flavin (34) in (A) Bayer-Villager monooxygenases, (B) flavindependent hydroxylases and (C) styrene monooxygenases. (D) Use of a Bayer-Villager Monooxygenase for asymmetric sulfoxidation in the synthesis of Esomeprazole (96). 


\subsubsection{Flavin-dependent Monooxygenases as Biocatalysts}

There are a number of factors which limit the prospect of applying the flavin-dependent monooxygenases, including Fl-Hals, as industrial biocatalysts including, which include the requirement for stoichiometric reductants, substrate or product inhibition, the requirement for careful control of oxygenation and poor enzyme stability. ${ }^{272,275}$

Reduced flavin co-factors, required by all enzymes of this class, are unstable with respect to oxygen. Stoichiometric reductants must therefore be provided in the form of nicotinamide co-factors which are more aerobically stable. With the hydroxylases and BVMOs, reduction of the flavin prosthetic group is carried out by a reductase domain of the monooxygenase. ${ }^{116,289,290}$ With the epoxidases and FI-Hals, freely diffusing reduced flavin is typically produced by a separate flavin-reductase enzyme before utilisation by the monooxygenase,${ }^{116}$ with the exception of a recently-discovered epoxidase-reductase fusion protein. ${ }^{291,292}$ In the case of monooxygenases utilising freely-diffusing reduced flavin co-factors, it is possible for reduced flavin to react directly with oxygen in solution, resulting in hydroperoxy-flavin being generated outside of the active site. ${ }^{293}$ Without stabilisation through hydrogen bonding to an active site, this can break down to produce $\mathrm{H}_{2} \mathrm{O}_{2}$ in solution (Figure 28). ${ }^{293,294}$ In addition to "uncoupling" the monooxygenase reaction and wasting the reductant co-substrate, accumulation of such reactive species can impair the stability of the biocatalysts and therefore reduce their productivity. ${ }^{275}$ Similar uncoupling reactions can also occur within the active site, including in those of enzymes which utilise flavin prosthetic groups, by inefficient transfer of oxygen from hydroperoxyflavin to substrate and therefore degradation to $\mathrm{H}_{2} \mathrm{O}_{2}$ and oxidised flavin. High concentrations of product are thought to promote uncoupling in this manner, by effectively blocking substrate from binding and preventing productive oxygen transfer. ${ }^{279,295}$ Such uncoupling means that the reducing co-substrate $(\mathrm{NAD}(\mathrm{P}) \mathrm{H})$ must either be supplied in excess, which is undesirable due to cost, or regenerated in situ from inexpensive co-substrates. Although oxygenation can promote uncoupling and impair productivity, it cannot simply be excluded from reaction media due to the requirement to generate hydroperoxy-flavin for productive cycles - consequently careful control of oxygenation is often required. ${ }^{296,297}$ 


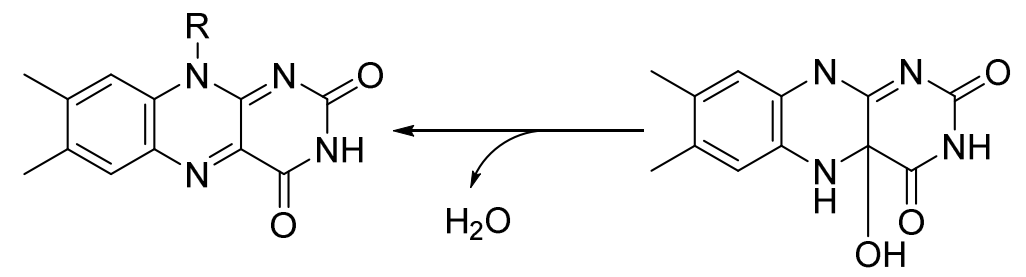

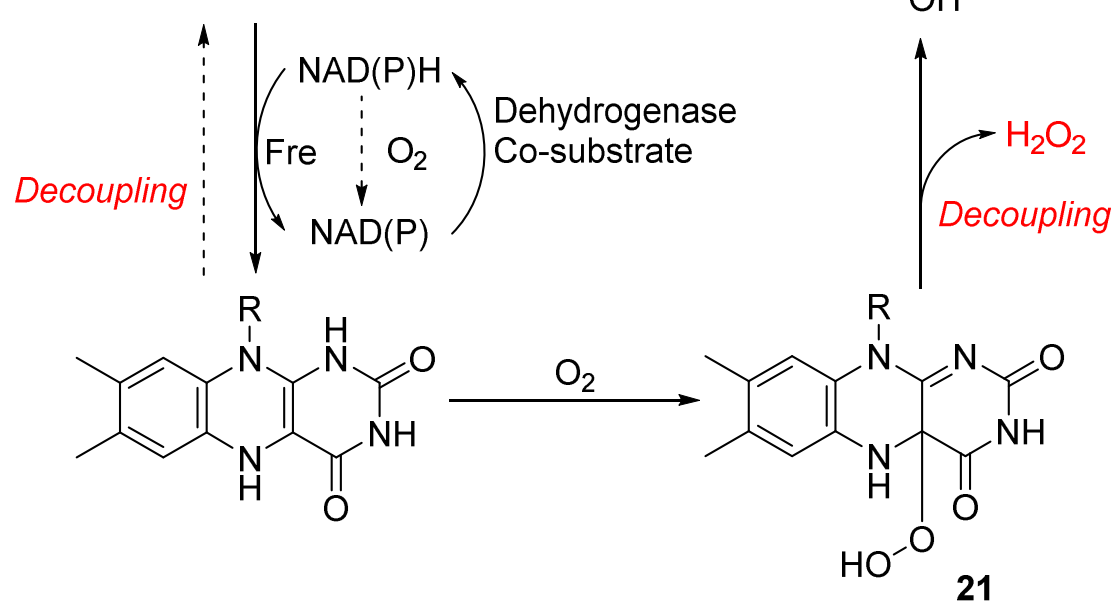

Figure 28: Cycle of peroxy-flavin (21) production showing potential uncoupling processes.

The use of additional enzymes in vitro to reduce nicotinamide co-factors using inexpensive cosubstrates such as glucose or isopropanol is widespread and has been applied to the FI-Hals, in addition to a number of other monooxygenases, to allow the use of sub-stoichiometric nicotinamide and flavin co-factors. ${ }^{155,220,298}$ Methods for the direct regeneration of FAD, without using nicotinamide cofactors or additional enzymes, have also been reported and applied with the flavin-dependent monooxygenases (Figure 29). ${ }^{128,299-303}$ These methods offer simplified electron-transfer cascades and therefore are envisioned to be a more robust alternative to enzymatic methods. A number of these examples utilise the organometallic complex $\left[\mathrm{Cp}^{*} \mathrm{Rh}(\mathrm{bpy})\left(\mathrm{H}_{2} \mathrm{O}\right)\right]^{2+}$ and formate to generate the reduced complex $\left[\mathrm{Cp}^{*} \mathrm{Rh}(\mathrm{bpy}) \mathrm{H}\right]^{+}$which can then directly transfer hydride to oxidised $\mathrm{FAD} .{ }^{128,302}$ The use of transition metal complexes may not be ideal, however, because of their potential deactivation of the monooxygenase and expense. Methods of light-driven flavin reduction have therefore also been investigated, utilising either water or EDTA as the sacrificial electron donor. ${ }^{300,304}$ In one case, this method has been applied to the BVMO-catalysed oxidation of cyclic ketones by using additional FAD in solution, to facilitate electron transport from EDTA to enzyme-bound FAD. ${ }^{300}$ Further simplification has been achieved using electrochemical methods to directly reduce FAD for biocatalytic vinyl aromatic epoxidations without the need for nicotinamide co-factors. ${ }^{301}$ Direct regeneration of $\mathrm{FADH}_{2}$ using nicotinamide mimics has also been reported, which allows efficient 
biocatalytic oxidations using styrene monooxygenase without the flavin-reductase domain or nicotinamide co-factors. ${ }^{303}$
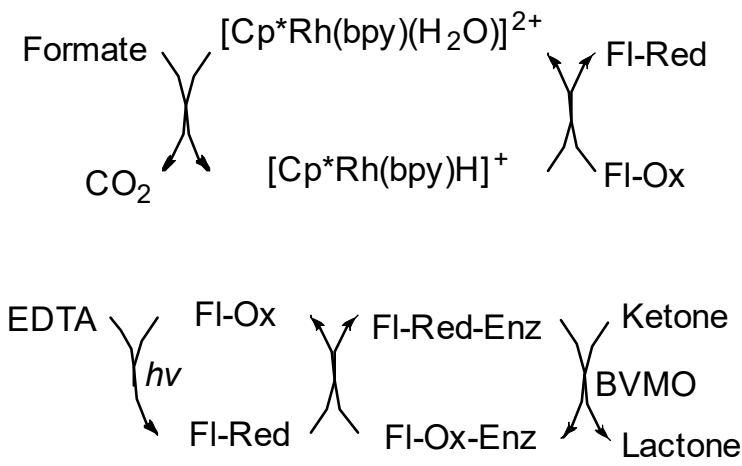

Figure 29: Non-enzymatic flavin recycling methods.

The inherent metabolism of a microbial host can also be used to re-generate the required co-factors, in addition to supplying enzymes such as super-oxide dismutase or catalyse which can degrade reactive oxygen species. ${ }^{305}$ Such an approach has the advantage of not requiring additional enzymes or co-substrates, as well as ease-of-preparation of the biocatalyst when compared to pure protein. This was achieved to good effect with the flavin-dependent hydroxylase HBP $1 .{ }^{306,307}$ In these examples, a number of substituted phenols were successfully converted to catechols in gram amounts by using growing E. coli expressing the hydroxylase of interest. ${ }^{306,307}$ The use of growing microbial host not only means that co-factors can be recycled by the inherent primary metabolism of the organism, but also that the biocatalyst is constantly being synthesised which is useful in the case of particularly unstable enzymes. ${ }^{305-307}$ The substrate phenols and subsequent catechols were found to be toxic to $E$. coli in fairly low concentrations however, and therefore batch-feeding of phenol at or below the rate of bio-oxidation was used to limit accumulation of substrate. In combination with in situ product removal (ISPR) to adsorb catechol product onto a solid resin, the accumulation of substrate and product was limited to sub-toxic levels - allowing constant bio-oxidation using the same whole cells. ${ }^{306,307}$ The combination of controlling both substrate and product concentration is often termed substrate-feeding product-removal (SFPR). A similar rationale has been applied to the BVMOs, with a number of examples allowing between gram and kilo-gram production of enantiopure lactones from ketones. $^{308-314}$ In these examples, substrate and product are allowed to adsorb and desorb freely from a resin, therefore limiting their concentration in the reaction broth. Additionally, specially designed 
reactors are used to control the extent of oxygenation and therefore limit the effects of uncoupling, whilst allowing sufficient oxygenation for bio-oxidation. ${ }^{308,314}$

Biphasic reaction media can also allow the concentration of substrates and products to be controlled and therefore limit toxicity or inhibition by high concentrations of either. A water-immiscible organic cosolvent is used to create a substrate and product reservoir, away from the biocatalyst. This has been successfully achieved with both the styrene monooxygenases and BVMOs, ${ }^{315,316}$ in one case allowing production of up to $388 \mathrm{~g}$ of styrene oxide. ${ }^{317}$

In addition to the methods of engineering monooxygenase-mediated biotransformations to overcome substrate/product inhibition, toxicity, oxygenation and uncoupling discussed above, significant work has focussed on engineering at the protein level and is responsible for some of the highly productive biocatalytic methods known. For example the BMVO used by Codexis for sulfoxidation in the production of esomeprazole (96, Figure 27D) is a cyclohexanone monooxygenase (CHMO) variant containing 41 mutations. ${ }^{318}$ Modulating activity of the BVMO in terms of substrate scope or enantioselectivity has been achieved using both rational (structure-guided) mutagenesis and directed evolution approaches. A widely used approach for this class is "Complete Active Site Saturation Test" (CASTing) whereby amino acid positions close to the binding pocket are selected for saturated mutagenesis, and has allowed the evolution of BVMO variants with modified substrate scope and improved enantioselectivity using homology models as a guide for targeting saturated mutagnesis. ${ }^{319-}$ ${ }^{323}$ To facilitate directed evolution by allowing rapid screening of larger variant libraries, a number of high-throughput screens for BVMO and hydroxylase activity have also been developed. The majority of the most recent methods require further reaction of the monooxygenase product, either enzymatically or non-enzymatically, to either induce a $\mathrm{pH}$ change,${ }^{324}$ or afford a compound with distinct UV-Vis characteristics which can then be easily detected. ${ }^{295,325-331}$ A number of structureguided approaches have also been used to modulate regioselectivity and substrate scope, ${ }^{332,333}$ or improve oxidative and thermostability. ${ }^{334}$ 


\section{Fluorinases}

\subsection{Discovery of Fluorinases in Nature}

The enzymes responsible for biosynthesis of fluorinated natural products have remained relatively elusive, due in part to their rarity compared to naturally-occurring organochlorine and organobromine compounds. ${ }^{335-338}$ Indeed only five fluorinated natural products have been definitively identified to date (Figure 30A), with fluoroacetate (97) being the most ubiquitous. ${ }^{339}$ A recent review has thoroughly discussed the enzymes involved in the biosynthesis of these compounds, ${ }^{336}$ however they will be discussed herein briefly to complete the survey of biocatalytic halogenations which might be applied to industrial or medical processes.

Enzymatic fluorination activity was first observed with mutants of the glycosyl transferase enzymes $\beta$-glucosidase and $\beta$-mannosidase from Agrobacterium sp. and Cellulosmonas fimi respectively. ${ }^{340-342}$ It was found that when catalytically essential nucleophilic residues were mutated, glycosyl transferase activity was abolished. Upon addition of high concentrations of fluoride, however, such activity was restored. NMR subsequently showed the production of fluorinated glycosides (Figure 30B) as intermediates which would allow attack by nucleophilic moieties of incoming sugar residues due to the polarised nature of the C-F bond. ${ }^{340-342}$

Nucleocidin (98), an antibiotic produced by Streptomyces calvus, was one of the first fluorinated metabolites to be identified, although elucidation of its biosynthetic pathway was hampered by poor fluorometabolite production under laboratory fermentation conditions. ${ }^{343}$ Streptomyces cattelya, which secretes fluoroacetate and 4 -fluorothreonine ${ }^{344}$ however proved to be sufficiently practicable to allow identification of the enzyme responsible for fluorination. ${ }^{345}$ This particular fluorinase has been shown to catalyse fluorination of S-adenosyl methionine (SAM), to generate 5'-deoxy-5'-fluoroadenosine $(F D A)$ in an $\mathrm{S}_{\mathrm{N}}$ 2-type reaction (Figure $30 \mathrm{C}$ ) and has informed much of the current mechanistic and functional understanding of these fluorinases. ${ }^{335,346-351}$ The mechanism of enzymatic fluorination is particularly interesting because the high electronegativity of fluoride means that oxidation to an electrophilic species, as is commonplace with the other classes of halogenase (vide infra), would not be possible. ${ }^{336}$ Moreover, tight solvation of $\mathrm{F}^{-}$in water decreases its nucleophilicity and creates a great energetic penalty for nucleophilic substitution with an aqueous fluoride source. ${ }^{336,352}$ 
A<smiles>O=C(O)CF</smiles>
97

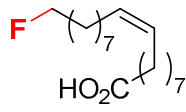<smiles>NC1=NC=NC2C1N=CN2C1OC(F)(C[C@H](N)O)C(O)C1O</smiles>

98

B<smiles>OC1OC2(O)OC(C(O)C(O)C(O)C1O)C2O</smiles><smiles>NC(C(=O)O)C(O)CF</smiles><smiles>O=C(O)CC(F)(CO)C(O)C(=O)O</smiles>
$\bar{F}$<smiles>OC1C(O)C2OC(O)(C(O)C2O)C(F)C1O</smiles>

C

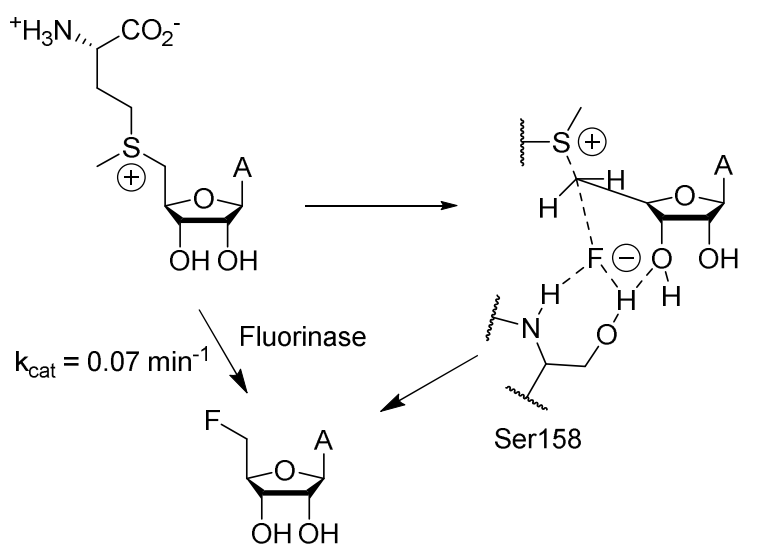

Figure 30: (A) Fluorinated natural products identified to date. (B) Fluorinated glycosides produced by mutants of glycosyl transferase enzymes. (C) Proposed mechanism of $\mathrm{F}^{-}$binding to fluorinase and arrangement for $S_{N} 2$ displacement. Kinetic parameters shown refer to the fluorination of SAM to FDA by the fluorinase from Streptomyces cattelya. ${ }^{349}$

Crystallography of the $S$. cattelya fluorinase revealed that fluoride ion is bound in the active site through electrostatic interactions, positioned in a $\mathrm{S}_{\mathrm{N}} 2$-like trajectory to the ribose $5^{\prime}-\mathrm{C}^{348}$ - consistent with the observation that introduction of fluoride occurs with inversion of stereochemistry using isotopically-labelled substrates. ${ }^{346,347}$ The energetic penalty for de-solvation of fluoride is thought to be compensated for by the retention of four hydrogen-bonded waters in the active site, in addition to the increased binding affinity of SAM. ${ }^{336,348-350,352}$

Since the seminal work on this fluorinase, a number of other enzymes have been identified with very high homology to the fluorinase from S. cattelya. ${ }^{353-355}$ Streptomyces sp. MA37 was found to produce fluoroacetate and 4-fluorothreonine in culture and subsequently a putitative fluorinase gene with $87 \%$ sequence identity to the fluorinase from S. cattelya was identified. ${ }^{353,354}$ Expression of this enzyme in E. coli confirmed fluorinase activity in vitro. Potential fluorinases have also been identified in Nocardia brasilensis and Actinoplanes sp. N902-109, and similarly demonstrated to have fluorinase activity in vitro. ${ }^{353,354}$ The marine organism S. xinghaiensis has been found to produce fluoroacetate, although in vitro activity of the fluorinase identified in this organism is yet to be demonstrated. ${ }^{355}$

A chlorinase, related mechanistically to the fluorinases, has also been identified in Salinispora tropica which is responsible for chlorination during biosynthesis of salinosporamide A (Scheme 32). ${ }^{356-358}$ 
Interestingly this chlorinase cannot utilise fluoride as nucleophile in place of chloride, whilst the fluorinase from S. cattelya is capable of utilising both halides. ${ }^{359}$ This selectivity is thought to be due to differences in active site organisation around halide binding between the fluorinase and chlorinase. ${ }^{360,361}$ Similarly a putative fluorinase from Pyrococcus horikoshii was found to utilise hydroxide (from water) as nucleophile rather than either chloride or fluoride in vitro - affording adenosine and L-methionine. ${ }^{362,363}$ Again crystallography revealed significant differences in the way in which the nucleophile is bound to active site. ${ }^{363}$

\subsection{Application of Fluorinases as Biocatalysts}

\subsection{1 ${ }^{18} \mathrm{~F}$ Labelling}

The radioisotope ${ }^{18} \mathrm{~F}$ is commonly used in positron-emission tomography $(\mathrm{PET})$ - a key medical imaging technique. ${ }^{336,364-366}$ The ${ }^{18} \mathrm{~F}$ required to produce the compounds used in this process is obtained from bombardment of $\mathrm{H}_{2}{ }^{18} \mathrm{O}$, which affords aqueous ${ }^{18} \mathrm{~F}^{-336}$ The potential to use fluorinases to prepare ${ }^{18} \mathrm{~F}$ labelled compounds, which can use aqueous fluoride directly without the need for drying or coordination to specialist ligands to allow reactivity in organic solvents, could therefore yield expeditious routes to these compounds in higher radiochemical yield (RCY). ${ }^{336} \mathrm{~A}$ great deal of the work on applying fluorinases for biocatalysis has therefore focussed on this area (Figure 31).

Early work found that using ${ }^{18} \mathrm{~F}^{-}$equivalents could afford ${ }^{18} \mathrm{~F}$-FDA (99) using L-AAO (L-amino acid oxidase) to oxidise L-methionine and therefore suppress the reverse reaction. ${ }^{367-369}$ Various other radionucleotides have been generated using the above fluorinase-mediated ${ }^{18} \mathrm{~F}$ introduction, followed by "base-swapping" with PNP (purine nucleotide phosphorylase) or PyNP (pyrimidine nucleotide phosphorylase) enzymes to allow introduction or other purine or pyrimidine bases. ${ }^{369,370}$ Interestingly this method has also been applied to the one-pot synthesis of a fluorinated analogue of the antiviral agent ribavirin 100 from SAM. ${ }^{369}$ A polymer-supported fluorinase has also been used for these radiofluorinations which, by allowing more facile removal of biocatalyst, may allow more efficient syntheses of these compounds with higher RCY. ${ }^{371,372}$ The ${ }^{18} \mathrm{~F}$-FDA nucleoside produced using fluorinase can also act as the substrate for a Kuhn-Roth oxidation, allowing the chemo-enzymatic synthesis of ${ }^{18} \mathrm{~F}$ fluoroacetate (97) - a common PET-imaging agent in neurology and oncology. ${ }^{365,366,373}$ 
<smiles>C[Si](CC[C@H](N)C(=O)O)C[C@H]1OC(n2cnc3c(N)ncnc32)[C@H](O)[C@@H]1O</smiles><smiles>CSCCC(=O)C(=O)O</smiles>

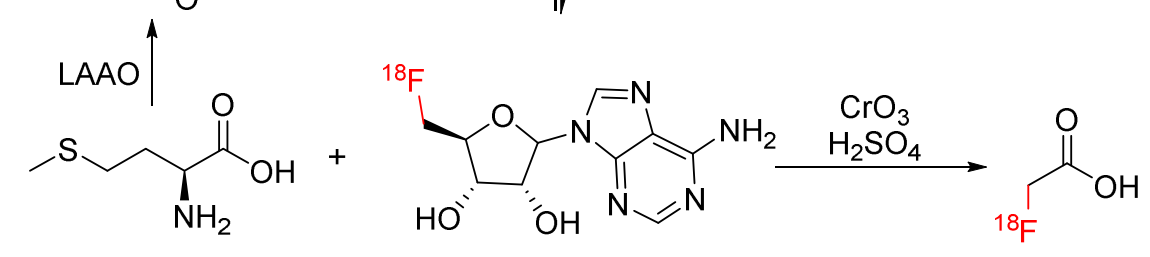

99

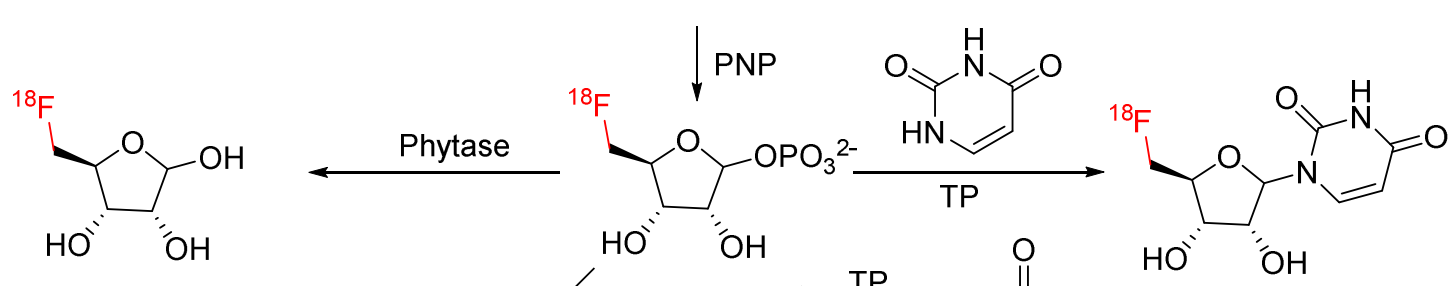
101<smiles>Nc1nc(N)c2ncn(C3OC(C[18F])[C@@H](O)[C@H]3O)c2n1</smiles><smiles>CC(c1[nH]cnc1C(N)=O)C(C)(C)C(=O)c1ncn(C2OC(C[18F])[C@@H](O)[C@H]2O)n1</smiles>

100

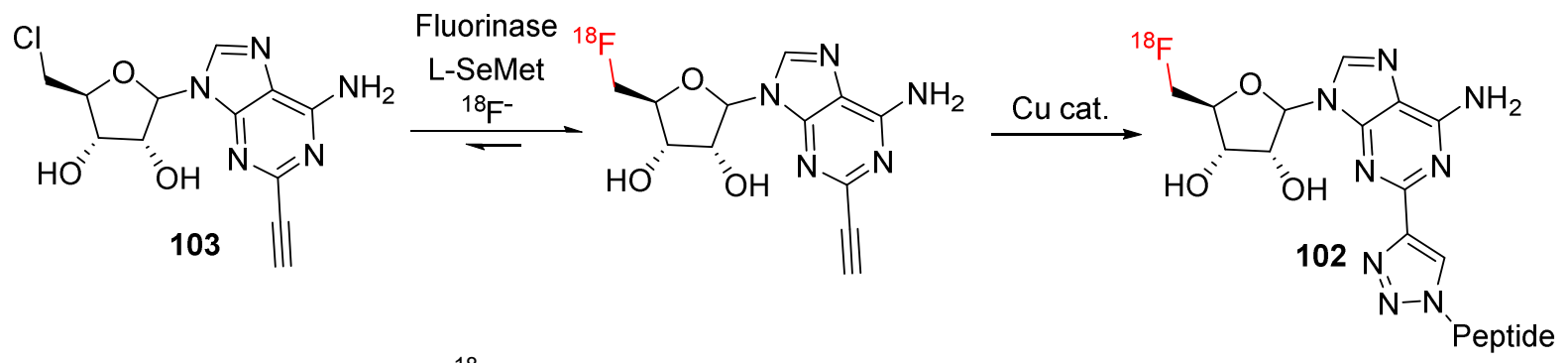

Figure 31: Preparation of ${ }^{18} \mathrm{~F}$ labelled nucleotide analogues, fluoroacetate and peptides using fluorinases in bio-bio and bio-chemo cascade reactions. LAAO = I-Amino Acid Oxidase. PNP = Purine Nucleotide Phosphorylase. PyNP - Pyrimidine Nucleotide Phosphorylase.

Combination of the above cascade with a phytase enzyme allows the nucleobase portion of ${ }^{18} \mathrm{~F}$-FDA to be replaced with a hydroxyl group, affording $5{ }^{\prime}-{ }^{18} \mathrm{~F}$ ribose $(101) \cdot{ }^{370,374} 101$ is of particular interest because of the potential to exploit this primed substrate in bio-conjugation due to its propensity for ring-opening. ${ }^{375,376}$ Bio-conjugation has also been achieved by using nucleotide mimics containing chemical handles for conjugation onto a peptide target. ${ }^{377,378}$ It was noted by crystallography that $\mathrm{H} 2$ 
of the adenine ring of SAM was positioned towards the surface of the enzyme, suggesting that analogues with substitution here may be accepted by the fluorinase. ${ }^{378}$ Introduction of an acetylene group allows facile attachment of a tagged peptide to 5'-chloro adenosine using an azide-alkyne cycloaddition "click" reaction. Because of the orientation of this substitution, the reverse chlorinase reaction of fluorinase could then be used to afford fluorination of the adenosine portion, affording ${ }^{18} \mathrm{~F}$ labelled peptide 102, a good PET imaging agent in rats. ${ }^{378}$ A simplified protocol, starting from "untagged" nucleoside 103 was subsequently reported which allowed preparation of the same agent in $90 \% \mathrm{RCY}^{377}$

\subsubsection{Production of Fluorinated Natural Products}

Natural products are a common source of medicinal compounds. Given that fluorination can often have a profound effect upon the bioactivity of a compound, ${ }^{13,14}$ methods for the facile preparation of fluorinated natural product analogues through fermentation are therefore desirable. ${ }^{336}$ In an attempt to achieve this goal, fluorinase enzymes have been incorporated into non-natural biosynthetic pathways (Figure 32).

A seminal example employing this rationale involved replacing the gene encoding salL with the fluorinase encoding gene fIA in the salinosporamide (104) producer Salinospora tropica. The resulting mutant produced fluorosalinosporamide (105) directly by fermentation. ${ }^{379,380}$ Fluorinated polyketide natural product analogues have also been obtained from substrate-directed biosynthesis. Through incubation of the re-constituted minimum components of the artinochodin PKS machinery with fluoroacetyl-CoA (106), a fluorinated octaketide could be produced, which is then subsequently cyclised to $107 .^{381} \mathrm{R}_{2} \mathrm{CHF}$ groups have also been introduced into polyketide natural products by feeding of fluoro-malonate. ${ }^{382}$ It was demonstrated that a malonyl-CoA synthetase could also accept fluoromalonate 109 which, when combined with part of the assembly module of the erythromycin PKS, allowed generation of the fluorinated polyketide analogue $110{ }^{382}$ The ability to produce fluorinated substrates for PKS machinery, from fluoroacetate or similar starting materials generated by integration of fluorinases in vivo, ${ }^{383}$ has the potential to allow the facile synthesis of fluorinated natural product analogous through fermentation. 


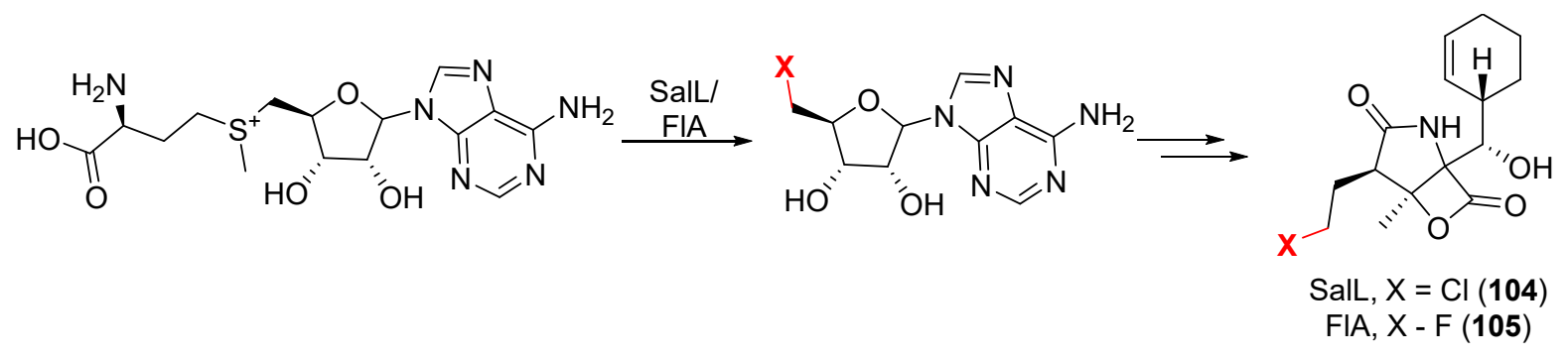<smiles>CCC(O)C(C(=O)SCCNC(C)=O)C(C)C(=O)OCCCCC(=O)O</smiles>

Figure 32: Preparation of fluorinated natural product analogues through either substrate-directed biosynthesis of fluorinated building blocks or heterologous expression of fluorinases.

\section{Future Perspectives}

The enzymes discussed herein show great versatility for regio- and stereo-controlled halogenations of unactivated $\mathrm{C}-\mathrm{H}$ bonds. Such transformations, affording highly bioactive compounds and ubiquitous synthetic intermediates, could have a great impact on the efficiency of synthesis in all sectors of the chemical industry. Given the importance of selectivity in these transformations, those classes of halogenases which utilise freely-diffusing hypohalous acid intermediates (vide infra) are unlikely to afford transformations of great value - with the exception of the limited number of examples which appear to show some selectivity. ${ }^{76}$ The $\alpha-K G$ and flavin-dependent halogenases, which show exquisite control of their active halogenation species and hence afford regio- and stereo-selective transformations, are the most promising. Together with fluorinases, the only class capable of introducing fluorine to organic compounds, these classes of halogenase will likely attract the most attention for industrial biocatalytic applications.

Despite this potential however, there is still some way to go before these enzymes can be reliably used on an industrial scale. The fluorinases have been applied on a laboratory scale for the ${ }^{18} \mathrm{~F}$ labelling of small molecules and for production of fluorinated natural product analogues, ${ }^{367-369,373,374,377-}$ ${ }^{380}$ although much research is still focussed on the discovery of additional flourinases and little attempt has been made to determine the scalability of these transformations. Immobilisation of the fluorinases, 
which would allow more facile removal of biocatalyst and therefore potentially higher RCY, in addition to higher purity products for medical applications and more productive enzyme preparations, is a promising direction. ${ }^{371}$ Unlike the other classes of halogenase discussed herein, this class ultimately require a methionine leaving group to be installed which fluoride can then displace. Although this can be transiently installed by using the reverse chlorinase reaction of the fluorinases, ${ }^{377}$ the need for prior functionalisation could limit the efficiency of synthesis using these enzymes. The unique ability of this class to produce organofluorine compounds, unlike the other classes which require oxidation of halide to an activated species prior to chlorination, means that the transformations involving the class will still be of great value.

The $\mathrm{Fe}(\mathrm{II}) / \alpha-\mathrm{KG}$ dependent halogenases are capable of halogenating aliphatic $\mathrm{C}-\mathrm{H}$ bonds without the need for a leaving group. This class were initially believed to be of little value for biocatalysis due their selectivity for carrier-protein tethered amino acid substrates, although the recent discovery of a $\alpha$ $\mathrm{Fe}(\mathrm{II}) / \alpha-\mathrm{KG}$ dependent halogenase capable of catalysing the regio- and stereo-selective halogenation of freely-diffusing substrates offers fresh promise for this class of halogenase. ${ }^{108-111}$ The substrate scope of this class is yet to be explored extensively, as is their amenability to engineering for modulation of substrate scope and selectivity, but the limited number of examples thus far is promising and is likely to broaden should further enzymes of this class be discovered. The demonstration that mutagenesis of an $\mathrm{Fe}(\mathrm{II}) / \alpha-\mathrm{KG}$ dependent hydroxylase can be engineered to provide a halogenase biocatalyst is also promising because this could allow the engineering of other $\alpha-K G / F e(I I)-d e p e n d e n t ~ h y d r o x y l a s e s$, which accept a broad range of freely-diffusing substrates, into additional biocatalysts for the halogenation of aliphatic $\mathrm{C}-\mathrm{H}$ bonds. ${ }^{111,113}$

The flavin-dependent halogenases are the most promising biocatalysts for the halogenation of aromatic $\mathrm{C}-\mathrm{H}$ bonds and as such have received much attention. The tryptophan halogenases are the most extensively studied class to date with a number of enzymes known which can halogenate complementary positions of a range of substrates. ${ }^{145,150,155,218,220,221,225}$ Given the number of phenolic flavin-dependent halogenases demonstrated to be involved in the biosynthesis of natural products, a great deal of which can accept freely-diffusing substrates (vide infra), the application of these enzymes will likely significantly broaden the substrate scope of these biotransformations. The FI-Hals 
are still of limited scalability, however, due to low productivity and stability. The efforts described above on engineering other flavin-dependent monooxygenases demonstrate the strides which can be made in process development, and in using rational protein engineering or directed evolution, towards developing flavin-dependent hydroxylases, epoxidases and BVMOs for practical biocatalysis and illustrates the need to apply such rationale to the improvement of the less well developed flavindependent halogenases. As the monooxygenase screening methods reported so far are dependent upon detection of a specific reaction product or sequence of reactions occurring, they are not appropriate for application to the flavin-dependent halogenases, although methods which could be applied to their directed evolution are slowly emerging and have been demonstrated feasible. ${ }^{223,240,241}$ In combination with what is known about the modification of their substrate scope, regioselectivity and stability through mutagenesis, ${ }^{150,155,222-225}$ in addition to the discovery of naturally-occurring thermostable $\mathrm{Fl}-\mathrm{Hals},{ }^{145}$ a number of reliable starting points for further engineering efforts are known. Other monooxygenases may also provide useful information about loci for targeting further engineering. Enzymes with lower rates of flavin decoupling, for example, could be used to focus engineering of $\mathrm{Fl}-\mathrm{Hals}$ with improved stabilisation of hydroperoxy-flavin - thereby reducing uncoupling and enzyme deactivation and potentially improving reaction efficiency and biocatalyst stability. ${ }^{275}$ Mutation of such co-factor binding sites has been demonstrated to have a positive effect upon catalytic parameters with FI-Hals and other enzymes. ${ }^{242,384}$ Knowledge of the mechanisms of oxygen activation by the monooxygenases could also be used to promote formation and stabilisation of this key intermediate. ${ }^{385}$ It is possible however that a lack of productivity with the Fl-Hals could be due largely to the fact that the rate-determining step (electrophilic aromatic substitution) is very energetically demanding and therefore engineering could be focussed upon stabilisation of the Wheland intermediate or increasing electrophilicity of the halogenating species. The outcomes from the rational methods to improve the oxidative and thermostability of BVMO could also be useful to FIHal engineering. As both classes suffer from deactivation from ROS, the mutation of active site and surface sulfur-containing residues to less oxidatively-labile residues, found to improve the oxidative stability of BVMOs, ${ }^{334}$ could develop halogenase biocatalysts more appropriate for industrial applications. 
The methods used to improve monooxygenase practicability and productivity at the reaction and process engineering level may be more directly applicable to the Fl-Hals in the short term. For example, there have been little published work on the effect of oxygenation upon Fl-Hal mediated biotransformations beyond mechanistic studies, ${ }^{128,132}$ and therefore optimisation in this regard may be a valuable avenue to peruse in their future development. It appears that the use of additional enzymes to destroy ROS is not commonplace in protocols for using $\mathrm{Fl}-\mathrm{Hals},{ }^{227}$ and therefore it may be useful to determine the extent of uncoupling in these reactions as well as its impact on enzyme productivity. Fairly straightforward and inexpensive methods of SFPR such as biphasic reactions and adsorbent resins do not seem to have been explored with the Fl-Hals either, and this may also provide some improvement of their scalability. Immobilisation of the Fl-Hals does seem to have had an impact on their practicability, ${ }^{150,244,267}$ and further work on immobilisation methods may be promising, especially since heterogeneous materials may allow an flow-style biocatalytic halogenation, and hence SFPR. Such a system could allow the concentration of substrate, product and ROS to be limited whilst allowing significant material to be halogenated with the same biocatalyst. Recovery of the biocatalyst in this manner may also allow more efficient halogenase-transition metal cascades. Additionally, work on adapting the Fl-Hals to accept larger, bioactive, substrates ${ }^{223,225}$ may mean that ultimately they find application as a means of late-stage $\mathrm{C}-\mathrm{H}$ activation.

Although this review has focussed largely upon halogenase enzymes and classes which are well understood and therefore closer to application in synthesis, halogenases which could be of significant utility may yet be discovered since there are halogenated natural products known with biosynthetic pathways which are yet to be fully elucidated. Study of the halogenation reactions involved in the biosynthesis of these compounds may lead to the discovery of synthetically relevant halogenation biocatalysts. Chlorosulfolipids for example were first isolated from algae in the 1970 's, ${ }^{386-388}$ but to date the enzymes responsible for installation of the halogen atoms have not been identified. ${ }^{389}$ The halogenases from chlorosulfolipid biosynthesis may be of particular interest as biocatalysts since natural products from this class contain numerous chlorine atoms with defined stereochemistry (Figure X), ${ }^{390-393}$ and the halogenases involved appear to be capable of utilising chloride and bromide interchangeably. ${ }^{394}$ With these natural products thought to be derived from fatty acids, ${ }^{395,396}$ the enzymes involved are likely capable of the stereo- and regio-selective halogenation of aliphatic $\mathrm{CH}$ 
bonds, similar to the $\mathrm{Fe}(\mathrm{II}) / \mathrm{a}-\mathrm{KG}$ halogenases. Additionally, the range of halogenation patterns observed in this class of natural products (Figure 33) suggests exquisite control by a set of halogenase enzymes. Identification of the enzymes involved may therefore reveal biocatalysts of great synthetic utility. Study of these halogenases has likely been hampered by the difficulties associated with mining marine genomes, although the recent identification of a $\mathrm{Fl}-\mathrm{Hal}$ from the metagenome of a marine sponge adds further promise to the successful identification and characterisation of enzymes from such environments. ${ }^{397}$

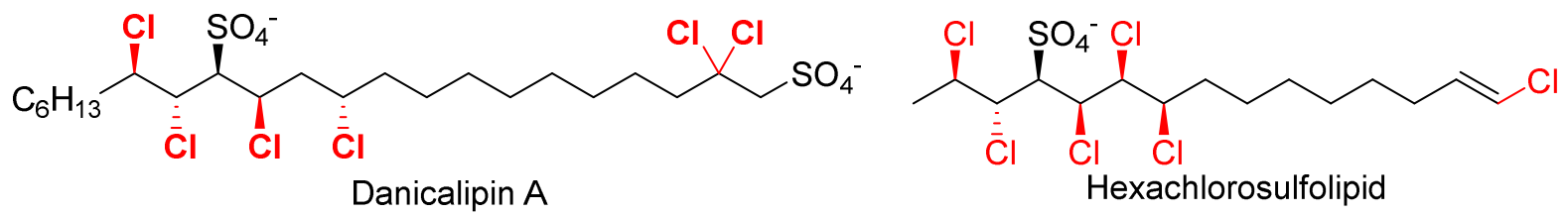<smiles>C[PH2]C(Cl)C(Cl)C(Cl)C(Cl)C(Cl)C(Cl)CCCCCCCC/C(Cl)=C\S(=O)(=O)O</smiles>

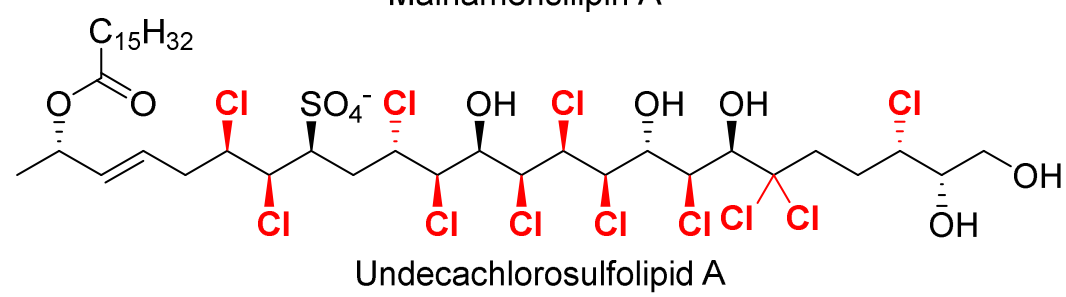

Figure 33: Chlorosulfolipid natural products identified to date identified from algae and toxic mussels.

\section{References}

(1) Ruiz-Castillo, P.; Buchwald, S. L. Applications of Palladium-Catalyzed C-N Cross-Coupling Reactions. Chem. Rev. 2016, 116 (19), 12564-12649.

(2) Han, F.-S. Transition-Metal-Catalyzed Suzuki-Miyaura Cross-Coupling Reactions: A Remarkable Advance from Palladium to Nickel Catalysts. Chem. Soc. Rev. 2013, 42 (12), 5270-5298.

(3) Nicolaou, K. C.; Bulger, P. G.; Sarlah, D. Palladium-Catalyzed Cross-Coupling Reactions in Total Synthesis. Angew. Chem. Int. Ed. 2005, 44 (29), 4442-4489.

(4) Hartwig, J. F. Carbon-Heteroatom Bond Formation Catalysed by Organometallic Complexes. Nature 2008, 455 (7211), 314-322.

(5) Tasker, S. Z.; Standley, E. A.; Jamison, T. F. Recent Advances in Homogeneous Nickel Catalysis. Nature 2014, 509 (7500), 299-309.

(6) Kuranaga, T.; Sesoko, Y.; Inoue, M. Cu-Mediated Enamide Formation in the Total Synthesis of Complex Peptide Natural Products. Nat. Prod. Rep. 2014, 31 (4), 514-532.

(7) Monnier, F.; Taillefer, M. Catalytic C-C, C-N, and C-O Ullmann-Type Coupling Reactions. Angew. Chem. Int. Ed. 2009, 48 (38), 6954-6971.

(8) Beletskaya, I. P.; Cheprakov, A. V. The Complementary Competitors: Palladium and Copper in C-N Cross-Coupling Reactions. Organometallics 2012, 31 (22), 7753-7808. 
(9) Slagt, V. F.; de Vries, A. H. M.; de Vries, J. G.; Kellogg, R. M. Practical Aspects of Carbon-Carbon Cross-Coupling Reactions Using Heteroarenes. Org. Proc. Res. Dev. 2010, 14 (1), 30-47.

(10) Xu, Z.; Yang, Z.; Liu, Y.; Lu, Y.; Chen, K.; Zhu, W. Halogen Bond: Its Role Beyond DrugTarget Binding Affinity for Drug Discovery and Development. J. Chem. Inf. Model. 2014, 54 (1), 69-78.

(11) Lu, Y.; Liu, Y.; Xu, Z.; Li, H.; Liu, H.; Zhu, W. Halogen Bonding for Rational Drug Design and New Drug Discovery. Expert Opin. Drug Discov. 2012, 7 (5), 375-383.

(12) Zhou, Y.; Wang, J.; Gu, Z.; Wang, S.; Zhu, W.; Aceña, J. L.; Soloshonok, V. A.; Izawa, K.; Liu, $\mathrm{H}$. Next Generation of Fluorine-Containing Pharmaceuticals, Compounds Currently in Phase li-lii Clinical Trials of Major Pharmaceutical Companies: New Structural Trends and Therapeutic Areas. Chem. Rev. 2016, 116 (2), 422-518.

(13) Wang, J.; Sánchez-Roselló, M.; Aceña, J. L.; del Pozo, C.; Sorochinsky, A. E.; Fustero, S.; Soloshonok, V. A.; Liu, H. Fluorine in Pharmaceutical Industry: Fluorine-Containing Drugs Introduced to the Market in the Last Decade (2001-2011). Chem. Rev. 2014, 114 (4), 24322506.

(14) Purser, S.; Moore, P. R.; Swallow, S.; Gouverneur, V. Fluorine in Medicinal Chemistry. Chem. Soc. Rev. 2008, 37 (2), 320-330.

(15) Harris, C. M.; Kannan, R.; Kopecka, H.; Harris, T. M. The Role of the Chlorine Substituents in the Antibiotic Vancomycin: Preparation and Characterization of Mono- and Didechlorovancomycin. J. Am. Chem. Soc. 1985, 107 (23), 6652-6658.

(16) Jeschke, P. The Unique Role of Halogen Substituents in the Design of Modern Agrochemicals. Pest Manag. Sci. 2010, 66 (1), 10-27.

(17) Jeschke, P. The Unique Role of Fluorine in the Design of Active Ingredients for Modern Crop Protection. ChemBioChem 2004, 5 (5), 570-589.

(18) Berger, G.; Soubhye, J.; Meyer, F. Halogen Bonding in Polymer Science: From Crystal Engineering to Functional Supramolecular Polymers and Materials. Polym. Chem. 2015, 6 (19), 3559-3580.

(19) Tang, M. L.; Bao, Z. Halogenated Materials as Organic Semiconductors. Chem. Mater. 2011, 23 (3), 446-455.

(20) Amanchukwu, C. V.; Harding, J. R.; Shao-Horn, Y.; Hammond, P. T. Understanding the Chemical Stability of Polymers for Lithium-Air Batteries. Chem. Mater. 2015, 27 (2), 550-561.

(21) Jiang, S.; Zhang, L.; Cui, D.; Yao, Z.; Gao, B.; Lin, J.; Wei, D. The Important Role of Halogen Bond in Substrate Selectivity of Enzymatic Catalysis. Sci. Rep. 2016, 6, 34750.

(22) Sirimulla, S.; Bailey, J. B.; Vegesna, R.; Narayan, M. Halogen Interactions in Protein-Ligand Complexes: Implications of Halogen Bonding for Rational Drug Design. J. Chem. Inf. Model. 2013, 53 (11), 2781-2791.

(23) Cavallo, G.; Metrangolo, P.; Milani, R.; Pilati, T.; Priimagi, A.; Resnati, G.; Terraneo, G. The Halogen Bond. Chem. Rev. 2016, 116 (4), 2478-2601.

(24) Lu, Y.; Wang, Y.; Zhu, W. Nonbonding Interactions of Organic Halogens in Biological Systems: Implications for Drug Discovery and Biomolecular Design. Phys. Chem. Chem. Phys. 2010, 12 (18), 4543-4551.

(25) Parisini, E.; Metrangolo, P.; Pilati, T.; Resnati, G.; Terraneo, G. Halogen Bonding in Halocarbon-Protein Complexes: A Structural Survey. Chem. Soc. Rev. 2011, 40 (5), $2267-$ 2278.

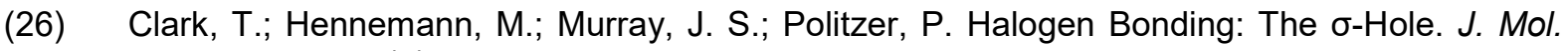
Model. 2007, 13 (2), 291-296.

(27) Wolters, L. P.; Schyman, P.; Pavan, M. J.; Jorgensen, W. L.; Bickelhaupt, F. M.; Kozuch, S. The Many Faces of Halogen Bonding: A Review of Theoretical Models and Methods. Wiley Interdiscip. Rev. Comput. Mol. Sci. 2014, 4 (6), 523-540.

(28) Wilcken, R.; Zimmermann, M. O.; Lange, A.; Joerger, A. C.; Boeckler, F. M. Principles and Applications of Halogen Bonding in Medicinal Chemistry and Chemical Biology. J. Med. Chem. 2013, 56 (4), 1363-1388.

(29) Gribble, G. W. Naturally Occurring Organohalogen Compounds - a Comprehensive Update; Springer Vienna: Vienna, 2010.

(30) Gribble, G. W. Natural Organohalogens: A New Frontier for Medicinal Agents? J. Chem. Educ. 2004, 81 (10), 1441.

(31) Gribble, G. W. Modern Alkaloids; Wiley-VCH: Weinheim, 2008. 
(32) Weichold, V.; Milbredt, D.; van Pée, K.-H. Specific Enzymatic Halogenation-from the Discovery of Halogenated Enzymes to Their Applications in Vitro and in Vivo. Angew. Chem. Int. Ed. 2016, 55 (22), 6374-6389.

(33) Brown, S.; O'Connor, S. E. Halogenase Engineering for the Generation of New Natural Product Analogues. ChemBioChem 2015, 16 (15), 2129-2135.

(34) Smith, D. R. M.; Grüschow, S.; Goss, R. J. M. Scope and Potential of Halogenases in Biosynthetic Applications. Curr. Opin. Chem. Biol. 2013, 17 (2), 276-283.

(35) Prakash, G. K. S.; Mathew, T.; Hoole, D.; Esteves, P. M.; Wang, Q.; Rasul, G.; Olah, G. A. NHalosuccinimide/ $/ \mathrm{BF}_{3}-\mathrm{H}_{2} \mathrm{O}$, Efficient Electrophilic Halogenating Systems for Aromatics. J. Am. Chem. Soc. 2004, 126 (48), 15770-15776.

(36) Alonso, F.; Beletskaya, I. P.; Yus, M. Metal-Mediated Reductive Hydrodehalogenation of Organic Halides. Chem. Rev. 2002, 102 (11), 4009-4092.

(37) Petrone, D. A.; Ye, J.; Lautens, M. Modern Transition-Metal-Catalyzed Carbon-Halogen Bond Formation. Chem. Rev. 2016, 116 (14), 8003-8104.

(38) Muralirajan, K.; Haridharan, R.; Prakash, S.; Cheng, C.-H. Rhodium(III)-Catalyzed in situ Oxidizing Directing Group-Assisted C-H Bond Activation and Olefination: A Route to 2Vinylanilines. Adv. Synth. Catal. 2015, 357 (4), 761-766.

(39) Teskey, C. J.; Lui, A. Y. W.; Greaney, M. F. Ruthenium-Catalyzed Meta-Selective C-H Bromination. Angew. Chem. Int. Ed. 2015, 54 (40), 11677-11680.

(40) Sandtorv, A. H. Transition Metal-Catalyzed C-H Activation of Indoles. Adv. Synth. Catal. 2015, 357 (11), 2403-2435.

(41) Xu, H.; Shang, M.; Dai, H.-X.; Yu, J.-Q. Ligand-Controlled Para-Selective C-H Arylation of Monosubstituted Arenes. Org. Lett. 2015, 17 (15), 3830-3833.

(42) Yu, J.-Q.; Shi, Z. C-H Activation; Springer, Berlin: Heidelberg, 2010.

(43) Leblanc, C.; Vilter, H.; Fournier, J. B.; Delage, L.; Potin, P.; Rebuffet, E.; Michel, G.; Solari, P. L.; Feiters, M. C.; Czjzek, M. Vanadium Haloperoxidases: From the Discovery 30 Years Ago to X-Ray Crystallographic and V K-Edge Absorption Spectroscopic Studies. Coord. Chem. Rev. 2015, 301-302, 134-146.

(44) Deboer, E.; Vankooyk, Y.; Tromp, M. G. M.; Plat, H.; Wever, R. Bromoperoxidase from Ascophyllum-Nodosum - a Novel Class of Enzymes Containing Vanadium as a Prosthetic Group. Biochim. Biophys. Acta 1986, 869 (1), 48-53.

(45) Soedjak, H. S.; Butler, A. Characterization of Vanadium Bromoperoxidase from Macrocystis and Fucus - Reactivity of Vanadium Bromoperoxidase toward Acyl and Alkyl Peroxides and Bromination of Amines. Biochemistry 1990, 29 (34), 7974-7981.

(46) Morris, D. R.; Hager, L. P. Chloroperoxidase I: Isolation and Properties of Crystalline Glycoprotein. J. Biol. Chem. 1966, 241 (8), 1763-1768.

(47) Wagner, C.; Molitor, I. M.; Konig, G. M. Critical View on the Monochlorodimedone Assay Utilized to Detect Haloperoxidase Activity. Phytochemistry 2008, 69 (2), 323-332.

(48) Bernhardt, P.; Okino, T.; Winter, J. M.; Miyanaga, A.; Moore, B. S. A Stereoselective Vanadium-Dependent Chloroperoxidase in Bacterial Antibiotic Biosynthesis. J. Am. Chem. Soc. 2011, 133 (12), 4268-4270.

(49) Diethelm, S.; Teufel, R.; Kaysser, L.; Moore, B. S. A Multitasking Vanadium-Dependent Chloroperoxidase as an Inspiration for the Chemical Synthesis of the Merochlorins. Angew. Chem. Int. Ed. 2014, 53 (41), 11023-11026.

(50) Hasan, Z.; Renirie, R.; Kerkman, R.; Ruijssenaars, H. J.; Hartog, A. F.; Wever, R. LaboratoryEvolved Vanadium Chloroperoxidase Exhibits 100-Fold Higher Halogenating Activity at Alkaline pH: Catalytic Effects from First and Second Coordination Sphere Mutations. J. Biol. Chem. 2006, 281 (14), 9738-9744.

(51) Gwon, H. J.; Teruhiko, I.; Shigeaki, H.; Baik, S. H. Identification of Novel Non-Metal Haloperoxidases from the Marine Metagenome. J. Microbiol. Biotechnol. 2014, 24 (6), 835842.

(52) de Boer, E.; Plat, H.; Tromp, M. G. M.; Wever, R.; Franssen, M. C. R.; van der Plas, H. C.; Meijer, E. M.; Schoemaker, H. E. Vanadium Containing Bromoperoxidase: An Example of an Oxidoreductase with High Operational Stability in Aqueous and Organic Media. Biotechnol. Bioeng. 1987, 30 (5), 607-610.

(53) Hunter-Cevera, J. C.; Sotos, L. Screening for a "New" Enzyme in Nature: Haloperoxidase Production by Death Valley Dematiaceous Hyphomycetes. Adv. Microb. Ecol. 1986, 12 (1), 121-127. 
(54) Hartung, J.; Brücher, O.; Hach, D.; Schulz, H.; Vilter, H.; Ruick, G. Bromoperoxidase Activity and Vanadium Level of the Brown Alga Ascophyllum Nodosum. Phytochemistry 2008, 69 (16), 2826-2830.

(55) Gao, Q.; Jiang, Y.; Gao, X.; Hu, M.; Li, S.; Zhai, Q. Activation Function of Chloroperoxidase in the Presence of Metal lons at Elevated Temperature from 25 to $55^{\circ} \mathrm{C}$. Chin. J. Chem. 2009, 27 (7), 1291-1294.

(56) Hager, L. P.; Morris, D. R.; Brown, F. S.; Eberwein, H. Chloroperoxidase li: Utilisation of Halogen Anions. J. Biol. Chem. 1966, 241 (8), 1769-1777.

(57) Taurog, A.; Howells, E. M. Enzymatic lodination of Tyrosine and Thyroglobulin with Chloroperoxidase. J. Biol. Chem. 1966, 241 (6), 1329-1339.

(58) Fujimori, D. G.; Walsh, C. T. What's New in Enzymatic Halogenations. Curr. Opin. Chem. Biol. 2007, 11 (5), 553-560.

(59) Sundaramoorthy, M.; Terner, J.; Poulos, T. L. The Crystal Structure of Chloroperoxidase: A Heme Peroxidase-Cytochrome P450 Functional Hybrid. Structure 1995, 3 (12), 1367-1378.

(60) Sundaramoorthy, M.; Terner, J.; Poulos, T. L. Stereochemistry of the Chloroperoxidase Active Site: Crystallographic and Molecular-Modeling Studies. Chem. Biol. 1998, 5 (9), 461-473.

(61) Kuhnel, K.; Blankenfeldt, W.; Terner, J.; Schlichting, I. Crystal Structures of Chloroperoxidase with Its Bound Substrates and Complexed with Formate, Acetate, and Nitrate. J. Biol. Chem. 2006, 281 (33), 23990-23998.

(62) Littlechild, J. Haloperoxidases and Their Role in Biotransformation Reactions. Curr. Opin. Chem. Biol. 1999, 3 (1), 28-34.

(63) Yi, X.; Conesa, A.; Punt, P. J.; Hager, L. P. Examining the Role of Glutamic Acid 183 in Chloroperoxidase Catalysis. J. Biol. Chem. 2003, 278 (16), 13855-13859.

(64) Poulos, T. L. Heme Enzyme Structure and Function. Chem. Rev. 2014, 114 (7), 3919-3962.

(65) Neumann, C. S.; Fujimori, D. G.; Walsh, C. T. Halogenation Strategies in Natural Product Biosynthesis. Chem. Biol. 2008, 15 (2), 99-109.

(66) Vazquez-Duhalt, R.; Ayala, M.; Marquez-Rocha, F. J. Biocatalytic Chlorination of Aromatic Hydrocarbons by Chloroperoxidase of Caldariomyces Fumago. Phytochemistry 2001, 58 (6), 929-933.

(67) Franssen, M. C. R.; Vanderplas, H. C. The Chlorination of Barbituric-Acid and Some of Its Derivatives by Chloroperoxidase. Bioorg. Chem. 1987, 15 (1), 59-70.

(68) Geigert, J.; Neidleman, S. L.; Dalietos, D. J. Novel Haloperoxidase Substrates - Alkynes and Cyclopropanes. J. Biol. Chem. 1983, 258 (4), 2273-2277.

(69) Geigert, J.; Neidleman, S. L.; Dalietos, D. J.; Dewitt, S. K. Haloperoxidases - EnzymaticSynthesis of Alpha,Beta-Halohydrins from Gaseous Alkenes. Appl. Environ. Microbiol. 1983, 45 (2), 366-374.

(70) Geigert, J.; Neidleman, S. L.; Dalietos, D. J.; Dewitt, S. K. Novel Haloperoxidase Reaction Synthesis of Dihalogenated Products. Appl. Environ. Microbiol. 1983, 45 (5), 1575-1581.

(71) Wannstedt, C.; Rotella, D.; Siuda, J. F. Chloroperoxidase Mediated Halogenation of Phenols. Bull. Environ. Contam. Toxicol. 1990, 44 (2), 282-287.

(72) Yaipakdee, P.; Robertson, L. W. Enzymatic Halogenation of Flavanones and Flavones. Phytochemistry 2001, 57 (3), 341-347.

(73) Vilter, H. Peroxidases from Phaeophyceae - a Vanadium(V)-Dependent Peroxidase from Ascophyllum-Nodosum .5. Phytochemistry 1984, 23 (7), 1387-1390.

(74) Wever, R.; de Boer, E.; Plat, H.; E. Krenn, B. Vanadium - an Element Involved in the Biosynthesis of Halogenated Compounds and Nitrogen Fixation. FEBS Lett. 1987, 216 (1), 13.

(75) Butler, A.; Walker, J. V. Marine Haloperoxidases. Chem. Rev. 1993, 93 (5), 1937-1944.

(76) Carter-Franklin, J. N.; Butler, A. Vanadium Bromoperoxidase-Catalyzed Biosynthesis of Halogenated Marine Natural Products. J. Am. Chem. Soc. 2004, 126 (46), 15060-15066.

(77) Coupe, E. E.; Smyth, M. G.; Fosberry, A. P.; Hall, R. M.; Littlechild, J. A. The Dodecameric Vanadium-Dependent Haloperoxidase from the Marine Algae Corallina Officinalis: Cloning, Expression, and Refolding of the Recombinant Enzyme. Protein Express. Purif. 2007, 52 (2), 265-272.

(78) Kamenarska, Z.; Taniguchi, T.; Ohsawa, N.; Hiraoka, M.; Itoh, N. A Vanadium-Dependent Bromoperoxidase in the Marine Red Alga Kappaphycus Alvarezii (Doty) Doty Displays Clear Substrate Specificity. Phytochemistry 2007, 68 (10), 1358-1366.

(79) Kaneko, K.; Washio, K.; Umezawa, T.; Matsuda, F.; Morikawa, M.; Okino, T. Cdna Cloning and Characterization of Vanadium-Dependent Bromoperoxidases from the Red Alga Laurencia Nipponica. Biosci. Biotechnol. Biochem. 2014, 78 (8), 1310-1319. 
(80) Itoh, N.; Izumi, Y.; Yamada, H. Characterization of Nonheme Type Bromoperoxidase in Corallina Pilulifera. J. Biol. Chem. 1986, 261 (11), 5194-5200.

(81) Plat, H.; Krenn, B. E.; Wever, R. The Bromoperoxidase from the Lichen Xanthoria Parietina Is a Novel Vanadium Enzyme. Biochem. J. 1987, 248 (1), 277-279.

(82) van Schijndel, J. W. P. M.; Simons, L. H.; Vollenbroek, E. G. M.; Wever, R. The Vanadium Chloroperoxidase from the Fungus, Curvularia Inaequalis. FEBS Lett. 1993, 336 (2), 239-242.

(83) Kaysser, L.; Bernhardt, P.; Nam, S. J.; Loesgen, S.; Ruby, J. G.; Skewes-Cox, P.; Jensen, P. R.; Fenical, W.; Moore, B. S. Merochlorins a-D, Cyclic Meroterpenoid Antibiotics Biosynthesized in Divergent Pathways with Vanadium-Dependent Chloroperoxidases. J. Am. Chem. Soc. 2012, 134 (29), 11988-11991.

(84) Carter, J. N.; Beatty, K. E.; Simpson, M. T.; Butler, A. Reactivity of Recombinant and Mutant Vanadium Bromoperoxidase from the Red Alga Corallina Officinalis. J. Inorg. Biochem. 2002, 91 (1), 59-69.

(85) Hemrika, W.; Renirie, R.; Macedo-Ribeiro, S.; Messerschmidt, A.; Wever, R. Heterologous Expression of the Vanadium-Containing Chloroperoxidase from Curvularia Inaequalis Insaccharomyces Cerevisiae and Site-Directed Mutagenesis of the Active Site Residues His496, Lys353, Arg360, and Arg490. J. Biol. Chem. 1999, 274 (34), 23820-23827.

(86) Ohshiro, T.; Hemrika, W.; Aibara, T.; Wever, R.; Izumi, Y. Expression of the VanadiumDependent Bromoperoxidase Gene from a Marine Macro-Alga Corallina Pilulifera in Saccharomyces Cerevisiae and Characterization of the Recombinant Enzyme. Phytochemistry 2002, 60 (6), 595-601.

(87) Yamada, R.; Higo, T.; Yoshikawa, C.; China, H.; Ogino, H. Improvement of the Stability and Activity of the Bpo-A1 Haloperoxidase from Streptomyces Aureofaciens by Directed Evolution. J. Biotechnol. 2014, 192 Pt A, 248-254.

(88) Yamada, R.; Higo, T.; Yoshikawa, C.; China, H.; Yasuda, M.; Ogino, H. Random Mutagenesis and Selection of Organic Solvent-Stable Haloperoxidase from Streptomyces Aureofaciens. Biotechnol. Prog. 2015, 31 (4), 917-924.

(89) Littlechild, J.; Garcia-Rodriguez, E.; Dalby, A.; Isupov, M. Structural and Functional Comparisons between Vanadium Haloperoxidase and Acid Phosphatase Enzymes. J. Mol. Recognit. 2002, 15 (5), 291-296.

(90) Soedjak, H. S.; Everett, R. R.; Butler, A. The Novel Nonheme Vanadium Bromoperoxidase from Marine-Algae - Phosphate Inactivation. J. Ind. Microbiol. 1991, 8 (1), 37-44.

(91) Tanaka, N.; Wever, R. Inhibition of Vanadium Chloroperoxidase from the Fungus Curvularia Inaequalis by Hydroxylamine, Hydrazine and Azide and Inactivation by Phosphate. J. Inorg. Biochem. 2004, 98 (4), 625-631.

(92) Messerschmidt, A.; Prade, L.; Wever, R. Implications for the Catalytic Mechanism of the Vanadium-Containing Enzyme Chloroperoxidase from the Fungus Curvularia Inaequalis by $\mathrm{X}$ Ray Structures of the Native and Peroxide Form. Biol. Chem. 1997, 378 (3-4), 309-315.

(93) Messerschmidt, A.; Wever, R. X-Ray Structure of a Vanadium-Containing Enzyme: Chloroperoxidase from the Fungus Curvularia Inaequalis. Proc. Natl. Acad. Sci. U.S.A 1996, 93 (1), 392-396.

(94) Weyand, M.; Hecht, H. J.; Kiess, M.; Liaud, M. F.; Vilter, H.; Schomburg, D. X-Ray Structure Determination of a Vanadium-Dependent Haloperoxidase from Ascophyllum Nodosum at 2.0 Angstrom Resolution. J. Mol. Biol. 1999, 293 (3), 595-611.

(95) Littlechild, J. Structural Studies on the Dodecameric Vanadium Bromoperoxidase from Corallina Species. Coord. Chem. Rev. 2003, 237 (1-2), 65-76.

(96) Itoh, N.; Hasan, A. K. M. Q.; Izumi, Y.; Yamada, H. Substrate Specificity, Regiospecificity and Stereospecificity of Halogenation Reactions Catalyzed by Non-Heme-Type Bromoperoxidase of Corallina Pilulifera. Eur. J. Biochem. 1988, 172 (2), 477-484.

(97) Wischang, D.; Brücher, O.; Hartung, J. Bromoperoxidases and Functional Enzyme Mimics as Catalysts for Oxidative Bromination-a Sustainable Synthetic Approach. Coord. Chem. Rev. 2011, 255 (19-20), 2204-2217.

(98) Wischang, D.; Hartung, J.; Hahn, T.; Ulber, R.; Stumpf, T.; Fecher-Trost, C. Vanadate(V)Dependent Bromoperoxidase Immobilized on Magnetic Beads as Reusable Catalyst for Oxidative Bromination. Green Chem. 2011, 13 (1), 102-108.

(99) Macedo-Ribeiro, S.; Hemrika, W.; Renirie, R.; Wever, R.; Messerschmidt, A. X-Ray Crystal Structures of Active Site Mutants of the Vanadium-Containing Chloroperoxidase from the Fungus Curvularia Inaequalis. J. Biol. Inorg. Chem. 1999, 4 (2), 209-219.

(100) Winter, J. M.; Moore, B. S. Exploring the Chemistry and Biology of Vanadium-Dependent Haloperoxidases. J. Biol. Chem. 2009, 284 (28), 18577-18581. 
(101) Teufel, R.; Kaysser, L.; Villaume, M. T.; Diethelm, S.; Carbullido, M. K.; Baran, P. S.; Moore, B. S. One-Pot Enzymatic Synthesis of Merochlorin a and B. Angew. Chem. Int. Ed. 2014, 53 (41), 11019-11022.

(102) Vaillancourt, F. H.; Yin, J.; Walsh, C. T. Syrb2 in Syringomycin E Biosynthesis Is a Nonheme Feii A-Ketoglutarate- and O2-Dependent Halogenase. Proc. Natl. Acad. Sci. U.S.A 2005, 102 (29), 10111-10116.

(103) Vaillancourt, F. H.; Yeh, E.; Vosburg, D. A.; O'Connor, S. E.; Walsh, C. T. Cryptic Chlorination by a Non-Haem Iron Enzyme During Cyclopropyl Amino Acid Biosynthesis. Nature 2005, 436 (7054), 1191-1194.

(104) Sitachitta, N.; Márquez, B. L.; Thomas Williamson, R.; Rossi, J.; Ann Roberts, M.; Gerwick, W. H.; Nguyen, V.-A.; Willis, C. L. Biosynthetic Pathway and Origin of the Chlorinated Methyl Group in Barbamide and Dechlorobarbamide, Metabolites from the Marine Cyanobacterium Lyngbya Majuscula. Tetrahedron 2000, 56 (46), 9103-9113.

(105) Sitachitta, N.; Rossi, J.; Roberts, M. A.; Gerwick, W. H.; Fletcher, M. D.; Willis, C. L. Biosynthesis of the Marine Cyanobacterial Metabolite Barbamide. 1. Origin of the Trichloromethyl Group. J. Am. Chem. Soc. 1998, 120 (28), 7131-7132.

(106) Galonić, D. P.; Vaillancourt, F. H.; Walsh, C. T. Halogenation of Unactivated Carbon Centers in Natural Product Biosynthesis: Trichlorination of Leucine During Barbamide Biosynthesis. J. Am. Chem. Soc. 2006, 128 (12), 3900-3901.

(107) Blasiak, L. C.; Vaillancourt, F. H.; Walsh, C. T.; Drennan, C. L. Crystal Structure of the NonHaem Iron Halogenase SyrB2 in Syringomycin Biosynthesis. Nature 2006, 440 (7082), 368371.

(108) Hillwig, M. L.; Liu, X. A New Family of Iron-Dependent Halogenases Acts on Freestanding Substrates. Nat. Chem. Biol. 2014, 10 (11), 921-923.

(109) Hillwig, M. L.; Zhu, Q.; Liu, X. Biosynthesis of Ambiguine Indole Alkaloids in Cyanobacterium Fischerella Ambigua. ACS Chem. Biol. 2014, 9 (2), 372-377.

(110) Hillwig, M. L.; Fuhrman, H. A.; Ittiamornkul, K.; Sevco, T. J.; Kwak, D. H.; Liu, X. Identification and Characterization of a Welwitindolinone Alkaloid Biosynthetic Gene Cluster in the Stigonematalean Cyanobacterium Hapalosiphon Welwitschii. ChemBioChem 2014, 15 (5), 665-669.

(111) Mitchell, A. J.; Zhu, Q.; Maggiolo, A. O.; Ananth, N. R.; Hillwig, M. L.; Liu, X.; Boal, A. K. Structural Basis for Halogenation by Iron- and 2-Oxo-Glutarate-Dependent Enzyme Welo5. Nat. Chem. Biol. 2016, 12 (8), 636-640.

(112) Matthews, M. L.; Neumann, C. S.; Miles, L. A.; Grove, T. L.; Booker, S. J.; Krebs, C.; Walsh, C. T.; Bollinger, J. M. Substrate Positioning Controls the Partition between Halogenation and Hydroxylation in the Aliphatic Halogenase, SyrB2. Proc. Natl. Acad. Sci. U.S.A 2009, 106 (42), 17723-17728.

(113) Mitchell, A. J.; Dunham, N. P.; Bergman, J. A.; Wang, B.; Zhu, Q.; Chang, W.-C.; Liu, X.; Boal, A. K. Structure-Guided Reprogramming of a Hydroxylase to Halogenate Its Small Molecule Substrate. Biochemistry 2017, 56, (3), 441-444.

(114) Dong, C.; Flecks, S.; Unversucht, S.; Haupt, C.; van Pée, K.-H.; Naismith, J. H. Tryptophan 7Halogenase (PrnA) Structure Suggests a Mechanism for Regioselective Chlorination. Science 2005, 309 (5744), 2216-2219.

(115) Mascotti, M. L.; Juri Ayub, M.; Furnham, N.; Thornton, J. M.; Laskowski, R. A. Chopping and Changing: The Evolution of the Flavin-Dependent Monooxygenases. J. Mol. Biol. 2016, 428 (15), 3131-3146.

(116) Huijbers, M. M.; Montersino, S.; Westphal, A. H.; Tischler, D.; van Berkel, W. J. Flavin Dependent Monooxygenases. Arch. Biochem. Biophys. 2014, 544, 2-17.

(117) van Berkel, W. J. H.; Kamerbeek, N. M.; Fraaije, M. W. Flavoprotein Monooxygenases, a Diverse Class of Oxidative Biocatalysts. J. Biotech. 2006, 124 (4), 670-689.

(118) Visitsatthawong, S.; Chenprakhon, P.; Chaiyen, P.; Surawatanawong, P. Mechanism of Oxygen Activation in a Flavin-Dependent Monooxygenase: A Nearly Barrierless Formation of C4a-Hydroperoxyflavin Via Proton-Coupled Electron Transfer. J. Am. Chem. Soc. 2015, 137 (29), 9363-9374.

(119) Badieyan, S.; Bach, R. D.; Sobrado, P. Mechanism of N-Hydroxylation Catalyzed by FlavinDependent Monooxygenases. J. Org. Chem. 2015, 80 (4), 2139-2147.

(120) Morrison, E.; Kantz, A.; Gassner, G. T.; Sazinsky, M. H. Structure and Mechanism of Styrene Monooxygenase Reductase: New Insight into the Fad-Transfer Reaction. Biochemistry 2013, 52 (35), 6063-6075. 
(121) Kamerbeek, N. M.; Janssen, D. B.; van Berkel, W. J. H.; Fraaije, M. W. Baeyer-Villiger Monooxygenases, an Emerging Family of Flavin-Dependent Biocatalysts. Adv. Synth. Catal. 2003, 345 (6-7), 667-678.

(122) Pang, A. H.; Garneau-Tsodikova, S.; Tsodikov, O. V. Crystal Structure of Halogenase Plta from the Pyoluteorin Biosynthetic Pathway. J. Struct. Biol. 2015, 192 (3), 349-357.

(123) Yeh, E.; Garneau, S.; Walsh, C. T. Robust in Vitro Activity of Rebf and Rebh, a TwoComponent Reductase/Halogenase, Generating 7-Chlorotryptophan During Rebeccamycin Biosynthesis. Proc. Natl. Acad. Sci. U.S.A 2005, 102 (11), 3960-3965.

(124) Onaka, H.; Taniguchi, S.; Igarashi, Y.; Furumai, T. Characterization of the Biosynthetic Gene Cluster of Rebeccamycin from Lechevalieria Aerocolonigenes ATCC 39243. Biosci. Biotechnol. Biochem. 2003, 67 (1), 127-138.

(125) Zeng, J.; Zhan, J. A Novel Fungal Flavin-Dependent Halogenase for Natural Product Biosynthesis. ChemBioChem 2010, 11 (15), 2119-2123.

(126) Ferrara, M.; Perrone, G.; Gambacorta, L.; Epifani, F.; Solfrizzo, M.; Gallo, A. Identification of a Halogenase Involved in the Biosynthesis of Ochratoxin a in Aspergillus Carbonarius. Appl. Environ. Microbiol. 2016, 82 (18), 5631-5641.

(127) Keller, S.; Wage, T.; Hohaus, K.; Hölzer, M.; Eichhorn, E.; van Pée, K.-H. Purification and Partial Characterization of Tryptophan 7-Halogenase (PrnA) from Pseudomonas Fluorescens. Angew. Chem. Int. Ed. 2000, 39 (13), 2300-2302.

(128) Unversucht, S.; Hollmann, F.; Schmid, A.; van Pée, K.-H. FADH ${ }_{2}$-Dependence of Tryptophan 7-Halogenase. Adv. Synth. Catal. 2005, 347 (7-8), 1163-1167.

(129) van Pee, K. H.; Patallo, E. P. Flavin-Dependent Halogenases Involved in Secondary Metabolism in Bacteria. Appl. Microbiol. Biotechnol. 2006, 70 (6), 631-641.

(130) Zhu, X.; De Laurentis, W.; Leang, K.; Herrmann, J.; Ihlefeld, K.; van Pée, K.-H.; Naismith, J. $\mathrm{H}$. Structural Insights into Regioselectivity in the Enzymatic Chlorination of Tryptophan. J. Mol. Biol. 2009, 391 (1), 74-85.

(131) Dong, C.; Kotzsch, A.; Dorward, M.; van Pee, K.-H.; Naismith, J. H. Crystallization and X-Ray Diffraction of a Halogenating Enzyme, Tryptophan 7-Halogenase, from Pseudomonas Fluorescens. Acta Crystallogr D 2004, 60 (8), 1438-1440.

(132) Yeh, E.; Cole, L. J.; Barr, E. W.; Bollinger, J. M.; Ballou, D. P.; Walsh, C. T. Flavin Redox Chemistry Precedes Substrate Chlorination During the Reaction of the Flavin-Dependent Halogenase Rebh. Biochemistry 2006, 45 (25), 7904-7912.

(133) Yeh, E.; Blasiak, L. C.; Koglin, A.; Drennan, C. L.; Walsh, C. T. Chlorination by a Long-Lived Intermediate in the Mechanism of Flavin-Dependent Halogenases. Biochemistry 2007, 46 (5), 1284-1292.

(134) Bitto, E.; Huang, Y.; Bingman, C. A.; Singh, S.; Thorson, J. S.; Phillips, G. N. The Structure of Flavin-Dependent Tryptophan 7-Halogenase Rebh. Proteins: Struct. Funct. Bioinf. 2008, 70 (1), 289-293.

(135) Flecks, S.; Patallo, E. P.; Zhu, X.; Ernyei, A. J.; Seifert, G.; Schneider, A.; Dong, C.; Naismith, J. H.; van Pée, K.-H. New Insights into the Mechanism of Enzymatic Chlorination of Tryptophan. Angew. Chem. Int. Ed. 2008, 47 (49), 9533-9536.

(136) Podzelinska, K.; Latimer, R.; Bhattacharya, A.; Vining, L. C.; Zechel, D. L.; Jia, Z. Chloramphenicol Biosynthesis: The Structure of CmIS, a Flavin-Dependent Halogenase Showing a Covalent Flavin-Aspartate Bond. J. Mol. Biol. 2010, 397 (1), 316-331.

(137) Kirner, S.; Hammer, P. E.; Hill, D. S.; Altmann, A.; Fischer, I.; Weislo, L. J.; Lanahan, M.; van Pee, K. H.; Ligon, J. M. Functions Encoded by Pyrrolnitrin Biosynthetic Genes from Pseudomonas Fluorescens. J. Bacteriol. 1998, 180 (7), 1939-1943.

(138) Kirner, S.; Krauss, S.; Sury, G.; Lam, S. T.; Ligon, J. M.; vanPee, K. H. The Non-Haem Chloroperoxidase from Pseudomonas Fluorescens and Its Relationship to Pyrrolnitrin Biosynthesis. Microbiol. UK 1996, 142, 2129-2135.

(139) Sanchez, C.; Butovich, I. A.; Brana, A. F.; Rohr, J.; Mendez, C.; Salas, J. A. The Biosynthetic Gene Cluster for the Antitumor Rebeccamycin: Characterization and Generation of Indolocarbazole Derivatives. Chem. Biol. 2002, 9 (4), 519-531.

(140) Jiang, W.; Heemstra, J. R., Jr.; Forseth, R. R.; Neumann, C. S.; Manaviazar, S.; Schroeder, F. C.; Hale, K. J.; Walsh, C. T. Biosynthetic Chlorination of the Piperazate Residue in Kutzneride Biosynthesis by Kthp. Biochemistry 2011, 50 (27), 6063-6072.

(141) Heemstra, J. R.; Walsh, C. T. Tandem Action of the O2- and Fadh2-Dependent Halogenases KtzQ and KtzR Produce 6,7-Dichlorotryptophan for Kutzneride Assembly. J. Am. Chem. Soc. 2008, 130 (43), 14024-14025. 
(142) Fujimori, D. G.; Hrvatin, S.; Neumann, C. S.; Strieker, M.; Marahiel, M. A.; Walsh, C. T. Cloning and Characterization of the Biosynthetic Gene Cluster for Kutznerides. Proc. Natl. Acad. Sci. U.S.A 2007, 104 (42), 16498-16503.

(143) Zeng, J.; Zhan, J. Characterization of a Tryptophan 6-Halogenase from Streptomyces Toxytricini. Biotechnol. Lett. 2011, 33 (8), 1607-1613.

(144) Milbredt, D.; Patallo, E. P.; van Pée, K.-H. A Tryptophan 6-Halogenase and an Amidotransferase Are Involved in Thienodolin Biosynthesis. ChemBioChem 2014, 15 (7), 1011-1020.

(145) Menon, B. R. K.; Latham, J.; Dunstan, M. S.; Brandenburger, E.; Klemstein, U.; Leys, D.; Karthikeyan, C.; Greaney, M. F.; Shepherd, S. A.; Micklefield, J. Structure and Biocatalytic Scope of Thermophilic Flavin-Dependent Halogenase and Flavin Reductase Enzymes. Org. Biomol. Chem. 2016, 14 (39), 9354-9361.

(146) Wang, Y.; Wang, J.; Yu, S.; Wang, F.; Ma, H.; Yue, C.; Liu, M.; Deng, Z.; Huang, Y.; Qu, X. Identifying the Minimal Enzymes for Unusual Carbon-Sulfur Bond Formation in Thienodolin Biosynthesis. ChemBioChem 2016, 17 (9), 799-803.

(147) Xu, L.; Han, T.; Ge, M.; Zhu, L.; Qian, X. Discovery of the New Plant Growth-Regulating Compound LyxIF2 Based on Manipulating the Halogenase in Amycolatopsis Orientalis. Curr. Microbiol. 2016, 73 (3), 335-340.

(148) Wang, Y.; Wang, J.; Yu, S.; Wang, F.; Ma, H.; Yue, C.; Liu, M.; Deng, Z.; Huang, Y.; Qu, X. Corrigendum: Identifying the Minimal Enzymes for Unusual Carbon-Sulfur Bond Formation in Thienodolin Biosynthesis. ChemBioChem 2016, 17 (9), 876.

(149) Milbredt, D.; Patallo, E. P.; van Pee, K. H. Characterization of the Aminotransferase Thdn from Thienodolin Biosynthesis in Streptomyces Albogriseolus. ChemBioChem 2016, 17 (19), 1859-1864.

(150) Shepherd, S. A.; Menon, B. R. K.; Fisk, H.; Struck, A.-W.; Levy, C.; Leys, D.; Micklefield, J. A Structure-Guided Switch in the Regioselectivity of a Tryptophan Halogenase. ChemBioChem 2016, 17 (9), 821-824.

(151) Zehner, S.; Kotzsch, A.; Bister, B.; Süssmuth, R. D.; Méndez, C.; Salas, J. A.; van Pée, K.-H. A Regioselective Tryptophan 5-Halogenase Is Involved in Pyrroindomycin Biosynthesis in Streptomyces Rugosporus LI-42D005. Chem. Biol. 2005, 12 (4), 445-452.

(152) Du, Y. L.; Ryan, K. S. Expansion of Bisindole Biosynthetic Pathways by Combinatorial Construction. ACS. Synth. Biol. 2015, 4 (6), 682-688.

(153) Ryan, K. S. Biosynthetic Gene Cluster for the Cladoniamides, Bis-Indoles with a Rearranged Scaffold. PloS One 2011, 6 (8).

(154) Ortega, M. A.; Cogan, D. P.; Mukherjee, S.; Garg, N.; Li, B.; Thibodeaux, G. N.; Maffioli, S.; Donadio, S.; Sosio, M.; Escano, J.et al. Two Flavoenzymes Catalyze the Post-Translational Generation of 5-Chlorotryptophan and 2-Aminovinyl-Cysteine During NAl-107 Biosynthesis. ACS. Chem. Biol., 2017, 12 (2), 548-557.

(155) Shepherd, S. A.; Karthikeyan, C.; Latham, J.; Struck, A.-W.; Thompson, M. L.; Menon, B. R. K.; Styles, M. Q.; Levy, C.; Leys, D.; Micklefield, J. Extending the Biocatalytic Scope of Regiocomplementary Flavin-Dependent Halogenase Enzymes. Chem. Sci. 2015, 6 (6), 34543460.

(156) El Gamal, A.; Agarwal, V.; Diethelm, S.; Rahman, I.; Schorn, M. A.; Sneed, J. M.; Louie, G. V.; Whalen, K. E.; Mincer, T. J.; Noel, J. P.et al. Biosynthesis of Coral Settlement Cue Tetrabromopyrrole in Marine Bacteria by a Uniquely Adapted Brominase-Thioesterase Enzyme Pair. Proc. Natl. Acad. Sci. U.S.A 2016, 113 (14), 3797-3802.

(157) Hammer, P. E.; Hill, D. S.; Lam, S. T.; VanPee, K. H.; Ligon, J. M. Four Genes from Pseudomonas Fluorescens That Encode the Biosynthesis of Pyrrolnitrin. Appl. Environ. Microb. 1997, 63 (6), 2147-2154.

(158) Dorrestein, P. C.; Yeh, E.; Garneau-Tsodikova, S.; Kelleher, N. L.; Walsh, C. T. Dichlorination of a Pyrrolyl-S-Carrier Protein by $\mathrm{FADH}_{2}$-Dependent Halogenase Plta During Pyoluteorin Biosynthesis. Proc. Natl. Acad. Sci. U.S.A 2005, 102 (39), 13843-13848.

(159) Wynands, I.; van Pee, K. H. A Novel Halogenase Gene from the Pentachloropseudilin Producer Actinoplanes Sp ATCC 33002 and Detection of in Vitro Halogenase Activity. Fems. Microbiol. Lett. 2004, 237 (2), 363-367.

(160) Zhao, Y.; Yan, B.; Yang, T.; Jiang, J.; Wei, H.; Zhu, X. Purification and Crystallographic Analysis of a Fad-Dependent Halogenase from Streptomyces Sp. JCM9888. Acta Crystallogr. F. 2015, 71 (8), 972-976. 
(161) Mantovani, S. M.; Moore, B. S. Flavin-Linked Oxidase Catalyzes Pyrrolizine Formation of Dichloropyrrole-Containing Polyketide Extender Unit in Chlorizidine A. J. Am. Chem. Soc. 2013, 135 (48), 18032-18035.

(162) Alvarez-Mico, X.; Jensen, P. R.; Fenical, W.; Hughes, C. C. Chlorizidine, a Cytotoxic 5Hpyrrolo[2,1-a]isoindol-5-one-Containing Alkaloid from a Marine Streptomyces Sp. Org. Lett. 2013, 15 (5), 988-991.

(163) Speck, K.; Magauer, T. The Chemistry of Isoindole Natural Products. Beilstein J. Org. Chem. 2013, 9, 2048-2078.

(164) Agarwal, V.; El Gamal, A. A.; Yamanaka, K.; Poth, D.; Kersten, R. D.; Schorn, M.; Allen, E. E.; Moore, B. S. Biosynthesis of Polybrominated Aromatic Organic Compounds by Marine Bacteria. Nat. Chem. BIOL. 2014, 10 (8), 640-647.

(165) Maansson, M.; Vynne, N. G.; Klitgaard, A.; Nybo, J. L.; Melchiorsen, J.; Nguyen, D. D.; Sanchez, L. M.; Ziemert, N.; Dorrestein, P. C.; Andersen, M. R.et al. An Integrated Metabolomic and Genomic Mining Workflow to Uncover the Biosynthetic Potential of Bacteria. mSystems 2016, 1 (3).

(166) Flecks, S.; Patallo, E. R.; Zhu, X. F.; Ernyei, A. J.; Seifert, G.; Schneider, A.; Dong, C. J.; Naismith, J. H.; van Pee, K. H. New Insights into the Mechanism of Enzymatic Chlorination of Tryptophan. Angew. Chem. Int. Ed. 2008, 47 (49), 9533-9536.

(167) Zhou, H.; Qiao, K.; Gao, Z.; Vederas, J. C.; Tang, Y. Insights into Radicicol Biosynthesis Via Heterologous Synthesis of Intermediates and Analogs. J. Biol. Chem. 2010, 285 (53), 4141241421.

(168) Zeng, J.; Lytle, A. K.; Gage, D.; Johnson, S. J.; Zhan, J. Specific Chlorination of Isoquinolines by a Fungal Flavin-Dependent Halogenase. Bioorg. Med. Chem. Lett. 2013, 23 (4), 10011003.

(169) Zeng, J.; Valiente, J.; Zhan, J. X. Specific Inhibition of the Halogenase for Radicicol Biosynthesis by Bromide at the Transcriptional Level in Pochonia Chlamydosporia. Biotechnol. Lett. 2011, 33 (2), 333-338.

(170) Wang, S.; Xu, Y.; Maine, E. A.; Wijeratne, E. M.; Espinosa-Artiles, P.; Gunatilaka, A. A.; Molnar, I. Functional Characterization of the Biosynthesis of Radicicol, an Hsp90 Inhibitor Resorcylic Acid Lactone from Chaetomium Chiversii. Chem. Biol. 2008, 15 (12), 1328-1338.

(171) Zhou, H.; Vederas, J. C.; Tang, Y. Insights into Radicicol Biosynthesis Via Heterologous Synthesis of Intermediates and Analogs. Abstr. Pap. Am. Chem. Soc. 2011, 241.

(172) Xu, F.; Merkley, A.; Yu, D.; Zhan, J. Selective Biochlorination of Hydroxyquinolines by a Flavin-Dependent Halogenase. Tetrahedron. Lett. 2016, 57 (47), 5262-5265.

(173) Banani, H.; Marcet-Houben, M.; Ballester, A. R.; Abbruscato, P.; Gonzalez-Candelas, L.; Gabaldon, T.; Spadaro, D. Genome Sequencing and Secondary Metabolism of the Postharvest Pathogen Penicillium Griseofulvum. BMC Genomics 2016, 17 (19), 1-14.

(174) Cacho, R. A.; Chooi, Y. H.; Zhou, H.; Tang, Y. Complexity Generation in Fungal Polyketide Biosynthesis: A Spirocycle-Forming P450 in the Concise Pathway to the Antifungal Drug Griseofulvin. ACS Chem. Biol. 2013, 8 (10), 2322-2330.

(175) Chooi, Y.-H.; Cacho, R.; Tang, Y. Identification of the Viridicatumtoxin and Griseofulvin Gene Clusters from Penicillium Aethiopicum. Chem. Biol. 2010, 17 (5), 483-494.

(176) Chankhamjon, P.; Boettger-Schmidt, D.; Scherlach, K.; Urbansky, B.; Lackner, G.; Kalb, D.; Dahse, H. M.; Hoffmeister, D.; Hertweck, C. Biosynthesis of the Halogenated Mycotoxin Aspirochlorine in Koji Mold Involves a Cryptic Amino Acid Conversion. Angew. Chem. Int. Ed. 2014, 53 (49), 13409-13413.

(177) Klausmeyer, P.; McCloud, T. G.; Tucker, K. D.; Cardellina, J. H., 2nd; Shoemaker, R. H. Aspirochlorine Class Compounds from Aspergillus Flavus Inhibit Azole-Resistant Candida Albicans. J. Nat. Prod. 2005, 68 (8), 1300-1302.

(178) Monti, F.; Ripamonti, F.; Hawser, S. P.; Islam, K. Aspirochlorine: A Highly Selective and Potent Inhibitor of Fungal Protein Synthesis. J. Antibiot. (Tokyo) 1999, 52 (3), 311-318.

(179) Sato, M.; Winter, J. M.; Kishimoto, S.; Noguchi, H.; Tang, Y.; Watanabe, K. Combinatorial Generation of Chemical Diversity by Redox Enzymes in Chaetoviridin Biosynthesis. Org. Lett. 2016, 18 (6), 1446-1449.

(180) Winter, J. M.; Sato, M.; Sugimoto, S.; Chiou, G.; Garg, N. K.; Tang, Y.; Watanabe, K. Identification and Characterization of the Chaetoviridin and Chaetomugilin Gene Cluster in Chaetomium Globosum Reveal Dual Functions of an Iterative Highly-Reducing Polyketide Synthase. J. Am. Chem. Soc. 2012, 134 (43), 17900-17903. 
(181) Kingsland, S. R.; Barrow, R. A. Identification of Chaetoviridin E from a Cultured Microfungus, Chaetomium Sp and Structural Reassignment of Chaetoviridins B and D. Aust. J. Chem. 2009, 62 (3), 269-274.

(182) Massi, F. P.; Sartori, D.; Ferranti Lde, S.; lamanaka, B. T.; Taniwaki, M. H.; Vieira, M. L.; Fungaro, M. H. Data on the Presence or Absence of Genes Encoding Essential Proteins for Ochratoxin and Fumonisin Biosynthesis in Aspergillus Niger and Aspergillus Welwitschiae. Data Brief 2016, 7, 704-708.

(183) Susca, A.; Proctor, R. H.; Morelli, M.; Haidukowski, M.; Gallo, A.; Logrieco, A. F.; Moretti, A. Variation in Fumonisin and Ochratoxin Production Associated with Differences in Biosynthetic Gene Content in Aspergillus Niger and A. Welwitschiae Isolates from Multiple Crop and Geographic Origins. Front. Microbiol. 2016, 7.

(184) Farber, P.; Geisen, R. Analysis of Differentially-Expressed Ochratoxin a Biosynthesis Genes of Penicillium Nordicum. Eur. J. Plant. Pathol. 2004, 110 (5-6), 661-669.

(185) Nielsen, M. T.; Nielsen, J. B.; Anyaogu, D. C.; Holm, D. K.; Nielsen, K. F.; Larsen, T. O.; Mortensen, U. H. Heterologous Reconstitution of the Intact Geodin Gene Cluster in Aspergillus Nidulans through a Simple and Versatile PCR Based Approach. PLoS One 2013, $8(8)$.

(186) Yin, Y.; Cai, M. H.; Zhou, X. S.; Li, Z. Y.; Zhang, Y. X. Polyketides in Aspergillus Terreus: Biosynthesis Pathway Discovery and Application. Appl. Microbiol. Biotechnol. 2016, 100 (18), 7787-7798.

(187) Neumann, C. S.; Walsh, C. T.; Kay, R. R. A Flavin-Dependent Halogenase Catalyzes the Chlorination Step in the Biosynthesis of Dictyostelium Differentiation-Inducing Factor 1. Proc. Natl. Acad. Sci. U.S.A 2010, 107 (13), 5798-5803.

(188) Thompson, C. R.; Kay, R. R. The Role of Dif-1 Signaling in Dictyostelium Development. Mol. Cell. 2000, 6 (6), 1509-1514.

(189) Mohri, K.; Hata, T.; Kikuchi, H.; Oshima, Y.; Urushihara, H. Defects in the Synthetic Pathway Prevent Dif-1 Mediated Stalk Lineage Specification Cascade in the Non-Differentiating Social Amoeba, Acytostelium Subglobosum. Biol. Open. 2014, 3 (6), 553-560.

(190) Motohashi, K. A.; Morita, N.; Kato, A.; Saito, T. Identification of Des-Methyl-Dif-1 Methyltransferase in Dictyostelium Purpureum. Biosci Biotech Bioch 2012, 76 (9), 1672-1676.

(191) Knobloch, T.; Harmrolfs, K.; Taft, F.; Thomaszewski, B.; Sasse, F.; Kirschning, A. Mutational Biosynthesis of Ansamitocin Antibiotics: A Diversity-Oriented Approach to Exploit Biosynthetic Flexibility. ChemBioChem 2011, 12 (4), 540-547.

(192) Yu, T. W.; Bai, L.; Clade, D.; Hoffmann, D.; Toelzer, S.; Trinh, K. Q.; Xu, J.; Moss, S. J.; Leistner, E.; Floss, H. G. The Biosynthetic Gene Cluster of the Maytansinoid Antitumor Agent Ansamitocin from Actinosynnema Pretiosum. Proc. Natl. Acad. Sci. U.S.A 2002, 99 (12), 7968-7973.

(193) Spiteller, P.; Bai, L.; Shang, G.; Carroll, B. J.; Yu, T. W.; Floss, H. G. The Post-Polyketide Synthase Modification Steps in the Biosynthesis of the Antitumor Agent Ansamitocin by Actinosynnema Pretiosum. J. Am. Chem. Soc. 2003, 125 (47), 14236-14237.

(194) Wu, Y. Y.; Kang, Q. J.; Shen, Y. M.; Su, W. J.; Bai, L. Q. Cloning and Functional Analysis of the Naphthomycin Biosynthetic Gene Cluster in Streptomyces Sp Cs. Mol. Biosyst. 2011, 7 (8), 2459-2469.

(195) Winter, J. M.; Moffitt, M. C.; Zazopoulos, E.; McAlpine, J. B.; Dorrestein, P. C.; Moore, B. S. Molecular Basis for Chloronium-Mediated Meroterpene Cyclization: Cloning, Sequencing, and Heterologous Expression of the Napyradiomycin Biosynthetic Gene Cluster. J. Biol. Chem. 2007, 282 (22), 16362-16368.

(196) Lu, Y. H.; Yue, C. W.; Shao, M. Y.; Qian, S. Y.; Liu, N.; Bao, Y. X.; Wang, M.; Liu, M. H.; Li, X. Q.; Wang, Y. Y.et al. Molecular Genetic Characterization of an Anthrabenzoxocinones Gene Cluster in Streptomyces Sp FJS31-2 for the Biosynthesis of BE-24566B and Zunyimycin Ale. Molecules 2016, 21 (6).

(197) Eustaquio, A. S.; Gust, B.; Luft, T.; Li, S. M.; Chater, K. F.; Heide, L. Clorobiocin Biosynthesis in Streptomyces: Identification of the Halogenase and Generation of Structural Analogs. Chem. Biol. 2003, 10 (3), 279-288.

(198) Pojer, F.; Li, S. M.; Heide, L. Molecular Cloning and Sequence Analysis of the Clorobiocin Biosynthetic Gene Cluster: New Insights into the Biosynthesis of Aminocoumarin Antibiotics. Microbiol. SGM. 2002, 148, 3901-3911.

(199) Puk, O.; Huber, P.; Bischoff, D.; Recktenwald, J.; Jung, G.; Sussmuth, R. D.; van Pee, K. H.; Wohlleben, W.; Pelzer, S. Glycopeptide Biosynthesis in Amycolatopsis Mediterranei 
DSM5908: Function of a Halogenase and a Haloperoxidase/Perhydrolase. Chem. Biol. 2002, 9 (2), 225-235.

(200) Schmartz, P. C.; Zerbe, K.; Abou-Hadeed, K.; Robinson, J. A. Bis-Chlorination of a Hexapeptide-PCP Conjugate by the Halogenase Involved in Vancomycin Biosynthesis. Org. Biomol. Chem. 2014, 12 (30), 5574-5577.

(201) Pelzer, S.; Sussmuth, R.; Heckmann, D.; Recktenwald, J.; Huber, P.; Jung, G.; Wohlleben, W. Identification and Analysis of the Balhimycin Biosynthetic Gene Cluster and Its Use for Manipulating Glycopeptide Biosynthesis in Amycolatopsis Mediterranei Dsm5908. Antimicrob. Agents Chemother. 1999, 43 (7), 1565-1573.

(202) Chiu, H. T.; Hubbard, B. K.; Shah, A. N.; Eide, J.; Fredenburg, R. A.; Walsh, C. T.; Khosla, C. Molecular Cloning and Sequence Analysis of the Complestatin Biosynthetic Gene Cluster. Proc. Natl. Acad. Sci. U.S.A 2001, 98 (15), 8548-8553.

(203) Park, O. K.; Choi, H. Y.; Kim, G. W.; Kim, W. G. Generation of New Complestatin Analogues by Heterologous Expression of the Complestatin Biosynthetic Gene Cluster from Streptomyces Chartreusis AN1542. ChemBioChem 2016, 17 (18), 1725-1731.

(204) Sosio, M.; Stinchi, S.; Beltrametti, F.; Lazzarini, A.; Donadio, S. The Gene Cluster for the Biosynthesis of the Glycopeptide Antibiotic A40926 by Nonomuraea Species. Chem. Biol. 2003, 10 (6), 541-549.

(205) Li, T. L.; Huang, F.; Haydock, S. F.; Mironenko, T.; Leadlay, P. F.; Spencer, J. B. Biosynthetic Gene Cluster of the Glycopeptide Antibiotic Teicoplanin: Characterization of Two Glycosyltransferases and the Key Acyltransferase. Chem. Biol. 2004, 11 (1), 107-119.

(206) Horbal, L.; Ostash, B.; Luzhetskyy, A.; Walker, S.; Kalinowski, J.; Fedorenko, V. A Gene Cluster for the Biosynthesis of Moenomycin Family Antibiotics in the Genome of Teicoplanin Producer Actinoplanes Teichomyceticus. Appl. Microbiol. Biotechnol. 2016, 100 (17), 76297638.

(207) Sosio, M.; Bianchi, A.; Bossi, E.; Donadio, S. Teicoplanin Biosynthesis Genes in Actinoplanes Teichomyceticus. Anton. Leeuw. Int. J. G. 2000, 78 (3-4), 379-384.

(208) Buedenbender, S.; Rachid, S.; Müller, R.; Schulz, G. E. Structure and Action of the Myxobacterial Chondrochloren Halogenase $\mathrm{CndH}$ : A New Variant of FAD-Dependent Halogenases. J. Mol. Biol. 2009, 385 (2), 520-530.

(209) Van Lanen, S. G.; Lin, S.; Horsman, G. P.; Shen, B. Characterization of Sgce6, the Flavin Reductase Component Supporting Fad-Dependent Halogenation and Hydroxylation in the Biosynthesis of the Enediyne Antitumor Antibiotic C-1027. FEMS Microbiol. Lett. 2009, 300 (2), 237-241.

(210) Lin, S.; Huang, T.; Shen, B. Tailoring Enzymes Acting on Carrier Protein-Tethered Substrates in Natural Product Biosynthesis. Method. Enzymol. 2012, 516, 321-343.

(211) Lin, S. J.; Van Lanen, S. G.; Shen, B. Characterization of the Two-Component, FadDependent Monooxygenase Sgcc That Requires Carrier Protein-Tethered Substrates for the Biosynthesis of the Enediyne Antitumor Antibiotic C-1027. J. Am. Chem. Soc. 2008, 130 (20), 6616-6623.

(212) Chen, J.-S.; Su, M.; Shao, L.; Wang, Y.-X.; Lin, H.-M.; Chen, D.-J. Investigation of Halogenation During the Biosynthesis of Ramoplanin in Actinoplanes Sp. ATCC33076. Appl. Microbiol. Biotechnol. 2016, 100 (1), 289-298.

(213) Yin, X. H.; Zabriskie, T. M. The Enduracidin Biosynthetic Gene Cluster from Streptomyces Fungicidicus. Microbiol. SGM. 2006, 152, 2969-2983.

(214) Yin, X. H.; Chen, Y.; Zhang, L.; Wang, Y.; Zabriskie, T. M. Enduracidin Analogues with Altered Halogenation Patterns Produced by Genetically Engineered Strains of Streptomyces Fungicidicus. J. Nat. Prod. 2010, 73 (4), 583-589.

(215) Han, J. G.; Chen, J. S.; Shao, L.; Zhang, J. L.; Dong, X. J.; Liu, P. Y.; Chen, D. J. Production of the Ramoplanin Activity Analogue by Double Gene Inactivation. PLoS One 2016, 11 (5).

(216) Rank, C.; Klejnstrup, M. L.; Petersen, L. M.; Kildgaard, S.; Frisvad, J. C.; Held Gotfredsen, C.; Ostenfeld Larsen, T. Comparative Chemistry of Aspergillus Oryzae (Rib40) and A. Flavus (NRRL 3357). Metabolites 2012, 2 (1), 39-56.

(217) Chankhamjon, P.; Tsunematsu, Y.; Ishida-Ito, M.; Sasa, Y.; Meyer, F.; Boettger-Schmidt, D.; Urbansky, B.; Menzel, K.-D.; Scherlach, K.; Watanabe, K.et al. Regioselective Dichlorination of a Non-Activated Aliphatic Carbon Atom and Phenolic Bismethylation by a Multifunctional Fungal Flavoenzyme. Angew. Chem. Int. Ed. 2016, 55 (39), 11955-11959.

(218) Frese, M.; Guzowska, P. H.; Voß, H.; Sewald, N. Regioselective Enzymatic Halogenation of Substituted Tryptophan Derivatives Using the FAD-Dependent Halogenase RebH. ChemCatChem 2014, 6 (5), 1270-1276. 
(219) Hölzer, M.; Burd, W.; Reißig, H.-U.; Pée, K.-H. v. Substrate Specificity and Regioselectivity of Tryptophan 7-Halogenase from Pseudomonas Fluorescens BL915. Adv. Synth. Catal. 2001, 343 (6-7), 591-595.

(220) Payne, J. T.; Andorfer, M. C.; Lewis, J. C. Regioselective Arene Halogenation Using the FADDependent Halogenase RebH. Angew. Chem. Int. Ed. 2013, 52 (20), 5271-5274.

(221) Payne, J. T.; Lewis, J. C. Upgrading Nature's Tools: Expression Enhancement and Preparative Utility of the Halogenase RebH. Synlett 2014, 25, A-E.

(222) Lang, A.; Polnick, S.; Nicke, T.; William, P.; Patallo, E. P.; Naismith, J. H.; van Pée, K.-H. Changing the Regioselectivity of the Tryptophan 7-Halogenase PrnA by Site-Directed Mutagenesis. Angew. Chem. Int. Ed. 2011, 50 (13), 2951-2953.

(223) Andorfer, M. C.; Park, H. J.; Vergara-Coll, J.; Lewis, J. C. Directed Evolution of RebH for Catalyst-Controlled Halogenation of Indole C-H Bonds. Chem. Sci. 2016, 7 (6), 3720-3729.

(224) Poor, C. B.; Andorfer, M. C.; Lewis, J. C. Improving the Stability and Catalyst Lifetime of the Halogenase RebH by Directed Evolution. ChemBioChem 2014, 15 (9), 1286-1289.

(225) Payne, J. T.; Poor, C. B.; Lewis, J. C. Directed Evolution of RebH for Site-Selective Halogenation of Large Biologically Active Molecules. Angew. Chem. Int. Ed. 2015, 54 (14), 4226-4230.

(226) Bar-Even, A.; Noor, E.; Savir, Y.; Liebermeister, W.; Davidi, D.; Tawfik, D. S.; Milo, R. The Moderately Efficient Enzyme: Evolutionary and Physicochemical Trends Shaping Enzyme Parameters. Biochemistry 2011, 50 (21), 4402-4410.

(227) Muffler, K.; Retzlaff, M.; van Pée, K.-H.; Ulber, R. Optimisation of Halogenase Enzyme Activity by Application of a Genetic Algorithm. J. Biotechnol. 2007, 127 (3), 425-433.

(228) Liao, H. H. Thermostable Mutants of Kanamycin Nucleotidyltransferase Are Also More Stable to Proteinase K, Urea, Detergents, and Water-Miscible Organic Solvents. Enzyme Microb. Tech. 1993, 15 (4), 286-292.

(229) Zhao, H.; Arnold, F. H. Directed Evolution Converts Subtilisin E into a Functional Equivalent of Thermitase. Protein Eng. 1999, 12 (1), 47-53.

(230) Haki, G. D.; Rakshit, S. K. Developments in Industrially Important Thermostable Enzymes: A Review. Bioresource Technol. 2003, 89 (1), 17-34.

(231) Wu, I.; Arnold, F. H. Engineered Thermostable Fungal Cel6a and Cel7a Cellobiohydrolases Hydrolyze Cellulose Efficiently at Elevated Temperatures. Biotechnol. Bioeng. 2013, 110 (7), 1874-1883.

(232) Chen, X.; Zhang, B.; Zhang, W.; Wu, X.; Zhang, M.; Chen, T.; Liu, G.; Dyson, P. Genome Sequence of Streptomyces Violaceusniger Strain SPC6, a Halotolerant Streptomycete That Exhibits Rapid Growth and Development. Genome Announc. 2013, 1 (4).

(233) Harrison, J.; Studholme, D. J. Recently Published Streptomyces Genome Sequences. Microb. Biotechnol. 2014, 7 (5), 373-380.

(234) Takahashi, S.; Furuya, T.; Ishii, Y.; Kino, K.; Kirimura, K. Characterization of a Flavin Reductase from a Thermophilic Dibenzothiophene-Desulfurizing Bacterium, Bacillus Subtilis WU-S2B. J. Biosci. Bioeng. 2009, 107 (1), 38-41.

(235) Strickler, S. S.; Gribenko, A. V.; Gribenko, A. V.; Keiffer, T. R.; Tomlinson, J.; Reihle, T.; Loladze, V. V.; Makhatadze, G. I. Protein Stability and Surface Electrostatics: A Charged Relationship. Biochemistry 2006, 45 (9), 2761-2766.

(236) Smith, M. D.; Rosenow, M. A.; Wang, M.; Allen, J. P.; Szostak, J. W.; Chaput, J. C. Structural Insights into the Evolution of a Non-Biological Protein: Importance of Surface Residues in Protein Fold Optimization. PLoS ONE 2007, 2 (5), e467.

(237) Chan, C.-H.; Wilbanks, C. C.; Makhatadze, G. I.; Wong, K.-B. Electrostatic Contribution of Surface Charge Residues to the Stability of a Thermophilic Protein: Benchmarking Experimental and Predicted Pka Values. PLoS ONE 2012, 7 (1), e30296.

(238) Lawrence, M. S.; Phillips, K. J.; Liu, D. R. Supercharging Proteins Can Impart Unusual Resilience. J. Am. Chem. Soc. 2007, 129 (33), 10110-10112.

(240) Schnepel, C.; Minges, H.; Frese, M.; Sewald, N. A High-Throughput Fluorescence Assay to Determine the Activity of Tryptophan Halogenases. Angew. Chem. Int. Ed. 2016, 55 (45), 14159-14163.

(241) Hosford, J.; Shepherd, S. A.; Micklefield, J.; Wong, L. S. A High-Throughput Assay for Arylamine Halogenation Based on a Peroxidase-Mediated Quinone-Amine Coupling with Applications in the Screening of Enzymatic Halogenations. Chem. Eur. J. 2014, 20 (50), 16759-16763. 
(242) Belsare, K. D.; Andorfer, M. C.; Cardenas, F. S.; Chael, J. R.; Park, H. J.; Lewis, J. C. A Simple Combinatorial Codon Mutagenesis Method for Targeted Protein Engineering. ACS. Synth. Biol., 2017, 6 (3), 416-420.

(243) Latham, J.; Henry, J.-M.; Sharif, H. H.; Menon, B. R. K.; Shepherd, S. A.; Greaney, M. F.; Micklefield, J. Integrated Catalysis Opens New Arylation Pathways Via Regiodivergent Enzymatic C-H Activation. Nature Communications 2016, 7, 11873.

(244) Frese, M.; Sewald, N. Enzymatic Halogenation of Tryptophan on a Gram Scale. Angewandte Chemie International Edition 2015, 54 (1), 298-301.

(245) Sheldon, R. A.; Arends, I. W. C. E.; Hanefeld, U. Green Chemistry and Catalysis; Wiley-VCH Verlag GmbH: Weinheim, 2007.

(246) Cao, L.; van Rantwijk, F.; Sheldon, R. A. Cross-Linked Enzyme Aggregates: A Simple and Effective Method for the Immobilization of Penicillin Acylase. Org. Lett. 2000, 2 (10), 13611364.

(247) Sheldon, R. A. Enzyme Immobilization: The Quest for Optimum Performance. Adv. Synth. Catal. 2007, 349 (8-9), 1289-1307.

(248) van Pelt, S.; Quignard, S.; Kubac, D.; Sorokin, D. Y.; van Rantwijk, F.; Sheldon, R. A. Nitrile Hydratase Cleas: The Immobilization and Stabilization of an Industrially Important Enzyme. Green Chem. 2008, 10 (4), 395-400.

(249) Runguphan, W.; Qu, X.; O/'Connor, S. E. Integrating Carbon-Halogen Bond Formation into Medicinal Plant Metabolism. Nature 2010, 468 (7322), 461-464.

(250) Glenn, W. S.; Nims, E.; O'Connor, S. E. Reengineering a Tryptophan Halogenase to Preferentially Chlorinate a Direct Alkaloid Precursor. J. Am. Chem. Soc. 2011, 133 (48), 19346-19349.

(251) Roy, A. D.; Grüschow, S.; Cairns, N.; Goss, R. J. M. Gene Expression Enabling Synthetic Diversification of Natural Products: Chemogenetic Generation of Pacidamycin Analogs. J. Am. Chem. Soc. 2010, 132 (35), 12243-12245.

(252) Sánchez, C.; Zhu, L.; Braña, A. F.; Salas, A. P.; Rohr, J.; Méndez, C.; Salas, J. A. Combinatorial Biosynthesis of Antitumor Indolocarbazole Compounds Proc. Natl. Acad. Sci. U.S.A 2005, 102 (2), 461-466.

(253) Kim, E.; Moore, B. S.; Yoon, Y. J. Reinvigorating Natural Product Combinatorial Biosynthesis with Synthetic Biology. Nat. Chem. Biol. 2015, 11 (9), 649-659.

(254) Du, Y.-L.; Ryan, K. S. Expansion of Bisindole Biosynthetic Pathways by Combinatorial Construction. ACS Synth. Biol. 2015, 4 (6), 682-688.

(255) Wenda, S.; Illner, S.; Mell, A.; Kragl, U. Industrial Biotechnology-the Future of Green Chemistry? Green Chem. 2011, 13 (11), 3007-3047.

(256) Grüschow, S.; Rackham, E. J.; Elkins, B.; Newill, P. L. A.; Hill, L. M.; Goss, R. J. M. New Pacidamycin Antibiotics through Precursor-Directed Biosynthesis. ChemBioChem 2009, 10 (2), 355-360.

(257) Fräbel, S.; Krischke, M.; Staniek, A.; Warzecha, H. Recombinant Flavin-Dependent Halogenases Are Functional in Tobacco Chloroplasts without Co-Expression of Flavin Reductase Genes. Biotechnol. J. 2016, 11 (12), 1586-1594.

(258) Wang, S.; Zhang, S.; Xiao, A.; Rasmussen, M.; Skidmore, C.; Zhan, J. Metabolic Engineering of Escherichia Coli for the Biosynthesis of Various Phenylpropanoid Derivatives. Metab. Eng. 2015, 29, 153-159.

(259) Li, X.-Z.; Wei, X.; Zhang, C.-J.; Jin, X.-L.; Tang, J.-J.; Fan, G.-J.; Zhou, B. Hypohalous AcidMediated Halogenation of Resveratrol and Its Role in Antioxidant and Antimicrobial Activities. Food Chem. 2012, 135 (3), 1239-1244.

(260) Weissman, K. J. Mutasynthesis - Uniting Chemistry and Genetics for Drug Discovery. Trends Biotechnol. 2007, 25 (4), 139-142.

(261) Durak, L. J.; Payne, J. T.; Lewis, J. C. Late-Stage Diversification of Biologically Active Molecules Via Chemoenzymatic C-H Functionalization. ACS Catal. 2016, 6 (3), 1451-1454.

(262) Gröger, H.; Hummel, W. Combining the 'Two Worlds' of Chemocatalysis and Biocatalysis Towards Multi-Step One-Pot Processes in Aqueous Media. Curr. Opin. Chem. Biol. 2014, 19 (0), 171-179.

(263) Reetz, M. T. Biocatalysis in Organic Chemistry and Biotechnology: Past, Present, and Future. J. Am. Chem. Soc. 2013, 135 (34), 12480-12496.

(264) Sato, H.; Hummel, W.; Gröger, H. Cooperative Catalysis of Noncompatible Catalysts through Compartmentalization: Wacker Oxidation and Enzymatic Reduction in a One-Pot Process in Aqueous Media. Angew. Chem. Int. Ed. 2015, 54 (15), 4488-4492. 
(265) Bruggink, A.; Schoevaart, R.; Kieboom, T. Concepts of Nature in Organic Synthesis: Cascade Catalysis and Multistep Conversions in Concert. Org. Proc. Res. Dev. 2003, 7 (5), 622-640.

(266) Kilpin, K. J.; Dyson, P. J. Enzyme Inhibition by Metal Complexes: Concepts, Strategies and Applications. Chem. Sci. 2013, 4 (4), 1410-1419.

(267) Frese, M.; Schnepel, C.; Minges, H.; Voß, H.; Feiner, R.; Sewald, N. Modular Combination of Enzymatic Halogenation of Tryptophan with Suzuki-Miyaura Cross-Coupling Reactions. ChemCatChem 2016, 8 (10), 1799-1803.

(268) Long, T. R.; Bowden, N. B. Polydimethylsiloxane Thimbles. Encyclopedia of Reagents for Organic Synthesis 2001.

(269) Millerli, A. L.; Bowden, N. B. Site-Isolation and Recycling of Pdcl2 Using Pdms Thimbles. J. Org. Chem. 2009, 74 (13), 4834-4840.

(270) Yang, Y.; Li, R.; Zhao, Y.; Zhao, D.; Shi, Z. Cu-Catalyzed Direct C6-Arylation of Indoles. J. Am. Chem. Soc. 2016, 138 (28), 8734-8737.

(271) Yang, Y.; Qiu, X.; Zhao, Y.; Mu, Y.; Shi, Z. Palladium-Catalyzed C-H Arylation of Indoles at the C7 Position. J. Am. Chem. Soc. 2016, 138 (2), 495-498.

(272) Holtmann, D.; Fraaije, M. W.; Arends, I. W. C. E.; Opperman, D. J.; Hollmann, F. The Taming of Oxygen: Biocatalytic Oxyfunctionalisations. Chem. Comm. 2014, 50 (87), 13180-13200.

(273) Huijbers, M. M. E.; Montersino, S.; Westphal, A. H.; Tischler, D.; van Berkel, W. J. H. Flavin Dependent Monooxygenases. Arch. Biochem. Biophys. 2014, 544, 2-17.

(274) Cochrane, R. V.; Vederas, J. C. Highly Selective but Multifunctional Oxygenases in Secondary Metabolism. Acc. Chem. Res. 2014, 47 (10), 3148-3161.

(275) Holtmann, D.; Hollmann, F. The Oxygen Dilemma: A Severe Challenge for the Application of Monooxygenases? ChemBioChem 2016, 17 (15), 1391-1398.

(276) Bučko, M.; Gemeiner, P.; Schenkmayerová, A.; Krajčovič, T.; Rudroff, F.; Mihovilovič, M. D. Baeyer-Villiger Oxidations: Biotechnological Approach. Appl. Microbiol. Biotechnol. 2016, 100 (15), 6585-6599.

(277) Leisch, H.; Morley, K.; Lau, P. C. K. Baeyer-Villiger Monooxygenases: More Than Just Green Chemistry. Chem. Rev. 2011, 111 (7), 4165-4222.

(278) Ellis, H. R. The Fmn-Dependent Two-Component Monooxygenase Systems. Arch. Biochem. Biophys. 2010, 497 (2), 1-12.

(279) Suske, W. A.; Held, M.; Schmid, A.; Fleischmann, T.; Wubbolts, M. G.; Kohler, H.-P. E. Purification and Characterization of 2-Hydroxybiphenyl 3-Monooxygenase, a Novel NADHDependent, FAD-Containing Aromatic Hydroxylase from Pseudomonas Azelaica Hbp1. J. Biol. Chem. 1997, 272 (39), 24257-24265.

(280) Schlaich, N. L. Flavin-Containing Monooxygenases in Plants: Looking Beyond Detox. Trends in Plant Sci. 2007, 12 (9), 412-418.

(281) Crosa, J. H.; Walsh, C. T. Genetics and Assembly Line Enzymology of Siderophore Biosynthesis in Bacteria. Microbiol. Mol. Biol. Rev. 2002, 66 (2), 223-249.

(282) Laden, B. P.; Tang, Y.; Porter, T. D. Cloning, Heterologous Expression, and Enzymological Characterization of Human Squalene Monooxygenase. Arch. Biochem. Biophys. 2000, 374 (2), 381-388.

(283) Breton, J.; Avanzi, N.; Magagnin, S.; Covini, N.; Magistrelli, G.; Cozzi, L.; Isacchi, A. Functional Characterization and Mechanism of Action of Recombinant Human Kynurenine 3Hydroxylase. Eur. J. Biochem. 2000, 267 (4), 1092-1099.

(284) Schwarcz, R.; Bruno, J. P.; Muchowski, P. J.; Wu, H.-Q. Kynurenines in the Mammalian Brain: When Physiology Meets Pathology. Nat. Rev. Neurosci. 2012, 13 (7), 465-477.

(285) Amaral, M.; Levy, C.; Heyes, D. J.; Lafite, P.; Outeiro, T. F.; Giorgini, F.; Leys, D.; Scrutton, N. S. Structural Basis of Kynurenine 3-Monooxygenase Inhibition. Nature 2013, 496 (7445), $382-$ 385.

(286) Mooney, A.; Ward, P. G.; O'Connor, K. E. Microbial Degradation of Styrene: Biochemistry, Molecular Genetics, and Perspectives for Biotechnological Applications. Appl. Microbiol. Biotechnol. 2006, 72 (1), 1.

(287) ten Brink, G. J.; Arends, I. W. C. E.; Sheldon, R. A. The Baeyer-Villiger Reaction: New Developments toward Greener Procedures. Chem. Rev. 2004, 104 (9), 4105-4124.

(288) Berry, D. F.; Francis, A. J.; Bollag, J. M. Microbial Metabolism of Homocyclic and Heterocyclic Aromatic Compounds under Anaerobic Conditions. Microbiol. Rev. 1987, 51 (1), 43-59.

(289) Alfieri, A.; Malito, E.; Orru, R.; Fraaije, M. W.; Mattevi, A. Revealing the Moonlighting Role of NADP in the Structure of a Flavin-Containing Monooxygenase. Proc. Natl. Acad. Sci. U.S.A 2008, 105 (18), 6572-6577. 
(290) Malito, E.; Alfieri, A.; Fraaije, M. W.; Mattevi, A. Crystal Structure of a Baeyer-Villiger Monooxygenase. Proc. Natl. Acad. Sci. U.S.A 2004, 101 (36), 13157-13162.

(291) Tischler, D.; Schlömann, M.; van Berkel, W. J. H.; Gassner, G. T. Fad C(4a)-Hydroxide Stabilized in a Naturally Fused Styrene Monooxygenase. FEBS Lett. 2013, 587 (23), 38483852.

(292) Tischler, D.; Gröning, J. A. D.; Kaschabek, S. R.; Schlömann, M. One-Component Styrene Monooxygenases: An Evolutionary View on a Rare Class of Flavoproteins. Appl. Biochem. Biotech. 2012, 167 (5), 931-944.

(293) Massey, V. Activation of Molecular Oxygen by Flavins and Flavoproteins. J. Biol. Chem. 1994, 269 (36), 22459-22462.

(294) Orru, R.; Dudek, H. M.; Martinoli, C.; Torres Pazmiño, D. E.; Royant, A.; Weik, M.; Fraaije, M. W.; Mattevi, A. Snapshots of Enzymatic Baeyer-Villiger Catalysis: Oxygen Activation and Intermediate Stabilization. J. Biol. Chem. 2011, 286 (33), 29284-29291.

(295) Meyer, A.; Schmid, A.; Held, M.; Westphal, A. H.; Röthlisberger, M.; Kohler, H.-P. E.; van Berkel, W. J. H.; Witholt, B. Changing the Substrate Reactivity of 2-Hydroxybiphenyl 3Monooxygenase from Pseudomonas Azelaica Hbp1 by Directed Evolution. J. Biol. Chem. 2002, 277 (7), 5575-5582.

(296) Baldwin, C. V. F.; Woodley, J. M. On Oxygen Limitation in a Whole Cell Biocatalytic BaeyerVilliger Oxidation Process. Biotech. Bioeng. 2006, 95 (3), 362-369.

(297) O'Sullivan, L. M.; Patel, S.; Ward, J. M.; Woodley, J. M.; Doig, S. D. Large Scale Production of Cyclohexanone Monooxygenase from Escherichia Coli Top10 PQR239. Enzyme Microb. Technol. 2001, 28 (2), 265-274.

(298) Schmid, A.; Vereyken, I.; Held, M.; Witholt, B. Preparative Regio- and Chemoselective Functionalization of Hydrocarbons Catalyzed by Cell Free Preparations of 2-Hydroxybiphenyl 3-Monooxygenase. J. Mol. Catal. B 2001, 11 (4-6), 455-462.

(299) Churakova, E.; Kluge, M.; Ullrich, R.; Arends, I.; Hofrichter, M.; Hollmann, F. Specific Photobiocatalytic Oxyfunctionalization Reactions. Angew. Chem. Int. Ed. 2011, 50 (45), 10716-10719.

(300) Hollmann, F.; Taglieber, A.; Schulz, F.; Reetz, M. T. A Light-Driven Stereoselective Biocatalytic Oxidation. Angew. Chem. Int. Ed. 2007, 46 (16), 2903-2906.

(301) Hollmann, F.; Hofstetter, K.; Habicher, T.; Hauer, B.; Schmid, A. Direct Electrochemical Regeneration of Monooxygenase Subunits for Biocatalytic Asymmetric Epoxidation. J. Am. Chem. Soc. 2005, 127 (18), 6540-6541.

(302) Hollmann, F.; Lin, P.-C.; Witholt, B.; Schmid, A. Stereospecific Biocatalytic Epoxidation: The First Example of Direct Regeneration of a Fad-Dependent Monooxygenase for Catalysis. I. Am. Chem. Soc. 2003, 125 (27), 8209-8217.

(303) Paul, C. E.; Tischler, D.; Riedel, A.; Heine, T.; Itoh, N.; Hollmann, F. Nonenzymatic Regeneration of Styrene Monooxygenase for Catalysis. ACS Catal. 2015, 5 (5), 2961-2965.

(304) Mifsud, M.; Gargiulo, S.; Iborra, S.; Arends, I. W. C. E.; Hollmann, F.; Corma, A. Photobiocatalytic Chemistry of Oxidoreductases Using Water as the Electron Donor. Nat. Commun. 2014, 5.

(305) Schrewe, M.; Julsing, M. K.; Buhler, B.; Schmid, A. Whole-Cell Biocatalysis for Selective and Productive C-O Functional Group Introduction and Modification. Chem. Soc. Rev. 2013, 42 (15), 6346-6377.

(306) Held, M.; Schmid, A.; Kohler, H.-P. E.; Suske, W.; Witholt, B.; Wubbolts, M. G. An Integrated Process for the Production of Toxic Catechols from Toxic Phenols Based on a Designer Biocatalyst. Biotech. Bioeng. 1999, 62 (6), 641-648.

(307) Held, M.; Suske, W.; Schmid, A.; Engesser, K.-H.; Kohler, H.-P. E.; Witholt, B.; Wubbolts, M. G. Preparative Scale Production of 3-Substituted Catechols Using a Novel Monooxygenase from Pseudomonas Azelaica HBP1. J. Mol. Catal. B. 1998, 5 (1-4), 87-93.

(308) Hilker, I.; Gutierrez, M. C.; Furstoss, R.; Ward, J.; Wohlgemuth, R.; Alphand, V. Preparative Scale Baeyer-Villiger Biooxidation at High Concentration Using Recombinant Escherichia Coli and in Situ Substrate Feeding and Product Removal Process. Nat. Protoc. 2008, 3 (3), 546554.

(309) Hilker, I.; Wohlgemuth, R.; Alphand, V.; Furstoss, R. Microbial Transformations 59: First Kilogram Scale Asymmetric Microbial Baeyer-Villiger Oxidation with Optimized Productivity Using a Resin-Based in situ SFPR Strategy. Biotech. Bioeng. 2005, 92 (6), 702-710.

(310) Hilker, I.; Alphand, V.; Wohlgemuth, R.; Furstoss, R. Microbial Transformations, 56. Preparative Scale Asymmetric Baeyer-Villiger Oxidation Using a Highly Productive "Two-inOne" Resin-Based in situ SFPR Concept. Adv. Synth. Catal. 2004, 346 (2-3), 203-214. 
(311) Hilker, I.; Gutiérrez, M. C.; Alphand, V.; Wohlgemuth, R.; Furstoss, R. Microbiological Transformations 57. Facile and Efficient Resin-Based in situ SFPR Preparative-Scale Synthesis of an Enantiopure "Unexpected" Lactone Regioisomer Via a Baeyer-Villiger Oxidation Process. Org. Lett. 2004, 6 (12), 1955-1958.

(312) Doig, S. D.; Avenell, P. J.; Bird, P. A.; Gallati, P.; Lander, K. S.; Lye, G. J.; Wohlgemuth, R.; Woodley, J. M. Reactor Operation and Scale-up of Whole Cell Baeyer-Villiger Catalyzed Lactone Synthesis. Biotech. Prog. 2002, 18 (5), 1039-1046.

(313) Baldwin, C. V. F.; Wohlgemuth, R.; Woodley, J. M. The First 200-L Scale Asymmetric Baeyer-Villiger Oxidation Using a Whole-Cell Biocatalyst. Org. Proc. Res. Dev. 2008, 12 (4), 660-665.

(314) Simpson, H. D.; Alphand, V.; Furstoss, R. Microbiological Transformations: 49. Asymmetric Biocatalysed Baeyer-Villiger Oxidation: Improvement Using a Recombinant Escherichia Coli Whole Cell Biocatalyst in the Presence of an Adsorbent Resin. J. Mol. Catal. B 2001, 16 (2), 101-108.

(315) Melgarejo-Torres, R.; Castillo-Araiza, C. O.; Dutta, A.; Bény, G.; Torres-Martinez, D.; Gutiérrez-Rojas, M.; Lye, G. J.; Huerta-Ochoa, S. Mathematical Model of a Three Phase Partitioning Bioreactor for Conversion of Ketones Using Whole Cells. Chem. Eng. J. 2015, 260, 765-775.

(316) Yang, J.; Wang, S.; Lorrain, M.-J.; Rho, D.; Abokitse, K.; Lau, P. C. K. Bioproduction of Lauryl Lactone and 4-Vinyl Guaiacol as Value-Added Chemicals in Two-Phase Biotransformation Systems. Appl. Microbiol. Biotechnol. 2009, 84 (5), 867-876.

(317) Panke, S.; Held, M.; Wubbolts, M. G.; Witholt, B.; Schmid, A. Pilot-Scale Production of (S)Styrene Oxide from Styrene by Recombinant Escherichia Coli Synthesizing Styrene Monooxygenase. Biotech. Bioeng. 2002, 80 (1), 33-41.

(318) Bong, Y. K.; Clay, M. D., Collier, Steven J.,; Mijts, B.; Vogel, M.; Zhang, X.; Zhu, J.; Nazor, J.; Smith, D. J.; Song, S.; Codexis, Inc.: United States, 2016.

(319) Reetz, M. T.; Wu, S. Greatly Reduced Amino Acid Alphabets in Directed Evolution: Making the Right Choice for Saturation Mutagenesis at Homologous Enzyme Positions. Chemical Communications 2008, 2008 (43), 5499-5501.

(320) Schulz, F.; Leca, F.; Hollmann, F.; Reetz, M. T. Towards Practical Biocatalytic Baeyer-Villiger Reactions: Applying a Thermostable Enzyme in the Gram-Scale Synthesis of Optically-Active Lactones in a Two-Liquid-Phase System. Beilstein J. Org. Chem. 2005, 1, 10.

(321) Reetz, M. T.; Daligault, F.; Brunner, B.; Hinrichs, H.; Deege, A. Directed Evolution of Cyclohexanone Monooxygenases: Enantioselective Biocatalysts for the Oxidation of Prochiral Thioethers. Angew. Chem. Int. Ed. 2004, 43 (31), 4078-4081.

(322) Reetz, M. T.; Brunner, B.; Schneider, T.; Schulz, F.; Clouthier, C. M.; Kayser, M. M. Directed Evolution as a Method to Create Enantioselective Cyclohexanone Monooxygenases for Catalysis in Baeyer-Villiger Reactions. Angew. Chem. Int. Ed. 2004, 43 (31), 4075-4078.

(323) Clouthier, C. M.; Kayser, M. M.; Reetz, M. T. Designing New Baeyer-Villiger Monooxygenases Using Restricted Casting. J. Org. Chem. 2006, 71 (22), 8431-8437.

(324) Watts, A. B.; Beecher, J.; Whitcher, C. S.; Littlechild, J. A. A Method for Screening BaeyerVilliger Monooxygenase Activity against Monocyclic Ketones. Biocatal. Biotransform. 2002, 20 (3), 209-215.

(325) Gutierrez, M. C.; Sleegers, A.; Simpson, H. D.; Alphand, V.; Furstoss, R. The First Fluorogenic Assay for Detecting a Baeyer-Villigerase Activity in Microbial Cells. Org. Biomol. Chem. 2003, 1 (20), 3500-3506.

(326) Wahler, D.; Reymond, J.-L. The Adrenaline Test for Enzymes. Angew. Chem. Int. Ed. 2002, 41 (7), 1229-1232.

(327) Kirschner, A.; Bornscheuer, U. T. Directed Evolution of a Baeyer-Villiger Monooxygenase to Enhance Enantioselectivity. Appl. Microbiol. Biotechnol. 2008, 81 (3), 465-472.

(328) Linares-Pastén, J. A.; Chávez-Lizárraga, G.; Villagomez, R.; Mamo, G.; Hatti-Kaul, R. A Method for Rapid Screening of Ketone Biotransformations: Detection of Whole Cell BaeyerVilliger Monooxygenase Activity. Enzyme Microb. Technol. 2012, 50 (2), 101-106.

(329) Sicard, R.; Chen, L. S.; Marsaioli, A. J.; Reymond, J.-L. A Fluorescence-Based Assay for Baeyer-Villiger Monooxygenases, Hydroxylases and Lactonases. Adv. Synth. Catal. 2005, 347 (7-8), 1041-1050.

(330) Balke, K.; Kadow, M.; Mallin, H.; Sa; Bornscheuer, U. T. Discovery, Application and Protein Engineering of Baeyer-Villiger Monooxygenases for Organic Synthesis. Org. Biomol. Chem. 2012, 10 (31), 6249-6265. 
(331) Meyer, A.; Würsten, M.; Schmid, A.; Kohler, H.-P. E.; Witholt, B. Hydroxylation of Indole by Laboratory-Evolved 2-Hydroxybiphenyl 3-Monooxygenase. J. Biol. Chem. 2002, 277 (37), 34161-34167.

(332) Balke, K.; Schmidt, S.; Genz, M.; Bornscheuer, U. T. Switching the Regioselectivity of a Cyclohexanone Monooxygenase toward (+)-Trans-Dihydrocarvone by Rational Protein Design. ACS Chem. Biol. 2016, 11 (1), 38-43.

(333) Wu, S.; Acevedo, J. P.; Reetz, M. T. Induced Allostery in the Directed Evolution of an Enantioselective Baeyer-Villiger Monooxygenase. Proc. Natl. Acad. Sci. U.S.A 2010, 107 (7), 2775-2780.

(334) Opperman, D. J.; Reetz, M. T. Towards Practical Baeyer-Villiger-Monooxygenases: Design of Cyclohexanone Monooxygenase Mutants with Enhanced Oxidative Stability. ChemBioChem 2010, 11 (18), 2589-2596.

(335) Deng, H.; O'Hagan, D.; Schaffrath, C. Fluorometabolite Biosynthesis and the Fluorinase from Streptomyces Cattleya. Nat. Prod. Rep. 2004, 21 (6), 773-784.

(336) O'Hagan, D.; Deng, H. Enzymatic Fluorination and Biotechnological Developments of the Fluorinase. Chem. Rev. 2015, 115 (2), 634-649.

(337) Harper, D. B.; O'Hagan, D. The Fluorinated Natural Products. Nat. Prod. Rep. 1994, 11 (0), 123-133.

(338) Wagner, C.; El Omari, M.; König, G. M. Biohalogenation: Nature's Way to Synthesize Halogenated Metabolites. J. Nat. Prod. 2009, 72 (3), 540-553.

(339) O'Hagan, D.; Perry, R.; Lock, J. M.; Meyer, J. J. M.; Dasaradhi, L.; Hamilton, J. T. G.; Harper, D. B. High Levels of Monofluoroacetate in Dichapetalum Braunii. Phytochemistry 1993, 33 (5), 1043-1045.

(340) Zechel, D. L.; Reid, S. P.; Stoll, D.; Nashiru, O.; Warren, R. A. J.; Withers, S. G. Mechanism, Mutagenesis, and Chemical Rescue of a B-Mannosidase from Cellulomonas Fimi. Biochemistry 2003, 42 (23), 7195-7204.

(341) Nashiru, O.; Zechel, D. L.; Stoll, D.; Mohammadzadeh, T.; Warren, R. A. J.; Withers, S. G. BMannosynthase: Synthesis of B-Mannosides with a Mutant B-Mannosidase. Angew. Chem. Int. Ed. 2001, 40 (2), 417-420.

(342) Zechel, D. L.; Reid, S. P.; Nashiru, O.; Mayer, C.; Stoll, D.; Jakeman, D. L.; Warren, R. A. J.; Withers, S. G. Enzymatic Synthesis of Carbon-Fluorine Bonds. J. Am. Chem. Soc. 2001, 123 (18), 4350-4351.

(343) Maguire, A. R.; Meng, W.-D.; Roberts, S. M.; Willetts, A. J. Synthetic Approaches Towards Nucleocidin and Selected Analogues; Anti-Hiv Activity in 4'-Fluorinated Nucleoside Derivatives. J. Chem. Soc. Perkin Trans. 1 1993, (15), 1795-1808.

(344) Sanada, M.; Miyano, T.; Iwadare, S.; Williamson, J. M.; Arison, B. H. J.; Smith, L.; Douglas, A. W.; Liesch, J. M.; Inamine, E. J. Antibiot. 1986, 39, 259.

(345) O'Hagan, D.; Schaffrath, C.; Cobb, S. L.; Hamilton, J. T. G.; Murphy, C. D. Biochemistry: Biosynthesis of an Organofluorine Molecule. Nature 2002, 416 (6878), 279-279.

(346) Cadicamo, C. D.; Courtieu, J.; Deng, H.; Meddour, A.; O'Hagan, D. Enzymatic Fluorination in Streptomyces Cattleya Takes Place with an Inversion of Configuration Consistent with an Sn2 Reaction Mechanism. ChemBioChem 2004, 5 (5), 685-690.

(347) O'Hagan, D.; Goss, R. J. M.; Meddour, A.; Courtieu, J. Assay for the Enantiomeric Analysis of $\left[{ }^{2} \mathrm{H} 1\right]-$ Fluoroacetic Acid: Insight into the Stereochemical Course of Fluorination During Fluorometabolite Biosynthesis in Streptomyces Cattleya. J. Am. Chem. Soc. 2003, 125 (2), 379-387.

(348) Dong, C.; Huang, F.; Deng, H.; Schaffrath, C.; Spencer, J. B.; O'Hagan, D.; Naismith, J. H. Crystal Structure and Mechanism of a Bacterial Fluorinating Enzyme. Nature 2004, 427 (6974), 561-565.

(349) Zhu, X.; Robinson, D. A.; McEwan, A. R.; O'Hagan, D.; Naismith, J. H. Mechanism of Enzymatic Fluorination in Streptomyces Cattleya. J. Am. Chem. Soc. 2007, 129 (47), 1459714604.

(350) Senn, H. M.; O'Hagan, D.; Thiel, W. Insight into Enzymatic C-F Bond Formation from Qm and Qm/Mm Calculations. J. Am. Chem. Soc. 2005, 127 (39), 13643-13655.

(351) Vincent, M. A.; Hillier, I. H. The Solvated Fluoride Anion Can Be a Good Nucleophile. Chem. Comm. 2005, 2005 (47), 5902-5903.

(352) Lohman, D. C.; Edwards, D. R.; Wolfenden, R. Catalysis by Desolvation: The Catalytic Prowess of Sam-Dependent Halide-Alkylating Enzymes. J. Am. Chem. Soc. 2013, 135 (39), 14473-14475. 
(353) Deng, H.; Ma, L.; Bandaranayaka, N.; Qin, Z.; Mann, G.; Kyeremeh, K.; Yu, Y.; Shepherd, T.; Naismith, J. H.; O'Hagan, D. Identification of Fluorinases from Streptomyces Sp MA37, Norcardia Brasiliensis, and Actinoplanes Sp N902-109 by Genome Mining. ChemBioChem 2014, 15 (3), 364-368.

(354) Wang, Y.; Deng, Z.; Qu, X. Characterization of a Sam-Dependent Fluorinase from a Latent Biosynthetic Pathway for Fluoroacetate and 4-Fluorothreonine Formation in Nocardia Brasiliensis. F1000Res. 2014, 61, 1.

(355) Huang, S.; Ma, L.; Tong, M. H.; Yu, Y.; O'Hagan, D.; Deng, H. Fluoroacetate Biosynthesis from the Marine-Derived Bacterium Streptomyces Xinghaiensis NRRL B-24674. Org. Biomol. Chem. 2014, 12 (27), 4828-4831.

(356) Eustáquio, A. S.; Härle, J.; Noel, J. P.; Moore, B. S. S-Adenosyl-L-Methionine Hydrolase (Adenosine-Forming), a Conserved Bacterial and Archeal Protein Related to SAM-Dependent Halogenases. ChemBioChem 2008, 9 (14), 2215-2219.

(357) Eustáquio, A. S.; McGlinchey, R. P.; Liu, Y.; Hazzard, C.; Beer, L. L.; Florova, G.; Alhamadsheh, M. M.; Lechner, A.; Kale, A. J.; Kobayashi, Y.et al. Biosynthesis of the Salinosporamide a Polyketide Synthase Substrate Chloroethylmalonyl-Coenzyme a from SAdenosyl-L-Methionine. Proc. Natl. Acad. Sci. U.S.A 2009, 106 (30), 12295-12300.

(358) Murphy, C. D.; O'Hagan, D.; Schaffrath, C. Identification of a PLP-Dependent Threonine Transaldolase: A Novel Enzyme Involved in 4-Fluorothreonine Biosynthesis in Streptomyces Cattleya. Angew. Chem. Int. Ed. 2001, 40 (23), 4479-4481.

(359) Deng, H.; Cobb, S. L.; McEwan, A. R.; McGlinchey, R. P.; Naismith, J. H.; O'Hagan, D.; Robinson, D. A.; Spencer, J. B. The Fluorinase from Streptomyces Cattleya Is Also a Chlorinase. Angew. Chem. Int. Ed. 2006, 45 (5), 759-762.

(360) Eustaquio, A. S.; Pojer, F.; Noel, J. P.; Moore, B. S. Discovery and Characterization of a Marine Bacterial SAM-Dependent Chlorinase. Nat. Chem. Biol. 2008, 4 (1), 69-74.

(361) Deng, H.; O'Hagan, D. The Fluorinase, the Chlorinase and the DUF-62 Enzymes. Curr. Opin. Chem. Biol. 2008, 12 (5), 582-592.

(362) Deng, H.; Botting, C. H.; Hamilton, J. T. G.; Russell, R. J. M.; O'Hagan, D. S-Adenosyl-LMethionine:Hydroxide Adenosyltransferase: A SAM Enzyme. Angew. Chem. Int. Ed. 2008, 47 (29), 5357-5361.

(363) Deng, H.; McMahon, S. A.; Eustaquio, A. S.; Moore, B. S.; Naismith, J. H.; O'Hagan, D. Mechanistic Insights into Water Activation in SAM Hydroxide Adenosyltransferase (DUF-62). ChemBioChem 2009, 10 (15), 2455-2459.

(364) Wängler, C.; Niedermoser, S.; Chin, J.; Orchowski, K.; Schirrmacher, E.; Jurkschat, K.; lovkova-Berends, L.; Kostikov, A. P.; Schirrmacher, R.; Wängler, B. One-Step ${ }^{18}$ F-Labeling of Peptides for Positron Emission Tomography Imaging Using the Sifa Methodology. Nat. Protoc. 2012, 7 (11), 1946-1955.

(365) Ponde, D. E.; Dence, C. S.; Oyama, N.; Kim, J.; Tai, Y.-C.; Laforest, R.; Siegel, B. A.; Welch, M. J. ${ }^{18}$ F-Fluoroacetate: A Potential Acetate Analog for Prostate Tumor Imaging-in vivo Evaluation of ${ }^{18} \mathrm{~F}$-Fluoroacetate Versus ${ }^{11} \mathrm{C}$-Acetate. J. Nuc. Med. 2007, 48 (3), 420-428.

(366) Marik, J.; Ogasawara, A.; Martin-McNulty, B.; Ross, J.; Flores, J. E.; Gill, H. S.; Tinianow, J. N.; Vanderbilt, A. N.; Nishimura, M.; Peale, F.et al. Pet of Glial Metabolism Using $2{ }^{18} \mathrm{~F}-$ Fluoroacetate. J. Nuc. Med. 2009, 50 (6), 982-990.

(367) Deng, H.; Cobb, S. L.; Gee, A. D.; Lockhart, A.; Martarello, L.; McGlinchey, R. P.; O'Hagan, D.; Onega, M. Fluorinase Mediated $\mathrm{C}^{18} \mathrm{~F}$ Bond Formation, an Enzymatic Tool for PET Labelling. Chem. Comm. 2006, 6 (6), 652-654.

(368) Martarello, L.; Schaffrath, C.; Deng, H.; Gee, A. D.; Lockhart, A.; O'Hagan, D. The First Enzymatic Method for C-18f Bond Formation: The Synthesis of $5^{\prime}-\left[{ }^{18} \mathrm{~F}\right]-$ Fluoro-5'Deoxyadenosine for Imaging with PET. J. Labelled Comp. Radiopharm. 2003, 46 (13), 1181 1189.

(369) Winkler, M.; Domarkas, J.; Schweiger, L. F.; O'Hagan, D. Fluorinase-Coupled Base Swaps: Synthesis of $\left[{ }^{18} \mathrm{~F}\right]-5^{\prime}-$ Deoxy-5'-Fluorouridines. Angew. Chem. Int. ED. 2008, 47 (52), 10141 10143.

(370) Deng, H.; Cobb, S. L.; Gee, A. D.; Lockhart, A.; Martarello, L.; McGlinchey, R. P.; O'Hagan, D.; Onega, M. Fluorinase Mediated $\mathrm{C}^{18} \mathrm{~F}$ Bond Formation, an Enzymatic Tool for PET Labelling. Chemical Communications 2006, 2006 (6), 652-654.

(371) Sergeev, M. E.; Morgia, F.; Javed, M. R.; Doi, M.; Keng, P. Y. Polymer-Immobilized Fluorinase: Recyclable Catalyst for Fluorination Reactions. J. Mol. Catal. B 2013, 92, 51-56. 
(372) Sergeev, M. E.; Morgia, F.; Javed, M. R.; Doi, M.; Keng, P. Y. Enzymatic Radiofluorination: Fluorinase Accepts Methylaza-Analog of SAM as Substrate for FDA Synthesis. J. Mol. Catal. B 2013, 97, 74-79.

(373) Li, X.-G.; Domarkas, J.; O'Hagan, D. Fluorinase Mediated Chemoenzymatic Synthesis of $\left[{ }^{18}\right.$ F]-Fluoroacetate. Chem. Comm. 2010, 46 (41), 7819-7821.

(374) Onega, M.; Domarkas, J.; Deng, H.; Schweiger, L. F.; Smith, T. A. D.; Welch, A. E.; Plisson, C.; Gee, A. D.; O'Hagan, D. An Enzymatic Route to 5-Deoxy-5-[ ${ }^{18}$ F]Fluoro-D-Ribose, a $\left[{ }^{18} \mathrm{~F}\right]-$ Fluorinated Sugar for PET Imaging. Chem. Comm. 2010, 46 (1), 139-141.

(375) Li, X.-G.; Dall'Angelo, S.; Schweiger, L. F.; Zanda, M.; O'Hagan, D. [ $\left.{ }^{18} \mathrm{~F}\right]-5-$ Fluoro-5Deoxyribose, an Efficient Peptide Bioconjugation Ligand for Positron Emission Tomography (PET) Imaging. Chem. Comm. 2012, 48 (43), 5247-5249.

(376) Dall'Angelo, S.; Zhang, Q.; Fleming, I. N.; Piras, M.; Schweiger, L. F.; O'Hagan, D.; Zanda, M. Efficient Bioconjugation of 5-Fluoro-5-Deoxy-Ribose (FDR) to RGD Peptides for Positron Emission Tomography (PET) Imaging of $[\alpha] V[\beta] 3$ Integrin Receptor. Org. Biomol. Chem. 2013, 11 (27), 4551-4558.

(377) Thompson, S.; Onega, M.; Ashworth, S.; Fleming, I. N.; Passchier, J.; O'Hagan, D. A TwoStep Fluorinase Enzyme Mediated ${ }^{18} \mathrm{~F}$ Labelling of an RSG Peptide for Positron Emission Tomography. Chem. Comm. 2015, 51 (70), 13542-13545.

(378) Thompson, S.; Zhang, Q.; Onega, M.; McMahon, S.; Fleming, I.; Ashworth, S.; Naismith, J. H.; Passchier, J.; O'Hagan, D. A Localized Tolerance in the Substrate Specificity of the Fluorinase Enzyme Enables "Last-Step" ${ }^{18} \mathrm{~F}$ Fluorination of a Rgd Peptide under Ambient Aqueous Conditions. Angew. Chem. Int. Ed. 2014, 53 (34), 8913-8918.

(379) Eustáquio, A. S.; O'Hagan, D.; Moore, B. S. Engineering Fluorometabolite Production: Fluorinase Expression in Salinispora Tropica Yields Fluorosalinosporamide. J. Nat. Prod. 2010, 73 (3), 378-382.

(380) Eustáquio, A. S.; Moore, B. S. Mutasynthesis of Fluorosalinosporamide, a Potent and Reversible Inhibitor of the Proteasome. Angew. Chem. Int. Ed. 2008, 47 (21), 3936-3938.

(381) Hong, H.; Spiteller, D.; Spencer, J. B. Incorporation of Fluoroacetate into an Aromatic Polyketide and Its Influence on the Mode of Cyclization. Angew. Chem. Int. Ed. 2008, 47 (32), 6028-6032.

(382) Walker, M. C.; Thuronyi, B. W.; Charkoudian, L. K.; Lowry, B.; Khosla, C.; Chang, M. C. Y. Expanding the Fluorine Chemistry of Living Systems Using Engineered Polyketide Synthase Pathways. Science 2013, 341 (6150), 1089.

(383) B. Harper, D.; T.G. Hamilton, J.; O' Hagan, D. Identification of Threo-ig-fluoro.9,10Dihydroxystearic Acid:A Novel Cofluorinated Fatty Acid from Dichapetalum Toxicarium Seeds. Tetrahedron Lett. 1990, 31 (52), 7661-7662.

(384) Cahn, J. K. B.; Baumschlager, A.; Brinkmann-Chen, S.; Arnold, F. H. Mutations in AdenineBinding Pockets Enhance Catalytic Properties of NAD(P)H-Dependent Enzymes. Protein Eng. Des. Sel. 2016, 29 (1), 31-38.

(385) McDonald, C. A.; Fagan, R. L.; Collard, F.; Monnier, V. M.; Palfey, B. A. Oxygen Reactivity in Flavoenzymes: Context Matters. J. Am. Chem. Soc. 2011, 133 (42), 16809-16811.

(386) Mercer, E. J.; Davies, C. L. Distribution of Chlorosulpholipids in Algae. Phytochemistry 1979, 18 (3), 457-462.

(387) Mercer, E. I.; Davies, C. L. Chlorosulpholipids in Algae. Phytochemistry 1975, 14 (7), 15451548.

(388) Mercer, E. I.; Davies, C. L. Chlorosulpholipids of Tribonema Aequale. Phytochemistry 1974, 13 (8), 1607-1610.

(389) Bedke, D. K.; Vanderwal, C. D. Chlorosulfolipids: Structure, Synthesis, and Biological Relevance. Nat. Prod. Rep. 2011, 28 (1), 15-25.

(390) Nilewski, C.; Geisser, R. W.; Carreira, E. M. Total Synthesis of a Chlorosulpholipid Cytotoxin Associated with Seafood Poisoning. Nature 2009, 457 (7229), 573-576.

(391) Landry, M. L.; Hu, D. X.; McKenna, G. M.; Burns, N. Z. Catalytic Enantioselective Dihalogenation and the Selective Synthesis of (-)-Deschloromytilipin a and (-)-Danicalipin A. J. Am. Chem. Soc. 2016, 138 (15), 5150-5158.

(392) Kawahara, T.; Kumaki, Y.; Kamada, T.; Ishii, T.; Okino, T. Absolute Configuration of Chlorosulfolipids from the Chrysophyta Ochromonas Danica. J. Org. Chem. 2009, 74 (16), 6016-6024.

(393) Fischer, S.; Huwyler, N.; Wolfrum, S.; Carreira, E. M. Synthesis and Biological Evaluation of Bromo- and Fluorodanicalipin A. Angew. Chem. Int. Ed. 2016, 55 (7), 2555-2558. 
(394) White, A. R.; Duggan, B. M.; Tsai, S.-C.; Vanderwal, C. D. The Alga Ochromonas Danica Produces Bromosulfolipids. Org. Lett. 2016, 18 (5), 1124-1127.

(395) Mooney, C. L.; Haines, T. H. Chlorination and Sulfation Reactions in the Biosynthesis of Chlorosulfolipids in Ochromonas Danica, in Vivo. Biochemistry 1973, 12 (22), 4469-4472.

(396) Mooney, C. L.; Mahoney, E. M.; Pousada, M.; Haines, T. H. Direct Incorporation of Fatty Acids into the Halosulfatides of Ochromonas Danica. Biochemistry 1972, 11 (25), 4839-4844.

(397) Smith, D. R. M.; Uria, A. R. R.; Helfrich, E. J. N.; Milbredt, D.; van-Pee, K.-H.; Piel, J.; Goss, R. J. M. An Unusual Flavin-Dependent Halogenase from the Metagenome of the Marine Sponge Theonella Swinhoei Wa. ACS Chem. Biol. 2017, DOI:10.1021/acschembio.6b01115.

\section{Author Biographies}

\subsection{Jonathan Latham}

Jonathan obtained his MChem in Chemistry with Medicinal Chemistry from the University of Manchester in 2013, where he spent his final year project in the Micklefield laboratory studying the application of flavin-dependent halogenases for biocatalysis. After graduation he remained at the University of Manchester to study for a PhD under the tutelage of Profs. Jason Micklefield and Michael Greaney on the integration of flavin-dependent halogenases with chemo-catalytic transformations.

\subsection{Eileen Brandenburger}

Eileen Brandenburger studied Chemistry at the Justus-Liebig-University in Germany where she obtained her Master's degree in 2013. In November 2013, she started her PhD in Chemical Biology at the University of Manchester within the Manchester Institute of Biotechnology under the supervision of Prof. Jason Micklefield. Her research is focused on the development of novel halogenase enzymes for application in synthetic pathways.

\subsection{Sarah A. Shepherd}

Sarah Shepherd graduated from the University of Warwick in 2010 with a MChem in Chemistry with Medicinal Chemistry. She then joined the Micklefield lab and received her PhD in Chemical Biology in 2014. Her research interests include biocatalysis and biosynthesis.

\subsection{Binuraj R. K. Menon}

Binuraj Menon has two Master's degrees in Pharmaceutical chemistry (2003) and Biocatalysis (2006). He obtained his PhD in 2009 on Molecular Enzymology with Prof. Nigel S. Scrutton at the University of Manchester. Before joining the Micklefield group in 2013 he was a postdoctoral researcher in structural biology with Dr. David Leys at the same university. Binuraj's research interests are in exploring novel proteins, their structural, functional and biophysical characterization for direct application in the pharmaceutical industry. 


\subsection{Jason Micklefield}

Jason Micklefield graduated from the University of Cambridge in 1993 with a PhD in Chemistry, with Prof. Sir Alan R. Battersby FRS. He then moved to the University of Washington as a NATO postdoctoral fellow working with Prof. Heinz G. Floss. In 1995 he became a lecturer in organic chemistry at the University of London, Birkbeck College, before moving to the University of Manchester in 1998 where he is Professor of Chemical Biology within the School of Chemistry and the Manchester Institute of Biotechnology. His research interests include biosynthesis, biocatalysis and riboswitches. 


\section{Table of Contents Graphic}

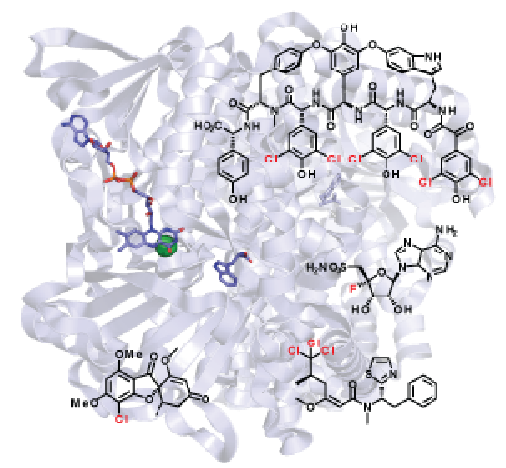

